MATTHEW CHARLES DEARING

\title{
TAMING THE WILD WEST - A FRAMEWORK FOR REGULATING AND APPLYING BROADCASTING STANDARDS TO INTERNET CONTENT IN NEW ZEALAND
}

LLM DISSERTATION: LAWS 591

FACULTY OF LAW

TE WHARE WÁNANGA O TE ÚPOKO O TE IKA A MÁUI

要 


\section{CONTENTS}

$\begin{array}{ll}\text { ABSTRACT } & 5\end{array}$

$\begin{array}{llr}\text { I INTRODUCTION } & 6\end{array}$

A. Definitions 8

II CURRENT REGULATORY SYSTEM IN NEW ZEALAND 9

A. Broadcasting Standards Authority 10

1. About the BSA 10

(a) Free to Air Television Code 11

(b) Pay Television Code $\quad 12$

(c) Radio Code 13

(d) Election Programs Code 14

2. BSA Complaints Process 14

3. The problem with Internet Content 17

4. Effectiveness of the BSA 18

B. Advertising Standards Authority 19

1. ASA's Complaints Process 20

2. Effectiveness of the ASA 21

C. New Zealand Press Council 23

1. PC's Complaints Process 25

2. Effectiveness of the PC 25

D. Office of Film and Literature Classification
and The Department of Internal Affairs

III THE PROBLEM 28

A. Media Convergence: The Blurring of Boundaries 28

1. What is Media Convergence? 28

2. Why addressing media convergence is important 32

B. Why the BSA's Lack of Jurisdiction is a Problem 39

IV THE SOLUTION $\quad 41$

A. What Changes Need to be Made 42

1. Updating the act 42

2. Creating the List 42

3. New Powers for the BSA 45

$\boldsymbol{V}$ THE PERPOSED FRAMEWORK $\quad 45$

A. Changes to the Broadcasting Act 46

1. The definition of "broadcasting 46 
2. Incorporation of the list 47

3. New Powers of the BSA 49

(a) Take down notices 49

(b) Change in edit notices 49

(c) Links 50

(d) Warnings and classifications 50

(e) Existing powers 50

4. Broadcasters as the first tier 51

(a) Making a complaint 53

(b) Broadcaster's response $\quad 54$

5. BSA as the second tier 54

6. High Court as the third tier 55

B. What standards should apply 56

VI POTENTIAL OBJECTIONS TO THE FRAMEWORK 58

A. Possible Criticisms and Alternatives 58

1. Potential Criticisms 58

(a) Fairfax's submissions $\quad 60$

(b) TVWorks' submissions 61

(c) Internet NZ's submissions 63

(d) BSA's submissions 63

(e) Summary 65

2. Possible Alternatives and Overseas actions 66

(a) The Possible Alternatives 66

(b) Action being taken overseas $\quad 69$

(i) Australia 70

(ii) United Kingdom 72

(iii) China 74

B. Domestic Jurisdictional Issues $\quad 76$

1. Problem scenario 76

VII EVALUATION OF REGULATORY OPTIONS 79

A. Historical Reasons for Media Regulation $\quad 80$

B. Forms of Media Regulation $\quad 82$

2. Statutory Regulation 83

3. Self-Regulation 86

4. Co-regulation 90

5. Suitability of co-regulation for the Internet 90

VIII THE CONCEPT OF RESPONSIVE REGULATION 94

A. Responsive Regulation 95 
IX NEW ZEALAND BILL OF RIGHTS ACT 98

A. Prescribed by Law 100

B. Demonstrable Justification 100

1. Significance of the social objectives addressed 101

2. Evidence social objectives address a pressing issue 102

3. Why the proposed changes will achieve the result 103

4. Impact on broadcasters' freedom of speech $\quad 104$

5. Proportionality 106

(a) Broadcasters' free speech concerns $\quad 107$

(b) Response to broadcasters' concerns 109

6. Summary 111

$\begin{array}{lll}\boldsymbol{X} & \text { CONCLUSION } & 111\end{array}$

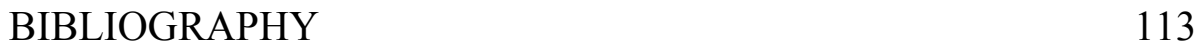




\begin{abstract}
The role of the Broadcasting Standards Authority (BSA) is to determine the areas where, and the extent to which, television and radio broadcasters' right to freedom of expression should give way to other interests that are highly valued in society. The BSA does this by applying the Codes of Broadcasting Practice, which contain standards relating to things such as good taste and decency, balance and accuracy in news and factual programmes, privacy and children's interests.
\end{abstract}

Due to a combination of media convergence onto the Internet and outdated legislation, the BSA is finding itself caught in a techno-legal time gap, where it has no ability to deal with programming content provided by broadcasters via the Internet. In the not-too-distant future, the Internet will become the dominant platform of choice, both for broadcasters to provide programming content and for consumers to receive it.

This dissertation examines the impact that the Internet has had on the modern media environment and the problems raised by the BSA's lack of jurisdiction to deal with programming content located on the websites of New Zealand-based broadcasters. To ensure that the BSA and the broadcasting standards regime in general does not become obsolete, this paper advocates for the BSA to be given express statutory jurisdiction to deal with complaints concerning programming content on New Zealand-based websites operated by Internet broadcasters. 


\section{INTRODUCTION}

This dissertation looks into the issue of whether the New Zealand Broadcasting Standards Authority should be given express statutory jurisdiction to deal with complaints arising out of certain programming content broadcast on the Internet. ${ }^{1}$

The BSA is a statutorily-based quasi-judicial body that is responsible for dealing with complaints about programming content on radio and television in New Zealand. Presently, the BSA is not considered to have any powers to deal with or receive complaints about audiovisual or audio programming content that has been broadcast on New Zealand-based websites. This lack of jurisdiction, along with the failure of the online media industry to appropriately selfregulate, has led to the development of a problematic wild-west type environment which now needs to be tamed.

The BSA does not have jurisdiction to deal with complaints about advertising material, newspaper or magazine content. The two industry-run bodies established to deal with these types of content are the New Zealand Advertising Standards Authority (ASA), who deals with complaints about advertising across all mediums including the Internet, and the New Zealand Press Council (PC), who deals with complaints arising out of content contained in New Zealandbased newspapers and magazines including their on-line versions.

To set the scene, Chapter Two of this paper begins with an outline of the current system of media regulation in New Zealand. It describes and analyses the regulatory roles currently played by the BSA, ASA, PC, the Office of Film and Literature (OFLC) and the Department of Internal Affairs (DIA).

Chapter Three is titled "The Problem" and it considers the effects of media convergence - the blurring of boundaries which have traditionally separated the different forms of media and why addressing its effects is both important and necessary. It provides a detailed outline as

\footnotetext{
${ }^{1}$ It should be noted that at the time of the writing of this dissertation the author was employed as a Legal Advisor at the Broadcasting Standards Authority. Also, all citations relating to online documents and websites were accurate at the time of writing this paper. The text of this paper (excluding contents page, footnotes and bibliography) is 35,296.
} 
to why the BSA's lack of jurisdiction over specific internet content is a problem that needs fixing. To provide some context as to why some form of Internet regulation is necessary, it looks into overseas and New Zealand-based research and opinions on where the Internet is headed in the future. It goes on to analyse and discuss the issues relating to media convergence and the potential effects this convergence may have on the way broadcasters choose to deliver their content and the way in which viewers choose to receive it.

Chapter Four provides this paper's proposed solution to the problem, including what changes will need to be made in terms of updating the Broadcasting Act, which organisations should be subject to Internet content regulation and what new powers the BSA will require to be effective.

Chapter Five outlines the proposed framework for the application of broadcasting standards to specific Internet content being made available by New Zealand-based broadcasters. It discusses the standards that should apply and considers possible ways in which they could be enforced. Suggestions on how to change the Broadcasting Act 1989 giving the BSA statutory powers regarding Internet content are also included.

Chapter Six tackles the potential objections that could be raised in relation to the proposed framework. It looks at a variety of possible criticisms, analyses the positive and negative aspects of the potential alternatives and provides an overview of what three different overseas jurisdictions are doing to try and regulate Internet content. The chapter goes onto outline possible jurisdictional issues which could arise, their impacts, and what can be done to ensure that any regulatory overlaps do not hinder the operation of the proposed framework.

Chapter Seven describes the historical reasons for regulating media content and discusses the three main forms of media regulation that exist globally - statutory regulation, self-regulation and co-regulation. The positive and negative attributes of each form are outlined and the argument is put forward that a co-regulatory approach should be adopted between the BSA and Internet broadcasters to ensure that the proposed framework works well in practice. 
Chapter Eight draws on the theory of responsive regulation to suggest future proofing changes to the Act and to see how certain strategies could be used to increase acceptance and compliance by Internet broadcasters with respect to them coming under this paper's proposed jurisdictional extension for the BSA.

The formation and application of Internet content regulation brings up a number of serious issues relating to the New Zealand Bill of Rights Act 1990. Chapter Nine of this paper discusses the inevitable implications and valid concerns that regulating New Zealand-based Internet content through broadcasting standards may have on freedom of expression.

Chapter Ten concludes the paper by arguing that there should be a process available for New Zealanders to complain about audiovisual, audio and even some associated textual content on the websites of selected New Zealand-based Internet broadcasters.

\section{A. Definitions}

When this dissertation refers to the term "content regulation", it means methods of intervention into the access or supply of particular types of broadcast and electronic content for

protective reasons, such as maintaining standards of good taste and decency or accuracy in news and factual programming.

For the purposes of this paper, the term "Internet broadcaster" means broadcasters who provide audio and/or audio-visual programming content on their websites.

The term "associated text" refers to online written material which is related to the audiovisual or audio content subject to complaint, such as a written article underneath a video link. It does not include text commentary or opinions from readers or viewers in sidebars or comment threads. 


\section{CURRENT REGULATORY SYSTEM OF MEDIA IN NEW ZEALAND}

New Zealand's current framework for regulating the various forms of media and their content relies on several different organisations, each having regulatory responsibilities for their specific spheres of influence. It is largely a complaints-based system with most regulatory organisations being unable to take action on media content unless a complaint is made by an individual or organisation. Because of the system's multi-organisational nature, some have described it as a patchwork of regulators, each with their own different set of rules and regulations applying to their particular area of responsibility. ${ }^{2}$ Some of the regulatory bodies have been created through statute and are funded by government, such as the BSA and the OFLC (statutory regulation). Others, like the ASA and the PC, have been created and are funded and run by the particular industries themselves (self-regulation).

This part of the paper will look mainly at the regulatory roles and effectiveness of the BSA, ASA and the PC. These organisations are the most commonly used complaints bodies dealing with media content in New Zealand, and hence they are the most relevant in terms of what this paper will be discussing - the application of broadcasting standards to particular Internet broadcasters.

It is acknowledged that there are other organisations who exercise jurisdiction over Internet publications, including The OFLC and the DIA. This chapter briefly looks into the roles played by these two bodies with respect to complaints about online material and how their role differs from that of the BSA.

In addition to the roles played by these regulatory bodies, people may seek remedies through civil court action in the form of bringing a case alleging defamation, contempt of court, breach of privacy or seeking injunctive relief. This dissertation does not intend to cover the civil law remedies available to people or organisations, but will instead focus on the non-court

\footnotetext{
${ }^{2}$ Russell Brown and Steven Price The Future of Media Regulation in New Zealand: Is There One? (Broadcasting Standards BSA, Wellington, 2006) 29.
} 
alternatives looking specifically at the public's ability to make complaints to regulatory bodies about media content.

\section{A. Broadcasting Standards Authority}

1 About the BSA

In New Zealand, programming content that is broadcast either on television or radio is subject to government regulation under the New Zealand Broadcasting Act 1989 (the Act). ${ }^{3}$ One of the functions of the Act was to, amongst other things, establish the BSA and to define its functions and powers. ${ }^{4}$

The Act requires television and radio broadcasters to maintain specific standards with respect to the programming content they broadcast. These standards are set out in sections 4 and 21 of the $\mathrm{Act}^{5}$ and broadcasters are responsible for ensuring that their programming complies with the following: ${ }^{6}$

- current norms of good taste and decency;

- maintenance of law and order;

- balance in reporting controversial issues of public importance;

- the protection of children;

- the portrayal of violence;

- fairness to individuals and organisations taking part or referred to;

- accuracy in news, current affairs and factual programming;

- discrimination and denigration;

- restrictions on the promotion of liquor;

- warnings and classifications;

- privacy of the individual; and

- any approved codes of broadcasting practice.

\footnotetext{
${ }^{3}$ Broadcasting Act 1989.

${ }^{4} \mathrm{Ibid}, \mathrm{s} 20$ establishes the BSA, its functions are set out in s 21 and its powers are set-out through Parts 1-3 of the Act.

${ }^{5}$ Ibid, s 4 and s 21(e)(i-vii).

${ }^{6} \mathrm{Ibid}, \mathrm{s} 4(1)(\mathrm{a})-(\mathrm{e})$.
} 
The Act also established a complaints framework which enables people and organisations to complain about a specific item that has been broadcast. ${ }^{7}$ The Act also required the formation of an independent body, other than a broadcaster, to be available to unsatisfied complainants to have the broadcaster's decision on their complaint reviewed. ${ }^{8}$ That body is the New Zealand Broadcasting Standards Authority. ${ }^{9}$ The BSA is an independent Crown Entity that has statutory powers to ensure broadcasters are fulfilling their obligations with respect to programming standards. Complaints are determined by the BSA's Board that comprises of four members appointed under statutory criteria and which is chaired by a long standing lawyer. ${ }^{10}$

In addition to determining complaints, the BSA, in conjunction with broadcasters, reviews and approves codes of broadcasting practice. Currently, there are four codes which cover free-to-air television, pay television, radio, and election programming. ${ }^{11}$

The BSA reviews the Codes approximately every five years (more often if required) and, while broadcasters are responsible for developing codes, the BSA approves them after consultation with a number of organisations. ${ }^{12}$ The public also has the opportunity to comment on the content of the codes, with the BSA posting draft codes on its website for public input when it is undertaking a review. ${ }^{13}$ Each code has a series of standards which are supported by guidelines and, in some cases, practice notes to assist with interpretation.

\section{(a) Free-to-Air Code of Broadcasting Practice}

This code was prepared by the Television Broadcasters' Council on behalf of TV One, TV2, TV3, C4, Prime, Maori Television and other free-to-air services ${ }^{14}$. With respect to programming content, it is the broadcaster's responsibility to maintain standards relating to: ${ }^{15}$

Standard 1. Good taste and Decency

\footnotetext{
${ }^{7}$ Broadcasting Act 1989, ss 5-19.

${ }^{8}$ Ibid, s 5(b). This section requires the formation of an independent body to ensure broadcasters are discharging their responsibilities.

${ }^{9}$ Ibid, s 20. This section establishes the BSA.

${ }^{10}$ Ibid, s 26. This section deals with the membership the BSA's Board.

${ }^{11}$ Broadcasting Standards BSA <www.bsa.govt.nz $>$.

${ }^{12}$ Broadcasting Act 1989, s $21(\mathrm{e})$.

${ }^{13}$ Broadcasting Standards Authority <www.bsa.govt.nz $>$.

${ }^{14}$ Ibid.

${ }^{15}$ Free-to-Air Television Code of Broadcasting Practice (Broadcasting Standards Authority, Wellington, last revised 1 July 2009) 1-6.
} 
Standard 2. Law and Order

Standard 3. Privacy

Standard 4. Controversial issues - Viewpoints

Standard 5. Accuracy

Standard 6. Fairness

Standard 7. Discrimination and Denigration

Standard 8. Responsible Programming

Standard 9. Children's Interests

Standard 10. Violence

Standard 11. Liquor (promotion of)

\section{(b) Pay Television Code of Broadcasting Practice}

Pay television enjoys a less restrictive environment than free-to-air television and radio because of the special choice subscribers make in paying to receive broadcasts. ${ }^{16}$ The less restrictive environment within which pay television operates is a good example of how the standards regime can be applied in different ways (e.g. pay television has a higher threshold applied to it for breaches of good taste and decency than free-to-air) depending on the platform upon which the content is made available. This flexibility in the regime would allow for the same sort of stance to be taken in relation to Internet content, that is, the standards imposed and the way in which they are applied to content could be tailored to suit the nature of the Internet and to cater for its differences from traditional media platforms.

Protective mechanisms available for subscribers of pay television include: ${ }^{17}$

- Electronic programme guides can be made available to provide additional programme information. Thus viewers can inform themselves on-screen about the content which they are accessing.

- Filtering technology (e.g. parental locks with PIN access) can be made available to protect younger viewers and limit access to unwanted content.

- Watersheds apply to content classified R18 if filtering technology is not automatically provided free of charge to subscribers.

- Subscribers are required to be aged over eighteen years.

\footnotetext{
${ }^{16}$ Pay Television Code of Broadcasting Practice (Broadcasting Standards Authority, Wellington, last revised 2006) 2.

${ }^{17}$ Ibid, 2.
} 
This code is based on four principles which balance adult freedom with responsibility to the vulnerable: ${ }^{18}$

- Adult viewers should be able to make informed choices with a reasonable prior understanding of what they will see or hear.

- Children and young people are protected from content that may harm or disturb.

- Pay television broadcasters should operate in a socially responsible manner.

- Freedom of information and expression is respected, and balanced with the requirement to adhere to broadcasting standards.

Pay television broadcasters are responsible for maintaining standards relating to: ${ }^{19}$

P1. Content Classification, Warning and Filtering

P2. Good Taste and Decency

P3. Children

P4. Violence

P5. Law and Order

P6. Balance

P7. Fairness

P8. Accuracy

P9. Privacy

P10. Liquor [promotion of]

\section{(c) Radio Code of Broadcasting Practice}

The radio code was prepared by the Radio Broadcasters Association (on behalf of commercial broadcasters), and Radio New Zealand and aims to ensure compliance with the law, prevention of misleading or deceptive practices, and the observance of social responsibility. ${ }^{20}$ Radio broadcasters are responsible for maintaining standards consistent with the following principles: ${ }^{21}$

Standard 1. Good Taste and Decency

Standard 2. Law and Order

Standard 3. Privacy

\footnotetext{
${ }^{18}$ Pay Television Code of Broadcasting Practice (Broadcasting Standards Authority, Wellington, last revised 2006), 2.

${ }^{19}$ Ibid, 3-6.

${ }^{20}$ Radio Code of Broadcasting Practice (Broadcasting Standards Authority, Wellington, last revised 2004), 1.

${ }^{21}$ Ibid, 2-6.
} 
Standard 4. Controversial Issues - Viewpoints

Standard 5. Accuracy

Standard 6. Fairness

Standard 7. Discrimination and Denigration

Standard 8. Responsible Programming

Standard 9. Liquor [promotion of]

(d) Election Programmes Code of Broadcasting Practice

The purpose of this Code is to emphasise important principles regulating the content of broadcast election programmes. ${ }^{22}$ It defines what an election programme is for the purposes of the Code and contains the following standards:

- Election programmes subject to other Codes

- Distinguishing factual information from opinion or advocacy

- Denigration

- Misleading programmes

- Opening and closing addresses

\section{BSA's Complaints Process}

The BSA's complaint process is designed to be as accessible as possible, and is free of charge and available to any person or organisation including those based overseas. In considering every complaint referred to it, the BSA is required to provide for as little formality and technicality as is permitted by the requirements of the Act, the proper consideration of the complaint and the principles of natural justice. ${ }^{23}$ The process for complaints about all broadcast material - apart from election programmes, which has slightly different rules - is relatively straightforward and in general it is as follows:

\footnotetext{
${ }^{22}$ Election Programmes Code Broadcasting Practice (Broadcasting Standards Authority, Wellington, last revised 2008), 3 .

${ }^{23}$ Broadcasting Act 1989, s 10(2)(a)-(c).
} 
- An individual or organisation must lodge a formal complaint with the relevant broadcaster within 20 working days from the date of broadcast. ${ }^{24}$ The exception to this rule is that privacy complaints can be referred directly to the BSA. ${ }^{25}$

- Upon receiving a formal complaint, a broadcaster has a statutory obligation to put the complaint to its standards committee or other such body for assessment. ${ }^{26}$

- The broadcaster has a statutorily defined time limit of 20 working days to provide the complainant with a reasoned decision either upholding or declining to uphold the complaint ${ }^{27}$. The 20 working day time limit can be extended up to 40 working days where the complaint deals with complex subject matter. ${ }^{28}$

- After having received the broadcaster's decision, a complainant has 20 working days to refer their complaint to the BSA if they are dissatisfied.

- Upon receiving a referral, the BSA requests a copy of the complainant's original formal complaint, the decision on the complaint and a recording of the item subject to complaint from the broadcaster. The BSA also asks the broadcaster if it has any submissions that it would like to make in support of its decision.

- If the broadcaster does make submissions in support of its decision, the complainant is then given an opportunity to respond. After the submissions process is complete, the material is put before the BSA's Board for determination.

- The BSA's decisions are made public and can be accessed via its website ${ }^{29}$.

If the BSA decides to uphold a complaint, it has several legally enforceable options available to it when deciding how to sanction the infringing broadcaster. The BSA can order a broadcaster to broadcast a statement (e.g. a correction or apology), ${ }^{30}$ direct the broadcaster to refrain from broadcasting programmes or advertising for a period no longer than 24 hours, ${ }^{31}$ refer the complaint back to the broadcaster for re-consideration, ${ }^{32}$ or order a broadcaster to pay

\footnotetext{
${ }^{24}$ Broadcasting Act 1989, s 6(2).

${ }^{25}$ Ibid, s 8(1A).

${ }^{26}$ Ibid, s 6(1)(a).

${ }^{27} \mathrm{Ibid}, \mathrm{s} 8(1 \mathrm{~A})$ if a complainant has not received a decision from the broadcaster or a letter giving the reasons why it cannot met the 20 working day time limit, they can refer their complaint directly to the BSA.

${ }^{28}$ Broadcasting Act 1989, s 8(1A)

${ }^{29}$ Broadcasting Standards Authority <www.bsa.govt.nz $>$.

${ }^{30}$ Broadcasting Act 1989, s 13(1)(a).

${ }^{31}$ Ibid, s 13(1)(b)(i)-(ii).

${ }^{32}$ Ibid, s 13(1)(c).
} 
compensation of up to $\$ 5,000$ to an individual whose privacy has found to have been breached. ${ }^{33}$ The BSA can also order a broadcaster to pay costs to the Crown for a sum not exceeding $\$ 5,000$ per offence. $^{34}$

The BSA has additional powers to make orders in respect of a series. If it considers that a series contains material injurious to the public good, it can order a broadcaster to withdraw programmes or specify conditions of broadcast that must be complied with. ${ }^{35}$ The Act gives the BSA the power to decline to determine complaints which it believes are vexatious, trivial, or frivolous or, in the circumstances, inappropriate for the BSA to determine. ${ }^{36}$

If a complainant or broadcaster disagrees with the BSA's final determination, they can appeal the decision in part or in whole to the High Court. ${ }^{37}$ The High Court treats appeals against decisions made by the BSA as if they were appeals from the exercise of a discretion. ${ }^{38}$ The Court of Appeal has stated that "the appeal should only be allowed if the BSA has proceeded on a wrong principle, given undue weight to some factor or insufficient weight to another, or is plainly wrong". ${ }^{39}$ The decision of the High Court is final, with no further rights of appeal. ${ }^{40}$

Pursuant to section 12 of the Act, sections 4B, 4C, 4D, 5, 6, 7, 8 and 9 of the Commissions of Inquiry Act 1908 apply to the BSA. ${ }^{41}$ This means that when the BSA is considering a complaint, it has powers to order the discovery of documents or any other materials it believes are required to determine the complaint, essentially acting as if it were a Commission of Inquiry. ${ }^{42}$ The BSA uses these powers sparingly, but if it has to it can make an order for discovery or production via an interlocutory decision, a recent example being Ministry

\footnotetext{
${ }^{33}$ Broadcasting Act 1989, s 13(1)(d).

${ }^{34}$ Ibid, s 16.

${ }^{35} \mathrm{Ibid}, \mathrm{s} 13 \mathrm{~A}(3)(\mathrm{a})-(\mathrm{b})$.

${ }^{36}$ Ibid, s 11 (a)-(b).

${ }^{37}$ Ibid, s 18.

${ }^{38}$ Ibid, s 18(4). See also, Professor John Burrows Assessment of Broadcasting Standards BSA Decisions (Broadcasting Standards Authority, Wellington, 2006) 1.

${ }^{39}$ Comalco NZ Ltd v Broadcasting Standards Authority (1995) 9 PRNZ 153, 161-162.

${ }^{40}$ Broadcasting Act 1989, s 19.

${ }^{41}$ Ibid, s 12 .

${ }^{42}$ Ibid, s 12(a)-(b).
} 
of Health $v$ CanWest TVWorks $L t d .{ }^{43}$ While the BSA can hold a formal hearing to determine a complaint, it has never done so preferring to let the parties make written submissions.

\section{The Problem with Internet Content}

The Act defines a broadcaster as "a person who broadcasts programmes". 44 The Act goes on to define "broadcasting" as: ${ }^{45}$

any transmission of programmes, whether or not encrypted, by radio waves or other means of telecommunication for reception by the public by means of broadcasting receiving apparatus but does not include any such transmission of programmes - (a) made on the demand of a particular person for reception only by that person or (b) made solely for performance or display in a public place.

This definition seemingly excludes content broadcast on the Internet, because programming on the Internet is 'on-demand' and is arguably only for the reception of the person who decides to download the material and then view it. In 2004, the BSA dealt with the issue of whether video clips available for download on Television New Zealand's (TVNZ) website were 'broadcasts' over which it had jurisdiction. It held that video clips available for download did not come under its jurisdiction because: ${ }^{46}$

...the material is not continually being shown on the website, regardless of whether users choose to view it, in the same manner that television stations broadcast irrespective of whether the audience chooses to watch. Downloadable video will not play unless specifically sought by the viewer...clicking on the relevant icon and downloading information from a website... amounts to "on-demand" transmission of a programme, for reception only by that person. As such, it falls directly within the exclusion contained in paragraph (a) of the definition of "broadcasting".

The suggestion remains, however, that the BSA may consider material that is continually being shown on a website regardless of whether users choose to view it - that is, streamed on a

\footnotetext{
${ }^{43}$ Ministry of Health $v$ CanWest TVWorks Ltd (10 October 2007) Broadcasting Standards Authority 012/07. Through an interlocutory decision the BSA ordered CanWest TVWorks Ltd to supply it with the field tape of an interview after the broadcaster had refused to supply it on request.

${ }^{44}$ Broadcasting Act 1989, s 2.

${ }^{45}$ Ibid, s 2.

${ }^{46}$ TVNZ v Davies (31 March 2005) Broadcasting Standards Authority 207/04, 1.
} 
fixed schedule - a 'broadcast', and hence be subject to the BSA's jurisdiction. ${ }^{47}$ The BSA has not received a complaint about such material to date, but this paper considers that, if the material subject to complaint had been streamed live, the BSA would have to accept the complaint because it arguably falls within the definition of "broadcasting" in the Act. Not accepting such a complaint (i.e. where the content subject to complaint was streamed live online) would be, in this paper's view, an abrogation of the BSA's statutory responsibilities.

Furthermore, broadcasters are tending to make extended coverage, uncut versions of programmes and increasingly edgier material available on their websites. For example, TV3's website contains extended coverage of the Boobs on Bikes Parade ${ }^{48}$ which would, in all likelihood, be considered salacious and intended to titillate viewers, and hence breach standards relating to good taste and decency if shown on TV3's free-to-air channel.

\section{Effectiveness of the BSA}

In 1996 the BSA commissioned Professor John Burrows to undertake an assessment of the BSA's decisions. ${ }^{49}$ Professor Burrows' overall impression was that, from a legal point of view, the BSA's decisions exhibited the appropriate level of rigour and analysis and were based on principles that were legally sound. ${ }^{50}$ He concluded his assessment by stating that: ${ }^{51}$

I think there can be very little objection from a legal point of view, or indeed any other point of view, to the way the Broadcasting Standards BSA is performing its statutory task. I am particularly impressed with the succinct yet persuasive nature of the decisions and with the consistency they display.

While Professor Burrows' sentiments reflect a legal point of view, various organisations and community groups believe that the BSA is not as effective as it could be in terms of

\footnotetext{
${ }^{47}$ Russell Brown and Steven Price above n 2, 29.

${ }^{48}$ MediaWorks Ltd <www.tv3.co.nz>, extended coverage of "Boobs on Bikes" parade available at $<$ www.3news.co.nz/Extended-footage-of-the-Boobs-on-Bikes-parade/tabid/312/articleID/33032/Default.aspx>.

${ }^{49}$ Professor Burrows' assessment only looked at the BSA's decisions and did not address the effectiveness of the regime or the need for it.

${ }_{50}^{50}$ Professor John Burrows, above n 38, 1.

${ }^{51}$ Ibid, 20.
} 
maintaining moral standards such as good taste and decency in relation to modern programming content. For example, The Society for the Promotion of Community Standards is of the view that: ${ }^{.2}$

The current broadcasting standards are vague and ill-defined leading to inconsistent and controversial decisions being issued by the BSA and Advertising Standards. The decisions appear to many to make a mockery of the very standards that the majority of the public want upheld.

While not everyone agrees with the outcomes of the BSA's decisions - usually due to the inherent value judgements that the BSA consistently has to make when determining complaints the BSA is upholding a portion of complaints being referred to it. Therefore, broadcasters are causing harm, including breaches of privacy and fairness or inaccurate and/or unbalanced news reporting, on the traditional platforms which are already subject to content standards regulation. In this paper's view, not only are these harms going to be just as bad when taken in the context of being online, but the effects of the harm could be even worse due to the continuous availability and timeless nature of digitalised programming material. To have any hope of being effective in the future, the BSA needs to be given modern tools to deal with a modern problem.

\section{B. Advertising Standards Authority (ASA)}

The ASA was formed in 1973 and its members, in accordance with self-regulatory principles, are requested to be bound by the decisions of the Advertising Standards Complaints Board. $^{53}$ The prime function of the ASA is to self-regulate advertising in New Zealand. ${ }^{54}$ Advertising codes of practice provide the rules with which all advertisements should comply and members of the public can complain at no cost about any advertisement on any media platform including the Internet. ${ }^{55}$

\footnotetext{
${ }^{52}$ Society for the Promotion of Community Standards Inc, submission to the Ministry of Culture and Heritage on the Ministry's consultation paper Broadcasting and New Digital Media: Future of Content Regulation, 1. The Society's submission is available on the Ministry's website through the following link

$<$ www.mch.govt.nz/publications/digital-tv/submissions.html $>$.

${ }_{53}$ Advertising Standards Authority $<$ www.asa.co.nz/asainc.php $>$.

${ }_{55}^{54}$ Advertising Standards Authority, Annual Report (Advertising Standards Authority, 2007, Wellington) 3.

${ }^{55}$ Ibid, 3.
} 
The ASA's membership is made up of representatives from all the major media advertising groups including free-to-air television, radio, pay television, magazines, community newspapers, cinema and outdoor advertisers. ${ }^{56}$ Unlike the BSA, the ASA is self-regulating and is completely funded by members of the advertising industry. ${ }^{57}$

The ASA has introduced and, from time to time, amends codes of practice that have been developed in consultation with industry, consumer groups and government departments for specific categories of advertising where they are considered necessary. ${ }^{58}$ There are currently 13 Advertising Codes of Practice which contain general ethical guidelines, as well as subjectspecific standards. The current codes cover the following topics: advertising to children, comparative advertising, environmental claims, financial advertising, food products, gaming and gambling, liquor, people in advertising, therapeutic products and services, vehicles and weight management.

\section{$1 \quad$ ASA's Complaints Process}

Like the BSA, the ASA has created a simple and straightforward process for members of the public to complain about advertisements. Complaints are dealt with by an independent Advertising Standards Complaints Board (ASCB) with complainants having the right to appeal ASCB's decisions, albeit on limited grounds, to the Advertising Complaints Appeal Board (ACAB). ${ }^{59}$ ASCB is comprised of eight people, with an equal split of four members from the industry and four members from the public (the chair being a member of the public). ${ }^{60}$ The ACAB is made up of three people, one from the industry and two from the public who adjudicate only on appeals. ${ }^{61}$

The process for making a complaint about an advertisement is as follows: ${ }^{62}$

\footnotetext{
${ }^{56}$ Advertising Standards Authority <www.asa.co.nz/asainc.php $>$.

${ }^{57}$ Andrea Millwood Hargrave, Geoff Lealand, Paul Norris and Andrew Stirling Issues Facing Broadcast Content Regulation (Broadcasting Standards Authority, Wellington, 2006) 23.

${ }_{58}$ Advertising Standards Authority $<$ http://www.asa.co.nz/asainc.php $>$.

${ }^{59}$ Advertising Standards Authority, above n 54, 3.

${ }^{60}$ Debra Harker, Michael Harker and Glen Wiggs Responsive Advertising Regulation: A case Study from New Zealand (Australian Journal of Political Science, Vol. 40, No.4, pp 1-14, 2005) 4. Available at $<$ www.ffar.org/PDFS/AJPS\%20CAJP130227.pdf >.

${ }^{61}$ Harker, Harker, Wiggs, above n 60, 4.

${ }^{62}$ Advertising Standards Authority $<$ http://www.asa.co.nz/asainc.php $>$.
} 
- Complaints can be made in writing or using the online complaints form at www.asa.co.nz.

- The Chairperson will determine whether the complaint is suitable for the Board's consideration and within the Board's jurisdiction.

- If a complainant does proceed, then the Board will then determine whether the Codes of Practice have been breached. A formal written decision is distributed to the complainant, the parties and to the media.

- In lodging a complaint, the complainant accepts that he/she will not pursue the complaint in any other forum and is required to sign a waiver to that effect.

- If a complaint is upheld the advertiser, in accordance with self-regulatory principles, is requested to voluntarily and immediately withdraw the advertisement. Additionally, the media are similarly requested not to publish or broadcast an advertisement which has been held by the Board to be in breach of the Codes of Practice.

- Decisions of the Complaints Board may be appealed to the Advertising Standards Complaints Appeal Board on certain grounds.

This section does not intend to evaluate the sensibilities of the ASA's decisions or whether they indicate any genuine problem exists in the advertising standards regime. It will, however, briefly look at the effectiveness of this industry-run body in dealing with complaints from the public.

The ASA stated that of the 1246 complaints it received in 2008, 314 substantive advertisements were dealt with by the ASCB, and combining the settlement (71) and uphold figures (92), the complaints upheld rate was fifty-two percent. ${ }^{63}$ The average time for a complaint to be processed from receipt to notification of decision was 22 working days. ${ }^{64}$. The

\footnotetext{
${ }^{63}$ Advertising Standards Authority, above n 54, 21.

${ }^{64}$ Ibid, 22.
} 
ASA states that, in practice, its decisions are invariably complied with and that its rulings have never been ignored by advertisers. ${ }^{65}$

The ASA and the PC are clearly more effective than the BSA is their ability to deal with complaints about on-line content. As mentioned above, the ASA can receive and determine complaints about advertising on any media platform including the Internet. This is a good example of how industry-run self-regulation can effectively adapt quicker to changing technologies and circumstances than government-regulated bodies such as the BSA. For example, changing legislation is inherently more difficult and time consuming than industry representatives agreeing to and implementing changes to self-imposed and self-enforced codes of practice.

However, it is important to note here that as a voluntary and self-regulating organisation, the ASA has no statutory powers to enforce its requests on advertisers. In theory, an advertiser could refuse the ASA's request to withdraw a particular advert and the ASA would have no legal recourse. But in the event that an advertiser regularly breaches advertising codes of conduct and/or does not abide by the decisions of the ASCB, the ASA can release an informal alert to all media, warning of the serial offender and requesting the withholding of advertising space against them. $^{66}$

No doubt advertisers also comply with the ASA's requests because the threat of government regulation provides them with a good incentive to accept the ASA's decisions. If the ASA was seen to be ineffective in performing its regulatory functions, the government may decide to intervene and establish a statutory regime in which non-compliance by advertisers could attract legally enforceable penalties such as fines. As stated in the recent review of the PC: ${ }^{67}$

...organisations self-regulate in order to avoid direct regulation by the state. Rules and regulations are often drawn up in order to pre-empt direct control, to obviate (at least from the organisation's point of view) the need for such intervention, and to placate public concern.

\footnotetext{
${ }^{65}$ Advertising Standards Authority $<$ http://www.asa.co.nz/asainc.php $>$.

${ }^{66}$ Harker, Harker and Wiggs, above n 60, 11.

${ }^{67}$ Sir Ian Barker and Professor Lewis Evans, Review of the New Zealand Press Council (New Zealand Press Council, Wellington, 2007) 14.
} 
The ASA's voluntary nature of compliance appears to be working well. The system emphasises that the codes should be followed not only by the letter but also in the spirit. Members who seek loopholes in the rules could be exposed to an adverse ruling, because such actions go against the spirit of the codes - technical compliance alone is insufficient. ${ }^{68}$

It is interesting to note, however, the provision in section 21 of the Broadcasting Act 1989 which not only sets out the complaint-taking functions of the BSA, but also sets out an exception where the BSA can determine a complaint on advertising material (including those for goods and services) in certain circumstances. ${ }^{69}$

In relation to public participation in the complaints determination process, both the ASCB and the ACAB are weighted in the public's favour and this gives a perception of independence from the industry in relation to dealing with complaints. The ASCB's chairperson is a member of the public and has the casting vote in the event of a four-to-four tie, and the $\mathrm{ACAB}$ has a majority two-to-one of public membership. All in all, the ASA seems to be an effective and representative self-regulatory body. ${ }^{70}$ In fact, New Zealand's system of selfregulated advertising has been described as one of the most comprehensive in the developed world. $^{71}$

\section{The New Zealand Press Council (PC)}

The PC is a self-regulatory body which was established in 1972 by newspaper publishers and by the then Journalists' Union, and is fully funded by members of the industry. ${ }^{72}$ Complaints about the print media are determined by a Council comprising of an independent chairperson (usually a retired High Court Judge) ${ }^{73}$, five members representing the public, two representing the Newspaper Publishers' Association, one representing magazine publishers, and two

\footnotetext{
${ }^{68}$ Harker, Harker and Wiggs, above n 60, 11

${ }^{69}$ See, Broadcasting Act 1989, s 21(3)

${ }^{70}$ Selene Mize Essay - From Goldstein to the Burger King Babes: People Issues in Advertising Contained in The Real Deal: Essays in Law and Advertising Edited by Ursula Cheer (The Centre for Commercial and Corporate Law Inc, Christchurch, 2008) p $109-159$. This essay provides a lot of detail about the ASA and how it is performing.

${ }^{71}$ Harker, Harker and Wiggs, above n 60, 4 .

${ }^{72}$ The New Zealand Press Council <www.presscouncil.org.nz $>$.

${ }^{73}$ Brown and Price, above n 2, 31.
} 
journalists appointed by the Journalists' Union and the NZ Amalgamated Engineering Printing \& Manufacturing Union. ${ }^{74}$

The PC has three principle objectives. These are: ${ }^{75}$

i. To consider complaints against newspapers and other publications. Such complaints must be directed at editorial content. The Council may also consider complaints about the conduct of persons and organisations towards the press.

ii. To promote freedom of speech and freedom of the press in New Zealand.

iii. To maintain the New Zealand press in accordance with the highest professional standards.

The PC considers complaints against newspapers, magazines, periodicals in public circulation in New Zealand, and their associated websites. ${ }^{76}$ Interestingly, it seems that the Press Council will also determine complaints about audio/audiovisual material contained on its members' websites. The PC has the discretion to decline a complaint if the publication complained about has a limited readership or, in the circumstances, the complaint is inappropriate for resolution by the Council. ${ }^{77}$ The PC has not created a set of rules by which publications and their editors should conduct themselves, rather the Council expects editors to take ultimate responsibility for the material contained in their publications and adhere to standards of ethical journalism. ${ }^{78}$ It has, however, created a set of principles as a guide to what ethical journalism is and the types of standards journalists should be maintaining. The Council state that the principles are not to be viewed as a rigid code - like those of the BSA or ASA - but that they can be used by complainants, if required, to help make the nature of their complaint more precise and/or clear to the Council. ${ }^{79}$ The PC's Statement of Principles covers accuracy, corrections, privacy, confidentiality (and reliability of sources), children and young people,

\footnotetext{
${ }^{74}$ The New Zealand Press Council, above n 72.

75 Ibid.

${ }^{76}$ Millwood Hargrave, Lealand, Norris and Stirling, above n 57, 24.

${ }^{77}$ The New Zealand Press Council, above n 72 .

78 Ibid.

${ }^{79}$ Ibid.
} 
comment and fact, advocacy (by the publisher), discrimination, subterfuge, headlines and captions, photographs, letters and Council adjudications. ${ }^{80}$

\section{$1 \quad$ PC's Complaints Process}

The procedure for making a complaint to the PC is as follows: ${ }^{81}$

- Complaints against publications must be in writing to the editor first, within three months of the date of publication.

- If a complainant is not satisfied with the editor's response (or, having allowed a reasonable interval, has received no reply) can write to the Secretary of the Press Council for review.

- If the Council upholds a complaint (in full or in part), the newspaper or magazine concerned must publish a shortened version of the adjudication, giving it fair prominence.

- There is no appeal from a Council decision, but it can be re-examined in the event of compelling new evidence.

- In circumstances where a legally actionable issue may be involved, complainants are required to sign a waiver that they will not take or continue court proceedings to sue the publisher separately (PC claims this is to avoid the possibility of the Council being used as a trial run for litigation).

The PC determines approximately 50 complaints a year with an average upheld/part upheld rate of 23 percent. $^{82}$ In early 2007 the PC commissioned a review of its activities and operations (released mid 2008); this being the first independent review of the Council since its formation in $1972 .{ }^{83}$ Surveys of the public, organisations, complainants and media organisations were conducted as part of the review and these yielded some interesting results with respect to the perceived effectiveness of the Council.

\footnotetext{
${ }^{80}$ The New Zealand Press Council, above n 72. The Council's principles and accompanying explanatory text can be viewed online at the following web address $<$ www.presscouncil.org.nz/principles.html $>$

${ }^{81}$ Ibid. A comprehensive description of the Council's complaints process is available at the following web address $<$ www.presscouncil.org.nz/complain.html>

${ }^{82}$ Millwood Hargrave, Lealand, Norris and Stirling, above n 57, 24.

${ }^{83}$ Barker and Evans, above n 67, 6.
} 
The surveys unearthed some common criticisms relating to the way in which the Council is run and how it deals with complaints. Whether these criticisms are valid is, of course, a matter of opinion based on personal experience. ${ }^{84} \mathrm{~A}$ common view of non-industry participants in the surveys was that they perceived the Council a partisan and not being independent of the publishers. ${ }^{85}$ The respondents who took this point of view saw the PC as having been set up by the industry as a device to deflect the imposition of a statutory regulatory authority like the BSA, and to not be independent of the funders. ${ }^{86}$ However, one could view the BSA in the same manner, as its board members are chosen by the government and could be seen as political appointees who are biased in favour of government bodies, although its decisions are appealable to the High Court. Non-industry respondents were nearly unanimous in their view that the Council is underfunded and many associated with the media were of the same view. ${ }^{87}$ The Council's annual budget is approximately $\$ 160,000$, compared to the ASA's budget of around $\$ 730,000$ and the BSA's of $\$ 1.2$ million. ${ }^{88}$ Regardless of the level of funding the Council receives, it seems that the organisation is dealing with the harms caused by the print media, such as inaccurate or unfair reportage, in an effective manner and with the support of its membership.

\section{The Office of Film and Literature Classification and the Department of Internal Affairs}

Along with the roles played by the ASA and PC, there are several other organisations that play a part in regulating New Zealand's Internet content including audio and audiovisual material. The Films, Videos, and Publications Classification Act 1993 - which defines 'objectionable material ${ }^{89}$ - covers "publications" ${ }^{90}$ including Internet content such as computer

\footnotetext{
${ }^{84}$ Barker and Evans, above $\mathrm{n} 67,68-84$. A full list of the common criticisms is contained in pages $68-84$ of the review.

85 Ibid, 67.

86 Ibid, 67.

${ }^{87}$ Ibid, 67.

${ }^{88}$ Barker and Evans, above n 67, 67.

${ }^{89}$ Films, Videos, and Publications Classifications Act 1993. Under the s 3(1) of the Act, any material that describes, depicts, expresses, or otherwise deals with matters such as sex, horror, crime, cruelty, or violence in such a manner that the availability of the publication is likely to be injurious to the public good is considered objectionable and hence illegal to possess to distribute. The Act was amended in 2005 by the Films, Videos, and Publications Classifications Amendment Act 2005, which made significant changes to the Act's enforcement provisions such as increasing the maximum fine and term of imprisonment.
} 
games, electronic media, all material on Internet websites, images, sound recordings and emails. It is administered by the Ministry of Justice and enforced by New Zealand's Department of Internal Affairs (DIA). The Office of Film and Literature Classification (OFLC) classify films, videos and publications. ${ }^{91}$ Objectionable material is material that deals with sex, violence, horror, crime and cruelty in such a manner that the availability of the publication is likely to be injurious to the public good. ${ }^{92}$ Complaints about objectionable material or discriminatory or hateful content, including Internet material, can be made to the DIA. ${ }^{93}$ New Zealand explicitly prohibits discrimination on the basis of race, religion, age, disability and sexual orientation, amongst other things, and the DIA uses the Human Rights Act 1993 and the Films, Videos and Publications Classifications Act 1993 to investigate complaints about discriminatory online material. $^{94}$

The OFLC classifies material as unrestricted, objectionable or objectionable except for restricted access in the case of educational, professional, scientific, artistic, literary or technical purposes. $^{95}$ However, the OLFC has no explicit legal mechanism, unlike Australia (See discussion of Australia's equivalent, ACMA, in Chapter 6), for the take-down of objectionable material. ${ }^{96}$ The non-profit organisation Internet NZ, however, is in the process of establishing an industry-wide code of conduct that would require its signers to agree not to host objectionable content. $^{97}$

\footnotetext{
${ }^{90}$ Films, Videos, and Publications Classifications Act 1993. s 2, the term 'publication' is defined as (a) any film, book, sound recording, picture, newspaper, photograph, photographic negative, plate or slide (b)any print or writing (c) any paper or other thing including an electronic disk or computer file.

${ }^{91}$ Department of Internal Affairs, Role of DIA in 'Censorship Compliance', available at $<$ http://www.dia.govt.nz/diawebsite.nsf/wpg_URL/Services-Censorship-Compliance-Index?OpenDocument\#one>.

${ }^{92}$ Films, Videos, and Publications Classifications Act 1993, s 3. defines "objectionable material".

${ }^{93}$ Department of Internal Affairs, Role of DIA in 'Censorship Compliance', available at: $<$ http://www.dia.govt.nz/diawebsite.nsf/wpg_URL/Services-Censorship-Compliance-Index?OpenDocument\#one>.

${ }^{94}$ Department of Internal Affairs, information on Acts used and for what type of content available at $<$ http://www.dia.govt.nz/diawebsite.nsf/wpg_URL/Services-Censorship-Compliance-What-isObjectionable?OpenDocument>.

${ }^{95}$ Office of Film and Literature Classification www.censorship.govt.nz, for more information on the OLFC see its website.

${ }^{96}$ Open Net Initiative (ONI) Link to ONI's report on New Zealand's Internet regulation $<\mathrm{http}: / /$ opennet.net/research/regions/au-nz $>$.

${ }^{97}$ Internet NZ < www.Internetnz.net.nz $>$, See the organisation's website for its various papers on the draft code of conduct including objectives and policies.
} 


\section{THE PROBLEM}

Currently there is no substantial system in place, other than the courts, for people to complain about audiovisual and audio programming content on the websites of New Zealandbased broadcasters. Due to rapid technological developments, New Zealand's current regulatory and legislative framework for broadcasting and the application of content standards does not adequately address the issues raised by new media platforms, nor the specific context in which these issues arise. The traditional concepts of broadcasting and who can be defined as being a broadcaster are becoming increasingly removed from the modern day reality. This chapter outlines how media convergence onto the Internet has led to this lacuna in broadcasting regulation and why the BSA's lack of jurisdiction to deal with broadcasters' websites is a problematic and pressing social issue which needs to be addressed.

\section{A. Media Convergence: The Blurring of Boundaries}

1 What is Media Convergence?

The complexities of regulating broadcasting activities in a converging media environment, where the various industries and markets are dissolving and reforming in the face of a rapidly evolving technological and business environment, are numerous. Media convergence has had and continues to have a huge effect on modern society and the way in which information is distributed and received. This paper puts forward the idea that the very need for broadcasting standards to apply to some New Zealand-based Internet content comes as a direct result of media convergence.

The Concise Oxford Dictionary defines converge as "to come together as if to meet or join, tend to meet at a point by approaching from different directions". ${ }^{98} \mathrm{~A}$ good basic example of media convergence is online newspapers, such as the New Zealand Herald's website. ${ }^{99}$ Online newspapers not only contain written material, but also audio and audiovisual content. To put it another way, print publishers have begun to move into the domain of broadcasters and the

\footnotetext{
${ }_{98}^{98}$ R. E. Allen (ed) The Concise Oxford Dictionary ( $8^{\text {th }}$ ed, Oxford University Press, New York, 1991).

${ }^{99}$ The New Zealand Herald <www.nzherald.co.nz>
} 
traditional boundaries which separate the different media mediums are becoming increasingly blurred. ${ }^{100}$ Another aspect of media convergence is that traditional media platforms are now branching out and providing their programming on new platforms. For example, Television New Zealand Ltd provides programming content such as One News and 20/20 on its website. ${ }^{101}$

The evidence that people and the media industry are shifting away from the traditional platforms and onto the Internet is beginning to appear. For example, a 2008 study looking at how Americans received their news and current affairs content found that: ${ }^{102}$

The Internet, which emerged this year as the leading source for [United States] campaign news, has now surpassed all other media except television as an outlet for national and international news. Currently $40 \%$ say they get most of their news about national and international issues from the Internet, up from just $24 \%$ in September 2007. For the first time in a PEW survey, more people say they rely mostly on the Internet for news and cite newspapers...For the young, however, the Internet now rivals television as a main source of national and international news. Nearly six-in-ten Americans younger than $30(59 \%)$ say they get most of their national and international news online.

Further, recent research conducted by Britain's Office of Communications (Ofcom) shows that one in three United Kingdom adults who use the Internet are watching online or downloading television programmes. ${ }^{103}$ The same research showed that, in general, the public believe all content, whether it be radio, television, the Internet or mobile phone television, is in fact already regulated and has standards applied to it. ${ }^{104}$ For example, 38 per cent of people surveyed thought Internet content was regulated and had similar broadcasting standards to those enforced on television and radio. ${ }^{105}$

\footnotetext{
${ }^{100}$ Brown and Price, above n 2, 25.

${ }^{101}$ Television New Zealand Limited <www.tvnzondemand.co.nz $>$.

${ }^{102}$ Pew Research Centre Internet Overtakes Newspapers as News Outlet 23 December, Pew Research Centre Publications, 2008), available online at: $<\mathrm{http} / /$ people-press.org/report/479/Internet-overtakes-newspapers-as-newssource $>$. The Pew Research Centre for the People \& the Press is an independent, non-partisan public opinion research organization that studies attitudes toward politics, the press and public policy issues. In this role it serves as a valuable information resource for political leaders, journalists, scholars and citizens.

${ }^{103}$ Office of Communications “UK Adults’ Media Literacy Interim Report 2009” (London, 15 October, 2009) 20.

The research involved 812 in-home interviews with adults aged 16 and over from April to May 2009 and is designed to give an accessible overview of media literacy among UK adults aged 16 and over. It is available at $<$ http://www.ofcom.org.uk/advice/media_literacy/medlitpub/medlitpubrss/uk_adults_ml/adult_ml.pdf > ${ }^{104}$ Ibid, 30.

${ }^{105}$ Ibid 30-31.
} 
One of the major problems when combining the notions of broadcasting, the Internet and media convergence is that it creates a lot of confusion, especially in the minds of regulators. The confusion surrounding Internet broadcasting and how to regulate it: ${ }^{106}$

...is a result, in part, of convergence, the fact that traditional offline activities are increasingly shifting online. On the one hand, the rapid development of the Internet is widely perceived as having occurred largely in, and possibly through, the absence of substantial government intervention. As such, regulation is viewed as an anathema to cyberspace, potentially restraining the creative forces that have underpinned its growth, and governments are concerned that undue or inappropriate regulatory intervention may kill the 'golden goose' that the Internet represents.

So the real issue for any government looking to regulate Internet content is deciding what Internet content, if any, should be subject to regulatory intervention. Governments are expected to govern, including acting to restrain behaviours considered harmful to society, such as breaches of privacy or advocacy of excess liquor consumption or inaccurate reporting. 107 "Convergence confronts governments with a dilemma between maintaining a hands-off stance and regulatory intervention". ${ }^{108}$ When trying to attain a better understanding of how powerful media convergence has been in shaping how people receive and impart information, it helps to take a global view. In his book Convergence Culture, ${ }^{109}$ Henry Jenkins provides a compelling example that demonstrates the powerful effects of media convergence in action. It is as follows: ${ }^{110}$

In 2001, an American high school student named Dino Ignacio created a Photoshop collage of Sesame Street's character Bert with terrorist leader Osama Bin Laden as part of his "Bert is Evil" series of images which he posted on his homepage. Just after the September 11 attacks in America, a publisher based in Bangladesh was looking for images of Osama Bin Laden to print on anti-American signs, posters and T-shirts. While an Arab version of Sesame Street was available, it did not contain the Western version's characters of Bert and Ernie and as

\footnotetext{
${ }^{106}$ Ian Walden Regulating Broadcasting in a Converging Environment: Without Frontiers and Without a Fuss! (Media and Arts Law Review, vol 12 No.4, 2007, Australia) 423, 429-430.

${ }^{107}$ As evidenced in 2009, the BSA upheld a number of complaints concerning various breaches relating to all the standards contained in the free-to-air television code. These ranged from Standard 1(good taste and decency) through to Standard 11 (liquor promotion). Copies of the upheld complaints are available on the BSA's website at www.bsa.govt.nz.

${ }^{108}$ Walden, above $\mathrm{n} 106,430$.

${ }^{109}$ Henry Jenkins Convergence Culture: Where Old and New Media Collide (New York Press, New York, 2006) 12.

${ }^{110}$ Ibid, $1-2$.
} 
such, nobody knew who the character Bert was. The publisher liked the particular picture of Bin Laden contained in Dino's creation and the image ended up in a collage of similar images that was then printed on thousands of posters and distributed across the Middle East. Then, CNN reporters located in the Middle East spotted a group of angry protestors marching through the streets chanting anti-American slogans and waving signs containing the image of Bert and Bin Laden. The reporters filmed the footage and it was broadcast on CNN that night and was made available on the organisations website.

As Jenkins states, "Welcome to the convergence culture, where the old and new media collide, where grassroots and corporate media intersect, where the power of the media producer and the power of the media consumer interact in unpredictable ways". ${ }^{111}$ The circuit through which the "Bert is Evil" image travelled is quite amazing. It went from Sesame Street, to Photoshop, to the Internet, from Dino's homepage to a publisher in Bangladesh, to posters held by anti-American protesters in the Middle East, to footage captured by CNN, and then televised into the living rooms of people all around the world and then placed on the broadcaster's website.

Jenkins defines media convergence as "the flow of content across multiple media platforms, the cooperation between multiple media industries, and the migratory behaviour of media audiences who will go almost anywhere in search of the kinds of entertainment experiences they want". ${ }^{112} \mathrm{He}$ goes on to say that the term convergence also manages to describe technological, industrial, cultural and social changes depending on who is speaking and what it is they think they are talking about. ${ }^{113}$ "Convergence represents a cultural shift as consumers are encouraged to seek out new information and make connections amongst dispersed media content", he says. ${ }^{114}$

\footnotetext{
${ }^{111}$ Jenkins, above n 1092.

${ }^{112}$ Ibid, 2.

${ }^{113}$ Ibid, 2 .

${ }^{114}$ Ibid, 3 .
} 
In her book Media Organisations and Convergence, Gracie Lawson-Borders provides a much simpler and straightforward definition of what she thinks media convergence actually is. ${ }^{115}$ She states that, while media convergence has been defined in many different ways and is an elusive term, the simplest definition is "the combining of old (traditional) media with new media for the dissemination of news, information and entertainment". ${ }^{116}$

There have been numerous attempts to explain and define what media convergence actually is, but the one thing they all describe is traditional media branching out onto the Internet and a blending of technological capabilities to deliver content (see figure 1 below). ${ }^{117}$

Figure 1. Convergence Definition Model

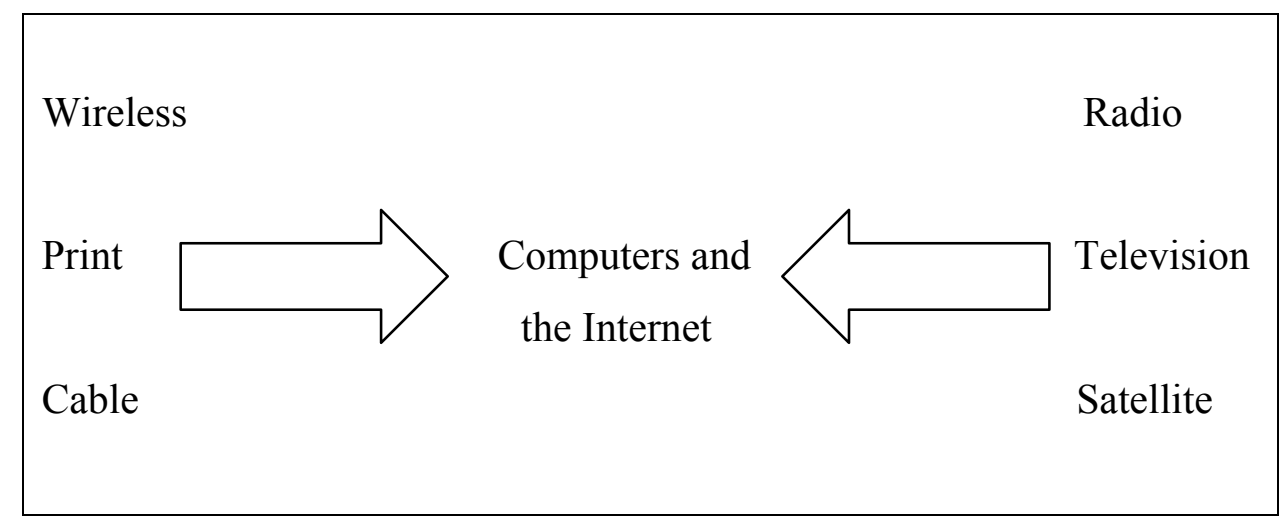

$2 \quad$ Why is Addressing the Effects of Media Convergence Important?

Addressing media convergence is fundamentally important because of the way in which it has impacted on how news and entertainment organisations disseminate their content and the effects it is having on changing the way people choose to receive information in this new multimedia environment. For example, people used to receive most of their news information from television, radio or hard copy newspapers. This is not necessarily the case anymore in a converged media environment, with people having much more control over how and when they receive information or programming content. The main driver for reform in New Zealand broadcasting legislation is the rapid growth in the variety and number of different media platforms over which New Zealanders receive programming material. Free-to-air terrestrial

\footnotetext{
${ }^{115}$ Gracie Lawson-Borders Media Organizations and Convergence: Case Studies of Media Convergence Pioneers (Routledge, New Jersey, 2005).

${ }^{116}$ Ibid, ix (preface).

${ }^{117}$ Ibid, 4.
} 
broadcasting and radio, the incumbent models, now compete with satellite, cable and broadband Internet and mobile services. ${ }^{118}$

A second fundamental change in the media consumption market concerns the mode by which audiovisual and audio content is supplied to consumers. The classic broadcasting paradigm (television and radio) was one where broadcasters transmitted or pushed programming material simultaneously to the general public, who simply chose whether to watch or listen to the material or not. ${ }^{119}$ At present, a new broadcasting environment is beginning to emerge and a shift away from the existing paradigm is occurring. As a result, the current regulatory framework for broadcasting is becoming increasingly out of step with the modern reality. Communications and Technology Law Professor Ian Walden believes that the paradigm shift and the inevitable increase in the ineffectiveness of existing broadcasting regulation has been occurring because: ${ }^{120}$

\begin{abstract}
In the current environment, while [the traditional broadcasting] paradigm continues to represent a dominant means of receiving audiovisual material, we are also witnessing the emergence of a wide range of alternatives, most specifically the provision of material in response to the demand of an individual viewer, often obtained (or 'pulled') from a selection of material made available by the broadcaster. However, the regulatory definition [in New Zealand] goes on to expressly exclude the provision of services 'on individual demand' from its scope. Such fundamental changes in the provision of broadcasting services has meant that the existing regime is no longer fit for purpose... the changing manner by which content is distributed, particularly in an Internet environment, has already required law reform in other fields.
\end{abstract}

Looking at the statistics regarding changes in media consumption (see, for example the statistics on pages 29-30), it is clear that media consumers are moving away from the traditional media platforms of hard copy newspapers, radio and television and becoming active in choosing the content they view, rather than having it fed to them by editors and broadcasters. It is not hard to imagine that in the not-too-distant future the dominant means for consumers to receive audiovisual and audio material is via the Internet. In fact, it is probably inevitable, as more and more broadcasters make their content available online. For example, in England the BBC

\footnotetext{
${ }^{118}$ Walden, above n 106, 424.

${ }^{119}$ Ibid, 425. See also Broadcasting Act 1989 s2, definition of a 'broadcasting'.

${ }^{120}$ Ibid, 425.
} 
(British Broadcasting Corporation) recently announced its decision to broadcast some of its most popular content (such as Doctor Who from its flagship channel BBC1) live over the Internet. ${ }^{121}$ The BBC already offers a selection of programming material from all its channels for download after they have aired and it already has two existing channels available live online called BBC3 and BBC News. ${ }^{122}$ This was the first instance in the United Kingdom of an analogue channel to make the shift to broadcasting live on the Internet; some digital channels such as ITV had made the shift one year prior. England's MP Philip Davies, who currently sits on England's Culture, Media and Sport Select Committee, was quoted as saying "This could be the beginning of the end for the conventional TV set...a shift to [online] programming is creating a generation of viewers, who may never use a television set." ${ }^{23}$ The BBC's website TV at a Click has proved to be popular for viewers, with millions accessing it every month. ${ }^{124}$

Media convergence and the rapid increase in traditional broadcasters making content available online, has led to what has been coined as the "TVisation" of the Internet. ${ }^{125}$ Many broadcasters including the major players in New Zealand have turned their attention to providing material to their online audience. Like any business, broadcasters are always searching for new ways to make money from the material that they own. In early 2008, major American television distributor Warner Brothers has opened their library of classic content online, making thousands of episodes of famous programmes such as the Twilight Zone and the Mary Tyler Moore Show available free of charge with Warner Brothers receiving money from advertisers. ${ }^{126}$ Other major American broadcasters such as CBS, NBC and TV Land have begun streaming some of their programming content on their websites. ${ }^{127}$ Warner Brothers has also re-started its WB broadcast network as an Internet destination offering consumers live streaming of its new programming content. $^{128}$ Advertising-supported television streaming sites like Hulu ${ }^{129}$, Veoh ${ }^{130}$ and Joost ${ }^{131}$

\footnotetext{
${ }^{121}$ Paul Revoir "Is this the end of the television set? BBC1 to broadcast live on the Internet" (5 June 2008) DailyMail Online, United Kingdom. See site at: $<$ www.dailymail.co.uk $>$.

122 Ibid.

123 Ibid.

${ }^{124}$ Ibid.

${ }^{125}$ Bruce Simpson "Devolution of the Internet" (12 March 2008) Aardvark Daily, New Zealand: $<$ www.aardvark.co.nz>.

${ }^{126}$ Brian Stelter "Golden Years of Television Given New Life on the Web" (28 April 2008) The New York Times (online). New York. <www.nytimes.com>.

127 Ibid.

${ }^{128}$ Ibid.
} 
are providing media consumers with access to the last 50-years-worth of television content at the touch of a button. President of Warner Brothers television group, Bruce Rosenblum, stated that "premium ad-supported digital destinations that are demographic specific are a key part of the company's strategy going forward". ${ }^{132}$ One of the aims of broadcasters both live streaming and providing downloadable content online is to drive people back to the linear channel viewing pattern. The online broadcasters' goal is to get people watching or listening to the Internet like they do television and radio through measures such as streaming content on their websites live and having archives containing a wide variety of programming content.

Around the world, more and more broadcasters are beginning to stream programming content live on their websites simultaneously with the material they broadcast on radio and television, which is then made available for download at any time. For example, New Zealand's largest television broadcaster, Television New Zealand Ltd (TVNZ), now streams all of its daily news programmes live on its Internet site, which are then archived for future access. ${ }^{133}$ It advertises its live-streaming feature by saying: ${ }^{134}$

\begin{abstract}
Are you stuck at work and don't want to miss ONE News? Or keen to catch that interview from Breakfast? Now, you never have to miss it again.

Breakfast Business, Breakfast, the ONE News midday and 6pm bulletins and Close Up are now available through a live stream on the ONE News website. All you need to do is click on the 'Watch' icon which appears in the header on our homepage, and you're away!

At $10 \mathrm{am}$ and $11 \mathrm{am}$, you can also catch the ONE News bulletins which play inside Good Morning on TV ONE, via their live stream.

In addition, for those on the run the top five news stories of the day will be podcast in both audio and video files so you can download them to your iPod or equivalent MP3 player to watch at your convenience.
\end{abstract}

One News - New Zealand's news. Anywhere, anytime.

\footnotetext{
${ }^{129} \mathrm{Hulu}<$ www.hulu.com>. This website provides free access to thousands of previously broadcast programmes.

${ }^{130}$ Veoh $<$ www.veoh.com $>$. This website provides free access to thousands of previously broadcast programmes.

131 Joost $<$ www.joost.com $>$. This website provides free access to thousands of previously broadcast programmes.

${ }^{132}$ Stelter, above n 125.

${ }^{133}$ Television New Zealand Ltd <www.tvnz.co.nz>.

134 Ibid.
} 
TVNZ is not the only major New Zealand broadcaster to be streaming news content live. TVWorks Ltd, which operates TV3, broadcasts its nightly 3News programme live on its website. $^{135}$

Another major problem that has recently arisen and which further calls into question the effectiveness of the current regulatory regime is the advent of the New Zealand-based online broadcaster "Ziln" "136. This company is an Internet television network that is exclusively aimed at New Zealanders and provides original New Zealand channels, such as TV One and TV3, as well as other domestic and international television channels. Some of its programming content is scheduled and streamed live, so that audiences use the site exactly like they would a television. In addition, this online broadcaster also provides on-demand content and has an extensive archive of national and international programmes available. Ziln describes itself as, "New Zealand's Internet Television Network" 137 and states that, "Affordable Internet television delivery is now available to a whole new wave of 'micro broadcasters' who can create new content and tap into tightly-focused consumer markets with specialist advertising and interactive marketing" ${ }^{\prime 138}$. This New Zealand-based Internet television company poses a real problem for the BSA, because it is broadcasting the same channels as regulated free-to-air broadcasters, but without any regulation - apart from the possibility that its live streaming content is subject to standards as it is not 'on-demand'.

Subscription television company SKY TV Ltd, who operates the free-to-air channel Prime TV, also streams Prime News at 5.30 live via Vodafone's mobile television network. Vodafone made this press announcement in relation to the live streaming of Prime News via the Internet connection available on its mobile phone network: ${ }^{139}$

Vodafone $3 \mathrm{G}$ customers can now watch a live streamed television news bulletin on their $3 \mathrm{G}$ mobile just like one they'd see on the box at home.

\footnotetext{
135 TVWorks Ltd <www.3news.co.nz>.

$136<$ www.ziln.co.nz>.

${ }^{137}$ Ibid.

${ }^{138}$ Ibid.

${ }^{139}$ Vodafone New Zealand Ltd <www.vodafone.co.nz>. Press release available at:

$<$ www.vodafone.co.nz/personal/about/media-centre/2006-media-releases/live-news-broadcast.jsp>.
} 
In a New Zealand first, Vodafone in partnership with Prime News will deliver 3G customers "Prime News: First at 5.30" daily as part of the Sky News streamed channel.

Radio broadcasters have also jumped on the online streaming band-wagon with a huge number of New Zealand-based radio stations now providing programming content live over the Internet. Presently, there are over $50 \mathrm{New}$ Zealand-based radio stations who stream their content live over the Internet including Radio New Zealand National, 95bFM, The Edge, More FM, Newstalk ZB, Radio Live, ZM, Radio Sport, The Rock and Radio Hauraki to name a few. ${ }^{140}$ Basically, all the major radio stations in this country are now broadcasting over the Internet 24 hours a day 7 days a week. Recognising this increasing trend, a number of television manufacturers are incorporating their new models with Internet capability to cater for those people who watch or listen to programming content online. During the 2009 Consumer Electronics Show held in America, vendors such as Panasonic and LG unveiled their new range of televisions that have an internal wireless Internet receiver box that enables people to view online as well as pay and free-to-air programming content. ${ }^{141}$

In 2007, New Zealanders consumed around 20 per cent of their media online, demonstrating that media consumption habits are rapidly transitioning to material available via the Internet. ${ }^{142}$ During 2008-2010, this number undoubtedly would have increased and will continue to do as consumers' behaviours change and evolve in the new converged media environment. It is difficult, with any certainty, to predict just what the effects of media convergence and the still developing Internet will be on media consumers and their viewing habits. When it first appeared, the Internet was completely different to anything that had come before; a global network of computers that supported the transfer of data between almost any of the machines on that network. ${ }^{143}$ People instantly began to develop software that took advantage of this connectivity to make life more fun, easy and entertaining. Gradually, those who created websites realised that delivering content was only half the equation; thanks to the two-way connection that was created by a browsing session, websites could also receive information and

\footnotetext{
${ }^{140}$ New Zealand Radio Guide, list of "New Zealand Radio Stations Streaming Live on the Internet". List can be accessed at: <www.nzradioguide.co.nz>. (see Appendix 1 for full list).

${ }^{141}$ Asher Moses "The CES [Consumer Electronic Show] free-for-all” (21 January 2009) stuff.co.nz, New Zealand $<$ www.stuff.co.nz>.

${ }^{142}$ Wilson Owen "Lawmakers tackle the web wild west" (12 March 2008) The Independent Financial Review, Auckland.

${ }^{143}$ Simpson, above n 125.
} 
be highly interactive. ${ }^{144}$ Now that the Internet has developed further, the services available to media consumers are in the millions and it is now a real-time interactive medium, a medium that is being increasingly used by broadcasters as a new platform to distribute content. However, opinions on how consumers will eventually end up utilising this platform are varied. Some possible outcomes were discussed by Bruce Simpson (founder of the New Zealand news and opinion website Aardvark Daily) who put forward the suggestion that: ${ }^{145}$

\begin{abstract}
What? The Internet has peaked? Yep that's right. The Net we use today is about to start devolving and the personal interactions we're seeing today will slowly slip away. Why? Because the vast majority of the world's population are lazy [people] who simply don't want to interact. They just want content delivered to their eyeballs with a minimum of fuss, bother and effort. These are the same people who sometimes can't even be bothered to change channels when ads come on TV. Unfortunately, those who shape the Net are already pandering to this crowd... More and more of the content we are seeing on the Net is formatted to look and act like TV.
\end{abstract}

The truth is that the Internet, instead of being a vibrant expanse of cyberspace where people are stimulated to interact with others, could in fact become a virtual couch, where consumers use the technology in a similar way to how they currently use television and radio (see discussion on Ziln above). ${ }^{146}$ For example, internationally in 2007 there were 12.3 million Internet television subscribers who used the Internet simply as another kind of television set. ${ }^{147}$ Further, when we look at the example of YouTube ${ }^{148}$ - perhaps the first portent of the 'TVisation' of the Net - the vast majority of YouTube users are simply consumers who watch videos on the site, as opposed to uploading their own material; they can be seen as the couch potatoes of the Internet. ${ }^{149}$ It is a future possibility that, along with a paradigm shift occurring in the traditional broadcasting environment, there also could be shifts occurring in the way people use the Internet - from a paradigm of interaction between users to a paradigm involving people taking or being fed programming material, without making the effort to interact. In just a few years time the

\footnotetext{
${ }^{144}$ Ibid.

${ }^{145}$ Ibid.

${ }^{146}$ Simpson, above n 125.

${ }^{147}$ Ibid.

${ }^{148}$ YouTube $<w w w . y o u t u b e . c o m>$. This website is considered by many to be the first global portent of what has been described as 'TVisation' of the Internet.

${ }^{149}$ Simpson, above n 125.
} 
average television set in the average house could well have Internet capabilities, as some already do, with people consuming a large portion of their viewing or radio content via live streaming or on-demand services. It is a highly realistic probability that, in an age where people are now switching to the Internet to receive audiovisual and audio content, broadcasting standards will need to be developed and applied to particular forms of online programming material.

\section{B Why is the BSA's Lack of Jurisdiction Over Internet Broadcasters is a Problem?}

This paper puts forward the notion that the BSA's lack of jurisdiction to deal with online broadcasting will lead to a number of problematic issues arising in the future, the most pressing of which is the inability to address harms caused by online programming content. The significant social objectives addressed by the current broadcasting standards regime include the desire to protect people from harm and abuse - especially those who require special protection such as children, the need to regulate what is 'acceptable' programming content (e.g. sex, violence, liquor promotion, good taste and decency), ensuring informed choice - providing the audience with classifications and warnings where appropriate, ensuring bottom-line standards for reporting and journalism and having ready redress for injustices that are not easily or affordably addressable in other ways (e.g. defamation or privacy actions brought through the courts). ${ }^{150}$

It is a fairly recent development of the new media environment that television and radio programming has gone online. The ongoing revolution in information technology means that New Zealanders, like many in the world, are increasingly receiving audiovisual and other programming from sources other than the traditional media platforms. ${ }^{151}$ The problem with our current Act is that it does not expressly give the BSA jurisdiction to deal with complaints about harm arising out of content broadcast on the Internet, even if the content is located on the website of a New Zealand-based television or radio broadcaster. Further, the lack of jurisdiction prevents it from fulfilling the other social objectives sought to be achieved by broadcasting regulation.

\footnotetext{
${ }^{150}$ BSA's submissions to the Ministry of Culture and Heritage's consultation paper; Ministry of Culture and Heritage - submissions received on broadcasting regulation review consultation papers. Submissions available online at: <www.mch.govt.nz/publications/digital-tv/index.html\#review>, 3.

${ }^{151}$ Brown and Price, above n 2, 24.
} 
Radio and television broadcasters do, on occasion, cause harm to individuals and organisations through particular content they broadcast. In 2009, the BSA received 162 complaints, of which $25(17 \%)$ were upheld as breaches in full or in part. ${ }^{152}$ These breaches related to standards of good taste and decency, accuracy, children's interests, violence, privacy, fairness and law and order. ${ }^{153}$ In 2008 the BSA received 148 complaints, of which 40 (29\%) were upheld as breaches in full or in part. So between 2008 and 2009 there has been a 10\% increase in the number of complaints being referred to the BSA for review and this upswing in numbers continues the trend experienced in the 2007-2008 year. ${ }^{154}$ In some of its determinations, the BSA made orders against the broadcaster concerned and imposed sanctions such as fines, legal costs and ordering the broadcast of statements summarising its decision. ${ }^{155}$ So there is clear evidence that broadcasters are failing to uphold complaints that should be upheld and the BSA is addressing the harms caused by those breaches.

There are no statistics showing the harm caused by online programming because there is no official standards or complaints system in place for people to use, including the ability to refer complaints to an independent body which makes its determinations publicly available and keeps records on numbers. But if one makes the logical extension that, if the same radio and television material or even more extreme material (such as extended or unedited versions of programmes) is available on the broadcasters' websites, then undoubtedly there will be times when standards would be breached. Therefore, it is reasonable to assume that if programming content on the regulated traditional platforms is causing harm on occasion, then the same applies to the programming content made available on the broadcasters' websites.

Already, the provision of programming content being made available on the broadcasters' websites is posing a difficult problem for the BSA to deal with. For example, the situation has arisen where the BSA has upheld a complaint that an item called "Let us Spray", broadcast on TV3's 60 Minutes programme, was unbalanced and unfair. The BSA penalised the broadcaster, but that same material is still available via on-demand on TV3's website and the BSA cannot do

\footnotetext{
${ }^{152}$ Broadcasting Standards Authority, Annual Report 2009 (BSA, Wellington, 2009) 10.

${ }^{153}$ Ibid, 35.

${ }^{154} \mathrm{Ibid}, 10$.

${ }^{155}$ See, for example: TVNZ and Lion Nathan Broadcasting Standards Authority, Decision No. 2009-069.
} 
anything about it, even upon receiving a complaint. ${ }^{156}$ This is a highly undesirable situation for the BSA, as TVWorks is continuing to make unbalanced and unfair programming content available on its website. To enable the government and the BSA to address the harms online broadcasting can cause and achieve the social objectives contained in the Act, a jurisdictional extension covering specific Internet broadcasters is required for the BSA, along with new powers to deal with the content Internet broadcasters make available.

\section{THE SOLUTION}

The Broadcasting Act should be amended so that the BSA has its jurisdiction extended to include programming material supplied online by New Zealand-based 'Internet broadcasters'. In conjunction with Internet broadcasters, the BSA should develop an Internet Code of Broadcasting Practice containing the applicable standards and the complaints process. The government will need to create a public list of organisations that it considers to be 'Internet Broadcasters' and who will be subject standards contained in the Internet code. The BSA's jurisdictional extension should only allow it to deal with complaints arising out of audiovisual (video) and purely audio (radio) programming content and, if necessary, any relevant associated text. New Zealand-based media organisations should be required to uphold the same journalistic standards for the information they provide on their websites as they do for the information they provide in newspapers, television and radio programmes.

The BSA's overall performance has been relatively sound, both in fulfilling its statutory functions and ensuring the workability of the complaints system through developing cooperative working relationships with a wide range of New Zealand television and radio broadcasters. The four individuals that comprise the BSA's Board have been chosen for their specialised expertise and over the years the BSA has built a body of well regarded jurisprudence in areas such as privacy, balance in news and current affairs and fairness.

\footnotetext{
${ }^{156}$ The BSA upheld a complaint against CanWest TVWorks about the 60 Minutes "Let us Spray" item in Decision No. 2007-012. The programme is still available for people to watch on TV3's website via this link: $<$ http://www.tv3.co.nz/NewsandCurrentAffairs/SpecialInvestigation/tabid/138/Default.aspx>.
} 
Regulating the Internet using the framework suggested in this dissertation (see Chapter 5) will provide an effective regime for dealing with complaints about New Zealand-based Internet content. It will also be beneficial to the country as a whole, because it will ensure that both members of the public and organisations have a free, comprehensive and accessible complaints system available to them, with the courts being the last resort.

\section{A What Changes Need to be Made}

To begin with, the Broadcasting Act will need to be amended in several ways to bring it up-to-date and future proof it against any further changes in the broadcasting environment. These changes are outlined fully in the chapter on the proposed framework below, but in summary they are: the definition of broadcasting needs to be changed to include Internet programming (both on-demand and streamed), a list of regulated Internet broadcasters needs to be developed, and the BSA will have to be given new powers to deal with infringing content.

\section{Updating the Act}

The updating of the definition of 'broadcasting' in the Act would ensure that New Zealand-based Internet broadcasters were held accountable for the programming content they make available on their websites. This paper proposes the following new definition:

The electronic distribution or transmission of audio and/or audiovisual content, whether made on-demand or not, in such a way as to make it available to many consumers.

This definition encompasses radio, television, the Internet, mobile television and most likely any other delivery platform created in the future. While this definition is all-encompassing and would include things such as email attachments and most websites, it should be remembered that only those websites named on the BSA's 'list' would be subject to broadcasting standards regulation. A more in-depth analysis of this change in definition is discussed later under "The Framework" in Chapter 5 below.

$2 \quad$ Creating the List 
The proposed list would ensure that the online content regulation was effectively and appropriately targeted at mainstream broadcasters, so that the reforms did not have any unjustified chilling effect on individuals' freedom of expression. Rather, it would be a rational progression of applying broadcasting standards to online material that would be subject to broadcasting regulation in an offline world. To decide what media organisations went on the list, the government, through the Broadcasting Minister and the Ministry of Culture and Heritage the department responsible for parts of the Broadcasting Act including prosecutions for noncompliance - would have to implement a set of criteria that would place an organisation broadcasting on the Internet in the 'regulated content' box. Further, there should be a key overriding subjective test that the set of criteria are subsidiary factors for. This overriding test would be: Is it reasonable and appropriate, when looking at the level of influence and impact on the New Zealand public, to impose content standards on the programming content made available by this particular broadcaster on its website? This paper proposes the following criteria to be applied when deciding if an Internet broadcaster should be included on the list:

- Is the broadcaster based in New Zealand?

- Is the broadcaster providing programming content on other media platforms (e.g. television or radio)?

- Are New Zealanders the broadcaster's main target audience?

- Is the broadcaster part of a mainstream media organisation with the potential to influence a large section of the New Zealand public (e.g. Media Works, Fairfax or Television New Zealand)?

- Is the broadcaster a large commercial organisation (i.e. does it have a large budget derived from advertising revenue)?

- Does the broadcaster have paid staff (e.g. reporters, marketing team)?

- Is the broadcaster a reputable source of news and factual information that a large part of the New Zealand public trust?

- How large is the broadcaster's audience $(10$ or 100,000$)$ ?

While the set above criteria may seem open ended, this paper would suggest it needs to be, and it is suggested that not all of the criteria would necessarily have to be met in order for a broadcaster to be put on the list. Flexibility and being able to adapt to a fast-changing 
environment is what is going to make this proposed framework successful. While it is possible that other factors may be relevant when determining whether to include a broadcaster on the list, the above list and the overriding test provide a sensible method for determining which online broadcasters should be subject to programming content standards regulation.

There would undoubtedly be occasions when interpretations and value judgements may conflict: for example - what is a large commercial organisation? But the powers that be would have to start somewhere and, over time and using an incremental approach, a series of precedents would be created that could be applied to new cases as they arose. The list would also provide absolute certainty as to which broadcasters were subject to content standards and the formal complaints framework.

Because New Zealand is a small island nation with a relatively small consumer base, there are not a huge number of major media organisations and/or broadcasters operating from within this country. For those that are based here, New Zealanders are their primarily target audience and the majority of people obtain their information and online programming content from a fairly limited range of content providers. As such, this paper's proposed 'list' of regulated Internet broadcasters would not be too daunting in terms of its size. The list would be available on the BSA's website and would also be contained in any hard copy of the Internet Code. This paper proposes that the following New Zealand-based broadcasters, who currently provide audio and audiovisual programming content on their websites, should be on the list:

- All radio stations with audio programming content available on their websites, including archive material

- Ziln.co.nz

- TVNZ.co.nz

- TVNZondemand.co.nz

- TV3.co.nz

- Mediaworks.co.nz

- 3news.co.nz

- C4tv.co.nz

- Primetv.co.nz (also skytv.co.nz if they begin broadcasting online again)

- NZHerald.co.nz (and all New Zealand-based online newspapers who have a corresponding hard copy and which provide audiovisual and/or audio material accompanying their articles) 
- Stuff.co.nz

- Scoop.co.nz

- Saturn TV (Telstra Clear)

- Vodafone (and Telecom if it starts broadcasting programming content through its mobile network)

The development of the list is more fully addressed in this paper's discussion of the proposed framework in the following chapter.

3 New Powers for the BSA

In order for this paper's proposal to work, the BSA would have been given additional powers to deal with infringing material. A comprehensive outline of the new powers needed are outlined in the following chapter, but in summary they are: the ability to order takedown, change and edit notices, the power to order links to BSA decisions or other information deemed necessary (e.g. right of reply), and the power to ensure adequate warnings and classifications are in place. These new powers will be in addition to the BSA's existing powers as outlined in Chapter 2.

\section{THE PROPOSED FRAMEWORK}

The framework for applying broadcasting standards to Internet content contained on the websites of New Zealand-based Internet broadcasters, in the manner proposed by this paper, should be relatively straightforward and as practical as possible. The implementation of the proposed framework and the application of broadcasting standards to material broadcast via the Internet would be a world-first in terms of content standards application. By utilising this proposed framework, New Zealand would be leading by example and showing the rest of the world that it is both possible and desirable in the modern converged media environment to implement a content standards regime to specific Internet material of concern, while ensuring that broadcasters' freedom of expression is not unjustifiably stifled. It is worth noting here that the BSA usually defends the broadcaster, typically upholding only a minority of complaints.

Part of the BSA's role is to be proactive and assist broadcasters and journalists in doing a better job through cooperation, mutual respect and the shared goal of providing a high standard 
of media services to the New Zealand public. There is no need for the framework or systems within it to be overly complex or onerous. The Internet is a special case and should be treated as such: its properties are unlike any other platform traditionally used by the media. Unlike television or radio - where the consumer has limited control over when, where or how they receive programming - the consumer usually has a greater measure of control over Internet programming. Even if the programming material is streamed live and they miss the live steam, a consumer can still search the site's archives, if available, and view the material when and where it suits them. As a result, the government is going to have to change the rules as they currently apply to traditional platforms, because the game has changed.

There is no doubt, in this paper's view, that the broadcasters are themselves in the best position to respond in the most efficacious manner and deal with content complained about, especially where there is a blatant breach of standards which requires speedy rectification. In saying that, however, there needs to be a safety net to deal with instances where an Internet broadcaster fails to fulfil its obligations with respect to the content it provides media consumers. That is why a responsive framework consisting of a tiered co-regulatory approach will work best in practice.

This paper favours a tiered framework, one in which the broadcasters have the lion's share of responsibility, acting as the first tier, and in which the BSA, the second tier, is a complainant's last resort before going to the High Court, the final tier. This is identical to the current regulatory framework, a framework that has worked well in the past, and one which this paper considers could be easily applied to Internet broadcasting. Of course, there will be some differences in the way in which complaints are dealt with and/or resolved, but overall the current Act, with its focus on co-regulation and cooperation between the state agency and the individual broadcasters, is well suited to the situation the Internet and media convergence has created. First of all, parts of the Act will need to be amended to bring New Zealand-based Internet programming content and those providing it within the BSA's remit.

\section{A Changes to the Broadcasting Act}

1 Definition of "broadcasting” 
To begin, the definition of "broadcasting" in the Act will have to be changed to encompass online content, including content that is 'on-demand' (i.e. archived). This paper proposes the following new definition:

The electronic distribution or transmission of audio and/or audiovisual content, whether made on-demand or not, in such a way as to make it available to many consumers.

The proposed definition of 'broadcasting' casts a very wide net and would encompass a variety of online organisations which should not necessarily be subject to regulation through the Act, for example, the website of a citizen journalist that contained audio/audiovisual material that was available to anyone who visited their site. In this paper's view, there is no role for the state (except for the interception of illegal activities) in communications one-to-one or one-to-afew; the state can only legitimately take an interest in the distribution of content aimed at many. The state's interest in this area is legitimised by the fact that the target of the activity is to the "many" and the influence of the activity could be potentially significant, such as the harms caused by programming material that breaches broadcasting standards (see discussion of 'harms' in Chapter 3). That is why the BSA should work with a list of regulated Internet broadcasters who have met certain criteria including broadcasting 'to many consumers'. This would provide absolute clarity as to which organisations were subject to the complaints regime.

The benefits of this definition are threefold. First, this all-encompassing definition would future-proof the Act to a certain extent, in that it could adapt and apply to new technologies and media platforms not yet created. Second, it would allow for the BSA to regulate those New Zealand-based Internet broadcasters whose programming content would be subject to standards regulation in an offline world. Third, while all New Zealand-based websites with audio and/or audiovisual content would come under the definition, the regulation only applies to those Internet broadcasters on the BSA's list, consequently the near absolute editorial freedom enjoyed by New Zealand-based Internet sites in general to make available whatever content they want would remain intact.

2 Incorporation of the "list of Internet broadcasters" 
The Act would have to be amended to expressly state that the BSA has the power to receive complaints about programming content contained on the websites of those organisations named on the list of regulated Internet broadcasters. The Act would also have to state that the broadcasting regulation for Internet content only applies to 'Internet broadcasters' named on the government's list and that the BSA is the body responsible for helping to develop (in conjunction with Internet broadcasters), approving and updating the Internet Code of Broadcasting Practice. The easiest way to incorporate the list would be to insert a new section called "Internet Broadcasters" that would outline the BSA's new responsibilities with respect to specific Internet content and state that all organisations named on the list must ensure their content complies with the standards set out in the Internet code and are subject to the complaints regime. The criteria used to decide which Internet broadcasters should be subject to content standards (see discussion of proposed criteria above under "The Solution"), would be set out in the Act and the list made publicly available.

As mentioned previously, New Zealand does not have a large number of media organisations that would qualify for the list and be classified as regulated 'Internet broadcasters'. The list would really just be incorporating the major New Zealand-based media players, who are already subject to content standards and complaints handling regimes on the traditional media platforms in which they also operate. There would be a small number of exclusively online broadcasters named on the list, such as Ziln, but if they needed assistance in establishing a complaints system the BSA would be available to help. Of course, any New Zealand-based broadcaster providing audio and/or audiovisual content via the Internet could voluntarily go on the list to enhance their credibility in the eyes of the consumer.

With respect to online "broadcasting" and mainstream broadcasters, we ought to regulate content sent over the Internet, if such content would be subject to regulation in an offline world. $^{157}$ Applying this reasoning, all the material available for viewing or listening on an Internet broadcaster's website would come under a new technology-neutral definition of "broadcasting" which would not exclude content that was on-demand.

${ }^{157}$ Walden, above n 106, 429. 
In order for this paper's proposed regulation of specific Internet content to work, the BSA would have been given additional powers to deal with infringing material. In terms of accessing content, the Internet is very different to television and radio and most of the current orders available to the BSA (e.g. simply upholding a complaint or broadcasting a summary of the BSA's decision) would be of limited use against offending online material, which could be accessible 24 hours a day, every day. To help the BSA deal with online content that infringes on standards, it must be given new powers that provide it with Internet appropriate tools/sanctions. The following is a set of new powers which should be given to the Authority so that it can effectively deal with online programming content that has been found to have breached standards.

\section{(a) Take-Down Notices}

Due to the timelessness of archived programming content, the BSA must have the discretion to order a Take-Down Notice that enables it to compel an Internet broadcaster to remove programming material on its website that has been found to have breached standards. Once a broadcaster receives an order telling it to remove infringing content, it would have effectively been put on notice to comply with the order or face further sanction for noncompliance, such as prosecution by the Ministry of Culture and Heritage. This proposed new discretion is relatively similar to the powers given to Australia's version of the BSA and of the common law situation in the United Kingdom, and would provide an effective method for ensuring that any offending material would cease to be available on the particular broadcaster's website (see discussion on overseas jurisdictions in Chapter 4).

An interim take-down notice should also be available to the BSA where a complaint has been referred to it and it considers it appropriate that the material be removed until a determination is made on the content.

\section{(b) Change or Edit Notices}

Similarly, the BSA should be given the discretion to order a Change or Edit Notice to an Internet broadcaster. The order would outline how the content would have to be amended, such 
as ordering the pixilation of faces or identifying features of individuals whose privacy had been breached in an item or the editing of audio in a broadcast (i.e. online radio) so that the offending parts were removed. This would allow the broadcaster to keep the programming content available, but in an edited form, so that the programme was standards-compliant.

\section{(c) Links}

Another tool that should be given to the BSA is the ability to order online 'links' be provided to its decision about a programme or to other relevant online material when infringing content is available via a broadcaster's online archive, so that people can be fully informed. This new power would be of most use in situations where a programme was found to be inaccurate, unbalanced or unfair. After determining that a programme was, for example, missing a significant viewpoint during a discussion of a controversial issue of public importance (i.e. Standard 4 controversial issues-viewpoints) the Authority could order an online link be attached to the location on the website where the programme is available either to its decision and/or to balancing information containing the missing significant viewpoint.

Another idea is the use of 'response' or 'right of reply' links allowing a complainant to respond to criticisms contained in a programme - this idea is more fully explored in the discussion of the "First Tier" below. As with the Edit or Change Notice, this method would allow the broadcaster to retain the particular programme on its website, while also remedying the breach of standards.

\section{(d) Warnings and Classifications}

The BSA should be able order a broadcaster to change an item's rating if it finds a complaint is justified which argues a programme has been incorrectly classified. In such instances, the BSA could order a broadcaster to change a programme's rating from PGR to AO for example. Further, if the BSA determines that a programme's content warrants a warning or an existing warning is ineffective, it could order the broadcaster add or to amend a pre-broadcast warning.

(e) Existing Powers 
Most of the existing powers to make orders would still be extremely useful including ordering costs to the Crown, compensation for breaches of privacy and ordering the publication of corrective statements or apologies ${ }^{158}$ The Act should expressly state that the BSA has the discretion to impose orders on websites in any manner it sees fit to, such as requiring a statement to be connected to an infringing item for the duration of that item's existence on the website.

Many of the solutions to deal with offending content could be developed through discussion and negotiation between the BSA and Internet broadcasters. Presently, the BSA has a good working relationship with the major broadcasters involving mutual respect and cooperation. In is argued that there no reason why this positive co-regulatory environment would not continue if the proposed regulatory changes were made and it is likely that by allowing Internet broadcasters to help create solutions to deal with infringing content good relations would be further fostered. However, as a safety net, the amended Act would be there outlining the BSA's powers if the situation deteriorated or a broadcaster was uncooperative.

\section{$4 \quad$ Broadcasters as the 'First Tier'}

To begin with, each Internet broadcaster should be required to have a robust system in place to deal with complaints about content they make available on their websites. The Act already states that, "Broadcasters have a responsibility to deal with complaints relating to broadcasts and must establish a proper procedure to deal with them". ${ }^{159}$ This statutory principle should be extended to regulated Internet broadcasters. As mentioned above, the complaints system does not need to be complex or unduly onerous; in fact the opposite is true, with the process needing to be as flexible and as relatively informal as possible. Again, the Act already makes this point clear stating, "Most complaints that are capable of being resolved by an independent complaints procedure should not be required to be resolved by that procedure but should be capable of being resolved by proper consideration and proper response on the part of the broadcaster". ${ }^{160}$ The Internet provides a variety of opportunities for broadcasters, including a

\footnotetext{
158 The BSA's powers to make orders are set out in the Broadcasting Act 1989, s 13, 13A and 16.

${ }^{159}$ Broadcasting Act 1989, s 5(a).

${ }^{160}$ Broadcasting Act 1989, s 5(g).
} 
vast range of new abilities and tools to deal with complaints in manner that is complementary to the medium itself.

Once content is made available on the Internet it can be there for a very long time and has a timeless quality about it once it has been digitalised. This is unlike television or radio, where it is here one minute and gone the next. Because of this difference, Internet broadcasters can develop new strategies for dealing with complaints. For example, if a 60 Minutes item about a company is available 'on demand' and the company considers that the item has omitted crucial information leading, in its opinion, to it being inaccurate and unfair, the broadcaster has a number of Internet-specific options open to it. First, upon receiving the complaint, the broadcaster could add a link stating something like 'company's response' and make a copy of the company's complaint or response to the programme available for consumers to access. MediaWorks, which owns and operates TV3 and TV3's website, have admittedly taken a small step towards implementing this type of solution with it posting a formal letter from the Ministry of Health, written two days before the broadcast, about the contents of a documentary called "Let us Spray" which it knew criticised the actions of the Ministry. ${ }^{161}$ While the Ministry's letter was available, it was hard to locate and neither a link to the Ministry's formal response to the item nor the BSA's decision upholding the complaint has been provided. This is a classic example of where the Authority has upheld a complaint about a programme, penalised the broadcaster, but the broadcaster is still making the offending content available with the BSA being unable to do anything about it. The development and implementation of a 'right of reply' in the form of the broadcaster posting an affected party's response to a programme, may actually resolve many complaints at the initial stages and would certainly be a factor the BSA would consider in reviewing a complaint, especially if it concerned fairness.

If a complaint is raised about an alleged breach of privacy, through the identification of a person about whom private facts are disclosed and the disclosure of which a reasonable person would consider highly offensive, the broadcaster is again in the best position to deal with the matter itself. If the broadcaster considers the privacy concerns are valid, it can pixellate the face

\footnotetext{
${ }^{161}$ MediaWorks have provided a link to the Ministry of Health's response to the documentary "Let us Spray" on TV3's website in the collection of links about the documentary "Let us Spray". Link to the Ministry's response available at: $<$ www.tv3.co.nz/SpecialInvestigation/tabid/138/Default.aspx $>$.
} 
of the person concerned or remove certain material that identifies them. The Internet has a created a unique position for both complainants and broadcasters with respect to the types of action that can be taken. Broadcasters can effectively work with complainants to quickly and efficiently deal with any concerns it considers valid about the programming content it makes available on its website 24 hours a day. In fact, the Act states that broadcasters must deal with complaints promptly and without undue formality. ${ }^{162}$ For programme content that has already been subject to a referral to the BSA and been found to have breached standards (except for privacy), but which is still available via the website's archive, a simple link to the BSA's decision could be inserted, therefore informing the consumer of any deficiencies contained in the programme. ${ }^{163}$

This first tier is the most crucial in the framework, because if considered and handled properly, broadcasters can not only deal with the vast majority of complaints in a way that does not require the involvement of the BSA - thus making the process quick and efficient - but the content they provide will arguably be better as a result. If a broadcaster declines to uphold the complaint and takes no action, the BSA is able to review the broadcaster's decision, as well as the adequacy of any action it has taken with respect to any complaint that it does uphold.

\section{(a) Making a Complaint}

As under the current system, people and organisations should be able to make a complaint by writing to the broadcaster concerned or completing an online complaints form on either the BSA's website (which is then forwarded to the relevant broadcaster) or via an online form available on the broadcaster's website. The complaint must: name the broadcaster, identify the website that contains the content subject to complaint or on which the material was streamed live, give the date and time of broadcast (if streamed live), outline the standards that have allegedly been breached and why.

The tricky part will be deciding the timeframe within which complaints can be made about online content. The 20 working day time limit to lodge a complaint that currently applies

\footnotetext{
162 Broadcasting Act 1989, s 5(h).

${ }^{163}$ Broadcasting Standards Authority, all the BSA's decisions are available online via its website:

$<$ www.bsa.govt.nz $>$, and incorporating links to the relevant decisions would be easy to implement.
} 
to programmes broadcast on television and radio would not suit the Internet, because some items are consistently available (i.e. if archived) and hence are timeless in nature. ${ }^{164}$ In this paper's submission, the only real and practical solution to this problem is to have no time limit within which complaints can be made about content that is available to consumers on the websites of Internet broadcasters. If content is available, people and organisations should be able to complain about it, as for all intents and purposes, it is being broadcast each time it is viewed. This is similar to the rule in defamation cases that each repetition of a defamatory statement is a new publication creating a new cause of action. ${ }^{165}$ However, once the BSA has already determined issues with respect to a complaint about a particular item and declined to uphold a complaint, the broadcaster should be able to advise a complainant of this as its response. Also, if the content was streamed live and is not available on the broadcaster's website (i.e. it is not available on demand) then the 20 working day time limit should apply.

\section{(b) Broadcaster's Response}

Like the current system, after receiving a valid formal complaint a broadcaster should be given 20 working days to issue a complainant with it decision on the complaint; either upholding the complaint and stating what action it is going to take or declining to uphold the complaint and providing the reasons why. ${ }^{166}$ In circumstances where the matter is a complex one, the broadcaster can advise the complainant that it cannot provide a decision within the statutory timeframe and use the additional 20 working day extension clause already contained in the Act. $^{167}$

5 BSA as 'Second Tier'

\footnotetext{
${ }^{164}$ Broadcasting Act 1989 s 6(2). The section states broadcasters do not have to consider complaints lodged after 20 working days from the date of broadcast of the item subject to complaint.

${ }^{165}$ See comments by Chisholm J and Gendal J stating that each repetition of a defamatory statement is a new cause of action in Solicitor General for New Zealand v Siemer HC AK CIV 2008404 472, at [67].

${ }^{166}$ Broadcasting Act s 8(1C), section states complainants can refer their complaint to the BSA if they have lodged a valid formal complaint and at least 20 working days has expired without them being notified by the broadcaster of its decision.

${ }^{167}$ Ibid, s 8(1D). This section provides an additional 20 working day extension for broadcasters when dealing with complaints that are complex and/or will take longer than the original 20 working days to determine.
} 
There are currently three instances where a complainant can refer the broadcaster's decision (or lack thereof) to the BSA for review. These instances should be carried through to apply to

decisions from Internet broadcasters, and are as follows: ${ }^{168}$

- If the complainant believes the broadcaster's decision on the complaint is wrong in part on in whole.

- If the broadcaster has upheld the complaint that an item breached broadcasting standards, but the complainant believes the action taken by the broadcaster to rectify the situation has been inadequate to remedy the breach.

- If the complainant lodged a formal complaint with a broadcaster and 20 working days has expired without the complainant receiving a decision from the broadcaster or notification of a time extension.

Under the current system, privacy complaints can be made directly to the BSA. ${ }^{169}$ This direct referral system should be carried forward to apply to Internet broadcasters, although a complainant should be advised by the BSA that they may wish to exercise their option to go to the broadcaster in the first instance, as the broadcaster is in the best position to deal quickly with any valid issues and remove or blur particular content.

Upon receiving a referral, the BSA should go through the same process it currently does, although it may not require a recording of the item from the broadcaster, as it could be told where to access the content on the broadcaster's website. The BSA would provide the broadcaster an opportunity to make submissions on its decision, with reference to the complainant's referral, and provide the complainant an opportunity to comment on the broadcaster's submissions. From there it can make a determination on the complaint and make orders.

$6 \quad$ High Court as 'Third Tier'

\footnotetext{
${ }^{168}$ Broadcasting Act 1989, s 8.

${ }^{169}$ Ibid, s 8(1A).
} 
As under the current system, the BSA's decisions would be appealable to the High Court by either the complainant(s) or the broadcaster. ${ }^{170}$

\section{B What Standards Should Apply Internet Programming}

If an Internet Code of Broadcasting Practice is to be developed, it must be decided what standards it should contain and any relevant guidelines that should accompany those standards. Currently, the Act requires television and radio broadcasters to maintain content standards as outlined in Chapter 2. Further, the Act states that it is one of the functions of the BSA to encourage the development and observance of codes of broadcasting practice in relation to the protection of children, the portrayal of violence, fair and accurate programmes and procedures for redressing unfairness, safeguards against discrimination and denigration, restrictions on the promotion of liquor, and warnings and classifications for programmes. ${ }^{171}$

Presently, there are differences between the various codes of broadcasting practice with respect to what the standards are named and their wording. For example, the Radio Code has Standard 8 (responsible programming) which has a guideline that says broadcasters should be mindful of the effect content may have on children during their normally accepted listening times. The Free-to-Air Code and Pay TV Code do not have identical standards, but both contain a separate standard dealing with children's interests, which are both worded differently. ${ }^{172}$ So both the BSA and broadcasters have accepted that it is justifiable that different media can have different standards applied to them, so long as the essence of the requirements outlined in the Act relating to what concerns the standards must cover are catered for.

In this paper's view, the content provided by Internet broadcasters should broadly address the same concerns, adjusted for the likely harm, child exposure, differences in viewer autonomy and protection mechanisms, as those addressed by the codes covering television and radio to ensure a level playing field. That is not to say, however, that the wording of the standards and how they should be applied and interpreted should necessarily be the same across the board. The

\footnotetext{
${ }^{170}$ Broadcasting Act 1989, s 18.

171 Ibid, s 21(1) (e)(i)-(vi).

${ }^{172}$ Free-to-Air Television of Broadcasting Practice, Standard 9 (children's interests) and the Pay Television Code of Broadcasting Practice, Standard P3 (children).
} 
application of standards, such as good taste and decency, children's interests and balance would need to be worded, interpreted and applied in a manner appropriate to the Internet as a medium, while taking into account the fundamental differences that exist between it and traditional mediums. For example, the guidelines to children's interests standard in free-to-air code refer to broadcasters being mindful of the effect any promo or programme could have on children during their normally accepted viewing times - usually up to $8.30 \mathrm{pm} .{ }^{173}$ Obviously this guideline could not apply to archived programming content with AO classifications available 24 hours a day on an Internet broadcaster's website. However, the guideline should apply to any programming content that is streamed live by the broadcaster during children's normally accepted viewing times. But as explained below, these types of issues, of which there are many, will have to be dealt with by the BSA and the Internet broadcasters when negotiating the contents of the Internet Code and after having considered any submissions made by members of the public after consultation.

The proposed Internet Code should have a heavy 'action taken' focus, with the BSA placing great weight on what the broadcaster has done with respect to a complaint and what steps it has taken to deal with the issue(s). There is a massive incentive for broadcasters to provide first-instance remedies themselves, because they can change the contents of their websites promptly and avoid the matter going any further if they feel a complaint is justified. Further, once a broadcaster has acted on a complaint and made changes to content or removed an item, it becomes an 'action taken' issue if referred to the BSA, as opposed to deciding whether standards were breached. This saves valuable time and resources for broadcasters as submissions on standards issues can be lengthy, costly and time consuming. For example, if a company believes they have been unfairly portrayed in an investigative programme such as 20/20 and the broadcaster has provided a link or tag to the company's response to the content of the programme on its site, this type of broadcaster action could count for a lot in the BSA's determination on whether the action taken by the broadcaster was sufficient.

It is not uncommon for the BSA to uphold fairness and balance complaints because a programme has failed to include an adequate response(s) from parties with significant viewpoints or who should have been asked for comment in response to criticism. If a broadcaster makes the

\footnotetext{
${ }^{173}$ Free-to-Air Television of Broadcasting Practice, Standard 9 (children's interests), guideline 9a.
} 
company's response available to consumers, then one could argue that fairness and/or balance has been achieved and therefore the BSA would be unlikely to uphold the complaint. If anything, the special abilities of the Internet would assist broadcasters in avoiding complaints about their actions being upheld by the BSA, because there are so many new ways for them to remedy or adequately mitigate any initial breach. The unofficial saying, 'Not wrong for long', refers to the Internet's special ability to deal with inaccurate news content through consistent updating of the same content - an inaccurate news piece can be can remedied within seconds of new information coming to hand. This is also another example of the types of quick-fix action that can be taken by an Internet broadcaster to avoid an adverse finding by the BSA.

\section{POTENTIAL OBJECTIONS TO THE FRAMEWORK}

\section{A Possible Criticisms of and Alternatives to the Proposed Solution}

There are a number of potential criticisms that could be raised concerning this paper's proposed framework, as well as some viable and not so viable alternatives. This section outlines these potential criticisms and various alternatives, it then goes on to respond to those criticisms and explains why the proposed changes and framework put forward in this paper are to be preferred.

\section{$1 \quad$ Potential criticisms of the proposed framework}

Many broadcasters and some members of the public would not see the need for Internet content regulation as self-evident and would consider the framework proposed in this paper to be unnecessary, largely futile and unfair because it only targets particular broadcasters. There is an argument that the Internet has created a diversity of sources of information accessible to everyone and that mainstream media audiences are falling. It could be said that balance requirements are simply no longer necessary, that accuracy can be addressed through a multitude of voices, and that privacy and defamation law can take care of the especially harmful breaches. It is true that the Internet has provided many more opportunities for people to interact with media and deal with issues that arise, such as posting replies on comment threads. Further, there is 
some validity to the argument that good taste and decency regulation will be swamped by the easy availability of impossible-to-control overseas material. While these points do raise some valid concerns about this paper's proposals, whether they are necessary or would even work, it does seem odd that under the current system a broadcaster can be penalised for a broadcast on a traditional platform, but be allowed to make it available online. And, when considering the social objectives being sought by broadcasting legislation in the first place, it seems even stranger that New Zealand-based broadcasters who tailor their online programming to their New Zealand target audience can operate in an environment free from content standards and without concern for those social objectives. That is to say, it seems strange that an uneven playing field exists when the programming content being provided on the old and new media platforms is essentially the same. Even the major media players in New Zealand have recognised the need for some online standards framework in respect of the content they provide on their websites, as can be evidenced in their submissions on broadcasting regulation to the Ministry of Culture and Heritage $(\mathrm{MCH})$ which are discussed below.

On 23 January 2008, the Ministry of Culture and Heritage (MCH) released two papers for public consultation. The first, Digital Broadcasting: Review of Regulation, consisted of a research report and an accompanying discussion paper that covered a range of topics relating to regulation, including the regulatory framework, content, distribution and networks. The second consultation paper was called Broadcasting and New Digital Media: Future of Content Regulation which focused in more detail on the broadcasting standards regime, and how that might change to accommodate developments in broadcasting and related fields. ${ }^{174} \mathrm{MCH}$ 's consultation papers formed part of a comprehensive review of regulations covering broadcast, telecommunications and Internet media. ${ }^{175}$ In pursuing the review, the government recognised that new media consumption trends have been occurring as a result of media convergence and the rapid development of the Internet and, against this background, a re-examination of the

\footnotetext{
${ }^{174}$ New Zealand Ministry of Culture and Heritage "Broadcasting and New Digital Media: Future of Content Regulation" - Consultation Paper, (Wellington, 2008).

${ }^{175}$ The review in to broadcasting regulation has been discontinued by the new National-led government with the new Broadcasting Minister, Jonathan Coleman, stating that "there is currently no strong case for the introduction of specific new regulation for the broadcasting sector". There is some probability that the discontinuance of the review has been prompted by the current economic situation and the need to reduce government spending. An article on the issue can be found at: <www.scoop.co.nz/stories/HL0904/S00090.htm>.
} 
regulatory regime for broadcasting was required. ${ }^{176}$ The then Minister of Broadcasting, Trevor Mallard, stated that the review looked at whether the current regulatory regime for broadcasting and related sectors needed changing and went on to note: ${ }^{177}$

Digitisation and increasing convergence between broadcasting, telecommunications and the Internet are causing profound changes in the ways in which people access and use broadcasting-like content. We need to ensure that our regulatory regime is both current and 'future-proofed' to serve the evolving broadcasting markets and to also meet the shifting needs and expectations of New Zealand communities.

In essence, the paper was a call for contributions to the debate about the shape of legislative oversight and regulation of digital broadcasting and content regulation which might be appropriate for the future in New Zealand. ${ }^{178}$ The following is a brief summary and analysis of the concerns and issues raised by Fairfax New Zealand Ltd, TVWorks Ltd and Internet NZ and the BSA on the future of content regulation. ${ }^{179}$ These organisations were chosen because they are broadly representative of the different interest groups involved in the submissions process.

\section{(a) Fairfax Ltd}

Fairfax New Zealand Ltd (Fairfax Media) is New Zealand's largest multi-media company with daily newspapers, magazines and a growing Internet and digital presence. It provides a mixture of text, photographic, audio and video content on its popular news and entertainment website: www.stuff.co.nz . Across Fairfax's digital sites, approximately 1.2 billion pages are viewed per month. The company agreed with the general proposition that there is a need to "adjust the regulatory lens" in New Zealand, but argued that it would be inappropriate to apply " $20^{\text {th }}$ century analogue broadcasting paradigms to $21^{\text {st }}$ century digital technologies". It saw a clear distinction between standards for content on the one hand and remaining commercial matters on the other. "Where regulation is required, the regimes governing content and social

\footnotetext{
${ }^{176}$ New Zealand Ministry of Culture and Heritage, above n 174, 8.

${ }^{177}$ Hon Trevor Mallard "Next phase of broadcasting review announced" Media Statement: Office of the Minister of Broadcasting, Trevor Mallard, and the Office of the Minister of Communications and Information Technology, David Cunliffe (Wellington, 22 September 2008).

${ }^{178}$ BSA's submissions to the Ministry of Culture and Heritage's consultation paper; Ministry of Culture and Heritage - submissions received on broadcasting regulation review consultation papers. Submissions available online at: <www.mch.govt.nz/publications/digital-tv/index.html\#review>.

${ }^{179}$ Ministry of Culture and Heritage - submissions received on broadcasting regulation review consultation papers. All submissions available online at: <www.mch.govt.nz/publications/digital-tv/index.html\#review>.
} 
issues should be self regulatory, while those commercial issues requiring intervention [e.g. competition laws] should be co-regulatory". As argued by most broadcasters, Fairfax Media saw the issue of content standards as a matter for self-regulation, to protect against government interference and influence to ensure a free press; basically the BSA should not exist. It contended that a new, self-regulatory body should be established which should develop standards for audio and audiovisual content produced by all mainstream media. "Consumers need to know the one place they can seek redress for inappropriate audiovisual material", it said. Fairfax made the point (one which this paper wholeheartedly agrees with) that broadcasters themselves should be the first port of call for complaints concerning online content, because they are in a position to move more swiftly and respond more easily to redress legitimate concerns about particular audio or visual material. Further, it argued that the standards developed by any new body should include content broadcast on mobile and online platforms. "Membership of such a selfregulatory body would act as a 'qualmark' for signatories, further supporting the value of mainstream content providers as trusted sources of information who bear such a mark". It also considered that the Press Council's complaint handling role should be extended to audiovisual content in online newspapers. Fairfax Media believed any Internet content code could only be extended to mainstream media (one-to-many), leaving user generated content (one-to-a-few) to be policed by more social means.

Fairfax Media's submissions are not too far removed from what this paper is suggesting. Instead of a self-regulatory framework, this paper endorses the BSA taking a co-regulatory approach with broadcasters, albeit statutorily based, in creating appropriate Internet content standards, initiating robust complaint handling processes, ensuring compliance and where appropriate imposing sanctions. Rather than having a voluntary opt-in system as proposed by Fairfax Media, this paper's system would be compulsory for all New Zealand-based mainstream Internet media labelled "Internet broadcasters", thus creating a level playing field with traditional media platforms and a statutorily based regulatory framework to ensure compliance.

\section{(b) TVWorks Ltd}

TVWorks Ltd own and operate the free-to-air television channels TV3 and C4, and have also moved into broadcasting online through websites linked to their television stations. It is part 
of a larger media company called MediaWorks Ltd, which also owns and operates RadioWorks Ltd; a company that runs a large number of popular radio stations throughout New Zealand. Like Fairfax Media, TVWorks advocated for a self-regulatory regime covering all broadcasting-like content available in New Zealand. It accepted that there was a need for broadcasting content to be regulated, albeit by members of the industry, in order to address legitimate concerns over the protection of minors, the portrayal of violence, accuracy in reporting, the protection of privacy and the fair treatment of people who are subjects of programmes.

The broadcaster stated that it had concerns over the growing inequity in content regulation between the different content providers, in particular, the fact that different platforms for content distribution, like the Internet, were not subject to broadcasting standards. It argued that, in the future, all content providers should be regulated in the same manner irrespective of the technology they use, with a government agency (possibly the BSA) having the mandate to generate a set of guidelines against which all broadcasters must self-regulate. TVWorks considered "there is no reason to judge the content of one broadcaster differently from another; if a programme was offensive, or invasive, or unfair, surely the same is true no matter which broadcaster carries the programme". This paper completely agrees with TVWorks' point, but would rather see the BSA operate regulatory control via a statutorily based co-regulatory approach as opposed to all out industry self-regulation.

TVWorks noted that there would always be calls from various sections of the community for additional regulation and tightening of existing regulation around television and radio broadcasting, because of the very broad reach the mediums have. However, it considered that the government needed to look at the future landscape of broadcasting, not the past, and recognise that there will be a proliferation of methods by which to view or listen to content. The most relevant method it mentioned with respect to this paper, was the fragmentation and shifting of the existing broadcasting paradigm due to the development of the Internet as broadband speeds increase and allow for full and live streaming of audio visual programming content. With that future in mind, the broadcaster argued it made no sense to continue the current regulatory burden on existing broadcasters and that content regulation should become self-regulatory and platform neutral. In conclusion, TVWorks said "We cannot look to the past or even the present to imagine 
what media consumption will be like in the next decade. We must do our very best to look into the future and develop a regulatory environment that fits that model". This paper agrees with that sentiment.

\section{(c) Internet $\mathrm{NZ}$}

Internet $\mathrm{NZ}^{180}$ is a membership-based not-for-profit organisation, which has management responsibility for the administration of the .nz domain name registry; a critical component of the Internet infrastructure in New Zealand. It is an advocate for the Internet and related telecommunications as well as public and technical policy issues on behalf of New Zealand's Internet community. It believed that there were a number of larger practical hurdles in simply replicating the regulatory regime for broadcasting content and applying it to the Internet. It argued that the question of what standards should apply in any given situation depended on the nature of the content provider, not the method of transmission. The organisation contended that it was impractical to impose a single regulatory regime to all broadcasting-like content no matter how it was distributed and considered that a tiered approach to content regulation would be best, taking into account the characteristics of the Internet. It said that the simplest and most appropriate method of tiering would be to apply varying codes for content regulation depending on the type of content provider.

The suggestion that there be different types of Internet content codes for different types of broadcasters could be a viable idea. For example, there could be a code for online radio broadcasters, one for Internet broadcasters who are also supplying content on television as well as online, a mobile phone code, and another for those broadcasting exclusively on the Internet. However, because the proposed list of regulated Internet broadcasters would be relatively small there may be no need to establish varying codes for different types of websites and the situation could become messy and disjointed in the future. To ensure a fair and level playing field, the same content standards should apply to all regulated Internet broadcasters.

\section{(d) BSA}

The BSA made a number of points regarding the future of content regulation in a converged and rapidly changing media environment. One of the major points was identifying the

\footnotetext{
${ }^{180}$ See Internet NZ's website at: <www.Internetnz.net.nz>.
} 
fact that the definition of "broadcasting" needed to be changed in order to future-proof New Zealand's Broadcasting Act and to create a level playing field among broadcasters regardless of whether they use old or new technologies or a combination of both.

If the current broadcasting regulatory regime was to be changed, the BSA believed that one of the core issues was effectively updating the definition of broadcasting in a way that provided regulatory equality for those who want to engage in the business, irrespective of whether they utilised old technologies like terrestrial transmitters, or new or as yet unknown technologies. It noted that there was unnecessary confusion resulting from the development of new technologies like the Internet, and it considered that defining "broadcasting" became a much simpler task if the definition was technology-neutral. It suggested that the definition of "broadcasting" in the Broadcasting Act should be updated to read, "The electronic distribution or transmission of audio and/or visual content in such a way as to make it available to many consumers". The BSA's rationale for changing the definition was twofold. First, it considered there was no role for the state (except for the interception of illegal activities) in communications one-to-one or one-to-a-few; the state can only legitimately take an interest in the distribution of content aimed at many. It believed that the state's interest in this area was legitimised by the fact that the target of the activity was "many" and the influence of the activity could be potentially significant. Second, the definition reduced the need to refer to specific types of technologies or mechanisms and was deliberately constructed to exclude printed material and audio and visual content available on physical format such as DVDs.

There are some problems with the BSA's proposed definition, for example "visual content" includes pictures, photos and graphics which are not, in themselves, broadcasts; they would have to be contained in a broadcast for the BSA to justifiably have jurisdiction. Another issue with the BSA's definition is that "visual content" being distributed or transmitted to "many consumers" could include actions such as file sharing or emailing a video clip to a number of people. To ensure that any revised definition of "broadcasting" does not overreach into areas that are were not intended to be regulated, the Act may have to contain specific exclusions for some types of transmissions or distributions, such as email or file sharing. In any event, because this paper proposes the BSA operate with a list of 'regulated Internet broadcasters', the 
regulation would not apply to people or companies broadcasting on the Internet who were not included on the list anyway. Also, decisions about whether a company was broadcasting to 'many consumers' would be made by the a government such as the $\mathrm{MCH}$ - using a combination of value judgements and set criteria - and as such, 'many' would not have to be defined in the Act, making the regulation more flexible and adaptive.

The future-proofing element of the BSA's proposed definition is that it would include content available on the Internet and mobile devices, as well as any other technology that may be created in years to come. ${ }^{181}$ In terms of applying broadcasting standards to specific New Zealand-based Internet content, the proposed definition works extremely well, as it treats all like content the same and will also have the effect of ensuring the necessary level playing field for all providers of programming content.

Another important point the BSA raised was that while its proposed definition would be technology neutral, this did not assume that the manner in which the standards were enforced would not take account of the different media platforms. As mentioned previously, the current regulatory regime has different codes of practice with varying requirements for different delivery platforms, such as free-to-air television having a stricter standards environment than pay television. If an Internet Code of Broadcasting Practice was to be established, the standards it contained and the manner in which they were enforced would need to reflect the nature of the medium itself and the differences in the various delivery methods that exist within it (e.g. live streaming/pushed content versus user accessed/pulled content). The BSA was of the view that if the definition of 'broadcasting' was changed in the manner it suggested there would be no key areas of content remaining unregulated in New Zealand.

\section{(e) Summary}

While many organisations including Fairfax Media, TVWorks and Internet NZ were of the opinion that self regulation was the key to addressing concerns about Internet content, it was encouraging to see that they all accepted there was a need for broadcasting-like content on the

\footnotetext{
${ }^{181}$ Note, it is unclear whether the BSA already has jurisdiction over programming content that it streamed on mobile devices or via the websites of New Zealand-based broadcasters.
} 
Internet to be regulated in some way, albeit by industry players only. While problems exist over how and to whom Internet content standards would apply, there is broad acceptance by many broadcasters that there is a need to impose broadcasting standards, such as accuracy in news reporting and the protection of minors, on mainstream media outlets operating on the Internet. This provides a reasonably solid foundation with respect to this paper's proposal of broadcasters and the BSA working to together to deal with complaints about broadcasting-like content on the Internet. Further, it should be noted that while all the broadcasters favour a self-regulatory framework, no such framework has been developed so far.

At present, there are no official content standards imposed by broadcasters with respect to their online programming content, nor have they established a joint/industry-wide formal complaints process for the public to use. It is hard to see how the broadcasters can argue that a self-regulatory regime would be the most effective framework when, so far, no moves have been made by them to impose regulatory measures (in the form of content standards) on their Internet material. The positive and negative attributes of the different forms of regulation and why, in the specific case of broadcasting standards, a co-regulatory framework should be favoured over a self-regulatory one is outlined in Chapter 7 below.

$2 \quad$ Possible alternatives to the proposed framework and what is occurring overseas

The framework proposed by this paper is, of course, not the only option available to deal with online broadcasting. The following is a description of the alternatives available and a brief analysis of the types of action being taken by three overseas jurisdictions (Australia, United Kingdom and China) with respect to dealing with Internet content and online broadcasting.

\section{(a) The possible alternatives}

The first of several alternatives is to keep the current status quo, where programming content provided by New Zealand-based broadcasters on their websites is not subject to the standards regime. But as argued in this paper, this option would be undesirable due to the inevitability of the current framework becoming obsolete as a result of media convergence and the public having robust recourse available to complain about online programming content. As 
mentioned above, even the big media players agree that some form of regulation is warranted to level the playing field.

Another alternative would be to recognise that, due to media convergence and the other options available to aggrieved parties (the censor at the OFLC or court action), the current broadcasting standards regime should be simply done away with, because it will become outdated. This would allow broadcasters across all platforms to decide for themselves what types of content were acceptable, fair, balanced, and the like - if they could be bothered. This would be the least acceptable scenario, because even the most basic and legitimate social objectives sought by broadcasting regulation, both statutory and self-regulatory, could be ignored with relative impunity. Even the advertising and newspaper industries have developed regulatory frameworks in the belief that some form of regulatory safety net is necessary, albeit under the constant threat of government intervention if their system fails to deliver.

Another alternative is to turn the standards and complaints regime over to the industry to self-regulate - this being the option favoured by broadcasters as outline in the submissions to $\mathrm{MCH}$ above. But as argued throughout this paper, there are drawbacks to self-regulation, and statutory regulation for that matter, which seem to be cured by a co-regulatory environment. As discussed in fuller detail in Chapter 7 below, forced self-regulation may end up being halfhearted and wrongly motivated (i.e. to stave off statutory regulation), and it requires committed buy-in from all the major industry members to be effective. Further, if the self-regulatory approach was taken by broadcasters in which they developed their own in-house codes of ethics and complaints systems, the argument is that such codes will likely be shaped, even warped, by the strong influence of owners, sometimes enforced, with journalists having little option but to toe the company line.

But the question must be asked: why is the BSA to be preferred over a comprehensive self-regulatory system that works well like the ASA? The answer to that question is that New Zealand broadcasters have, on many occasions, shown to be inept in their decision making and stubbornly resistant to upholding complaints which are clear breaches of the codes of broadcasting practice. As detailed in Chapter 3 above, the BSA upholds around one-in-five complaints referred to it for review and there have been occasions where a breach of standards 
has been glaringly obvious, but nevertheless the broadcaster has found a range of excuses and illconsidered justifications in declining to uphold a valid complaint. ${ }^{182}$ If broadcasters are incorrectly declining to uphold approximately twenty percent of the decisions referred to the BSA, then it would hardly be a sound proposition to allow them to completely self-regulate, especially considering the industry's lack of appetite to be regulated in the first place. While advertising newspapers and magazines are hugely influential mediums, the special nature and impact of actually seeing and hearing video footage means that audiovisual programming content is the most powerful and important method of influencing, entertaining and informing the general public. As stated by Lord Hoffmann: ${ }^{183}$

\begin{abstract}
The main reason for singing out television and, to a lesser extent, radio for the imposition of standards of taste and decency is the intimate relationship which these media establish between the broadcaster and the viewer or the listener. Television in particular makes the viewer feel a participant in the events it depicts... The visual image brings home the reality which lies behind the words...The power of the medium is the reason why television and radio broadcasters have been required to confirm to standards.
\end{abstract}

Ads and newspapers are less powerful in shaping peoples' views and lives than audiovisual and audio programming content. That is why the ASA and PC can get away with having internal appeal bodies, while the BSA's determinations - which generally have a greater effect on restricting freedom of speech due to the orders it can legally enforce - can be appealed to the external and independent the High Court. Put simply, the programming content supplied by broadcasters on their websites is just as powerful as the content on the traditional platforms of television and radio. As such, any scheme to apply content standards to Internet programming content that involved a self-regulatory organisation who only answered to itself (like the ASA and PC) would be wholly inappropriate when considering the importance and power of the Internet as a broadcasting platform.

Further, the BSA has proven itself as a body that makes rational and fair decisions, which can be evidenced in Professor Burrows' evaluation of its decision making, the fact that High

\footnotetext{
${ }^{182}$ For an example of one such BSA decision see TVNZ and Lion Nathan and Others Decision No. 2009-069. For statistics on the percentages of upheld referrals to the BSA from 2007-2009, See the BSA's 2009 Annual Report at: $<$ www.bsa.govt.nz/pdfs/BSA_Annual_Report_09.pdf $>$.

${ }^{183}$ Prolife Alliance v British Broadcasting Corporation [2003] UKHL 23, at [20]-[21] per Lord Hoffman.
} 
Court appeals are rare and that they are usually not upheld. Other factors in the BSA's favour include the fact that its uphold rate is not unjustifiably high, the care it takes to act in a reasonable, proportionate and justified manner (See also Colin Peacock's assessment of the BSA $)^{184}$ and the role it plays in picking up seriously defective journalism. Also, any selfregulatory system could run into problems because the media market is becoming increasingly commercial and competitive, which will inevitably create pressures to cut corners. These are just some of the major reasons why the BSA's existence is justified, but also why a moderate extension into the Internet domain is also justified.

In addition, these three alternatives take away important measures which can be utilised by the public and give nothing back in return. Both alternatives would remove the public's ability to refer their complaint to an independent tribunal made up of appointed specialists who make legally robust determinations and who have the ability to impose sanctions, including financial penalties and awards for breaches. There is no legitimate reason why a broadcaster should be subject to content regulation on one media platform and not on another, especially when the content is the same on both platforms.

\section{(b) Action being taken by overseas jurisdictions}

It is a fairly recent development of the new media environment that television and radio programming has gone online. The ongoing revolution in information technology means that New Zealanders, like many in the world, are increasingly receiving audiovisual and other programming from sources other than the traditional media platforms. ${ }^{185}$ Most developed countries are now grappling with the problem of Internet content regulation and what regulatory framework, if any, they should apply to their specific circumstances. Due to varying social, cultural and economic values, every country has different policy objectives in terms of regulation and different governments are trying a variety of techniques to "Tame the Wild West".

The next section of this paper takes a brief look at the types of Internet content regulation in Australia, United Kingdom and China. These countries have been selected because they are a

\footnotetext{
${ }^{184}$ Colin Peacock Principles and Pragmatism: An assessment of the Broadcasting Standard Authority - Decisions From a Journalist's Perspective (Broadcasting Standards Authority, Wellington, 2009).

${ }^{185}$ Brown and Price, above n 2, 24.
} 
good representation of the contrasting frameworks implemented by different nations in an effort to tackle, and in some cases control, Internet content.

\section{(i) Australia}

The Australian Communications and Media Authority (ACMA) is the government agency responsible for the regulation of broadcasting, the Internet, radio communications and telecommunications. ${ }^{186}$ Its system is similar to New Zealand's in that television and radio broadcasters have developed codes of practice in consultation with the ACMA, which monitors these codes and deals with unresolved complaints made under them. ${ }^{187}$ ACMA is also responsible for monitoring online content, including Internet and mobile phone content, and enforcing Australia's anti-spam law. ${ }^{188}$ The Australian Broadcasting Services Amendment (Online Services) Act 2000 entitles any Australian citizen to complain to AMCA about prohibited content ${ }^{189}$ on the Internet. ${ }^{190}$

ACMA can only take action about material that is prohibited, or potentially prohibited, under the Australian Broadcasting Services Act 1992. ${ }^{191}$ Prohibited Internet content is treated differently under the law, depending on whether it is hosted in Australia or outside Australia and on the classification category. ${ }^{192}$ With respect to dealing with prohibited content, AMCA makes the following statement on its website about what powers it has: ${ }^{193}$

\footnotetext{
${ }^{186}$ Australian Media and Communications Authority <www.acma.gov.au>.

${ }^{187}$ Australian Broadcasting Services Act 1992, s 123.

${ }^{188}$ Australian Media and Communications Authority, above n 186.

${ }^{189}$ Prohibited Internet content includes any online content that is classified RC* or X 18+* by the Classification Board (formerly the Office of Film and Literature Classification). This includes real depictions of actual sexual activity, child pornography, depictions of bestiality, material containing excessive violence or sexual violence, detailed instruction in crime, violence or drug use, and/or material that advocates the doing of a terrorist act. Or content which is classified R $18+^{*}$ and not subject to a restricted access system (the restricted access system requires content providers to verify the age of users and provide them with pin code access to material rated M15+and R18+) that prevents access by children. This includes depictions of simulated sexual activity, material containing strong, realistic violence and other material dealing with intense adult themes.

${ }^{190}$ Australian Broadcasting Services Amendment (Online Services) Act 2000, $1^{\text {st }}$ sch, ss 22(1) and 22(2) amend the relevant sections in the $5^{\text {th }}$ schedule of the Australian Broadcasting Services Act 1992 to allow complaints to be made about Internet content.

${ }_{191}^{191}$ Australian Broadcasting Services Act 1992, $5^{\text {th }}$ sch.

${ }^{192}$ Electronic Frontiers Australia Incorporated <www.efa.org.au>. Electronic Frontiers Australia Inc (EFA) is a non-profit national organisation representing Internet users concerned with on-line freedoms and rights.

${ }^{193}$ Australian Media and Communications Authority, above n 185. ACMA's powers to issue take-down notices are contained in the Broadcasting Services Act 1992, Schedule 7, Clauses 47(1),(2),(3) and (4).
} 
If content is hosted in, or provided from Australia and is prohibited, or is likely to be prohibited, ACMA can direct the content service provider to remove [via a take-down notice] or prevent access to the content from their service. Or, if content is not hosted in or provided from Australia and is prohibited, or likely to be prohibited, ACMA can notify the content to suppliers of approved filters in accordance with the Internet industry association's code of practice.

Failure to comply with AMCA's request for an Australian-based Internet provider to remove or prevent access to prohibited content is a criminal offence and providers who do not comply can be fined up to $\$ 27,500$ per day. ${ }^{194}$

While ACMA seems to have an extremely wide ambit to work in, it does have some jurisdictional gaps in its ability to take action on certain online materials. For example, the Australian government has not given ACMA authority to investigate complaints or issue takedown notices for hateful or racist materials online, even if they would be illegal under its Racial Discrimination Act $1975 .{ }^{195}$ The only way to get such material taken down is through the system, such as the Jones $v$ Toben case which involved Holocaust denial material on a website. ${ }^{196}$

Currently, the Australian Labour-led government is in the process of enacting legislation for what has been dubbed "The Great Aussie Firewall". ${ }^{197}$ The firewall is a proposed compulsory Internet filter to be used by all ISPs operating in Australia that would block access to all websites, whether based in Australia or not, contained on an existing blacklist determined solely by ACMA. ${ }^{198}$ At, present, trials of the new filtering system are occurring to test the system's effectiveness. ${ }^{199}$

\footnotetext{
${ }^{194}$ Brown and Price, above n 2, 7.

195 Open Net Initiative, <http://opennet.net/>. See ONI's research report on Australia's Internet regulation, which is available on its website.

${ }^{196}$ See Jones $v$ Toben [2002] FCA 1150. Australian court ordered Mr Toben to remove material from his website that related to Holocaust denial.

${ }^{197}$ Tanalee Smith "Uproar as Great Aussie Firewall threatens Internet freedom" (29 December 2008) The New Zealand Herald (online version) <www.nzherald.co.nz > . See also press release dated 15 December 2009 from the Australian Liberal Party's shadow Minister for Broadband, Communications and the Digital Economy, Tony Smith, who outlines the opposition's concerns over the proposed filter at: <www.liberal.org. au/news.php?Id=4361 $>$. ${ }^{198}$ Ibid.

${ }^{199}$ See speech made by Australia's Minister for Broadband, Communications and the Digital Economy, Stephen Conroy, made on 15 December 2009 regarding the trials and imposition of the mandatory filter at: $<$ www.minister.dbcde.gov.au/media/speeches/2009/075>.
} 
With respect to the issue of broadcasting standards, Australia's Internet regulation focuses solely on classifications for types of content and the removal of illegal or offensive content through the issuing of take-down notices to ISPs. So far, no plans or proposals have been made to implement any form of broadcasting-type standards for audiovisual or audio content on any Australian-based websites.

\section{United Kingdom}

The Office of Communications (Ofcom) is the regulator for the United Kingdom's communications industries, with responsibilities across television, radio, telecommunications and wireless communications services. ${ }^{200}$ The United Kingdom also has a similar framework to New Zealand which utilises standards for regulating content on television and radio. Rules covering harmful and offensive material, fairness and privacy, and the accuracy and impartiality of news and current affairs, are set out in Ofcom's code of broadcasting practice. ${ }^{201}$ These are monitored and enforced by Ofcom and it can impose sanctions on infringing broadcasters such as financial penalties or even revocation of a broadcasting licence. ${ }^{202}$ Partly as a result of these rules, UK-based broadcasters like the BBC have a high public reputation for trustworthiness and honesty in its presentation of news and comment. ${ }^{203}$

Ofcom, however, has no jurisdiction over the Internet, except in so far that it has a remit for media literacy and the industry has a self regulatory system run by the Internet Service Providers Association. ${ }^{204}$ Ofcom does not have any plans to push for jurisdiction over the Internet and its views on Internet regulation are best summed up below in its response to the Byron Review 2008: ${ }^{205}$

\footnotetext{
${ }^{200}$ Office of Communications $<$ www.ofcom.org.uk $>$.

${ }^{201}$ Ofcom, Code of Broadcasting, available online at: $<$ www.ofcom.org.uk/tv/ifi/codes/bcode/ $>$.

${ }^{202}$ Robin Foster, Future of Broadcasting Regulation (Report commissioned for the Department for Culture, Media and Sport, 2007, United Kingdom), 52. This report looks at the regulatory and policy challenges that the UK will need to address over the next 10 years with respect to the transformation of the broadcasting sector brought on by the Internet and media convergence. This report can be accessed at: http://www.culture.gov.uk/reference_library/publications/3617.aspx. Note Ofcom's powers to revoke a broadcaster's broadcasting license do not apply to the BBC, S4C or Channel 4. Information on Ofcom's sanctioning powers are available on Ofcom's website via this link: $<$ www.ofcom.org.uk/radio/ifi/ifiguidance/sanctions/ $>$. 203 Ibid, 52.

${ }^{204}$ Millwood Hargrave, Lealand, Norris and Stirling, above n 57, 25.

${ }^{205}$ Office of Communications < www.ofcom.org.uk>. Ofcom's response to the Byron Review. The Byron Review, published in March 2008, was an independent review conducted by Dr Tanya Byron for England's Department of
} 
At a time of sweeping change in content delivery, and in the type of content that is available, the overall goals of content regulation persist. These are to ensure that people have the information and skills they need to take responsibility for their media choices. In linear broadcasting, the schedule and the watershed are powerful and well understood tools for signalling the characteristics of content to audiences. Our aim must now be to help inform consumers for the online world.

Although the goals are the same, the broadcast model of content regulation is not appropriate for potentially harmful online content. Rather, a new approach to content regulation is required: one which is built on a model of shared responsibility, which gives people the tools they need to take personal responsibility and which supports effective industry self-regulation. The growing importance of online media literacy derives from this: media-literate parents and children, equipped to take on this personal responsibility, provide a significant means of protection. Ofcom's research, analysis and experience lead us to believe at this stage that this approach is the likeliest to be successful, and to build confidence for children, young people, their parents, and wider society.

Ofcom seems solely focused on the idea that the best form of Internet consumer protection is media literacy; the need for consumers to be better educated as to the nature of the content they consume in order to be better able to exercise choice and control over such content. $^{206}$

However, many of the problems created by Internet broadcasters involve issues such as accuracy in news reporting, balance in discussions of controversial issues of public importance, fairness and privacy. There have been signals from the government itself supporting the idea that there should be a common set of standards for Internet content in the face of concerns about the impact of violent and sexual output online. ${ }^{207}$ The Culture Secretary for England, Andy Burnham, has stated that he believed online content should meet the same standards required for television and radio as the boundaries between the media platforms continue to blur. ${ }^{208}$ With

Children, Schools and Families. It looked at the risks to children from exposure to potentially harmful or inappropriate material on the Internet and in video games.

${ }^{206}$ Walden, above $\mathrm{n} 106,438$.

${ }^{207}$ Andy Burnham, Minister for the Department of Media, Culture and Sport, Secretary of State speech to the Convergence Think Tank, speech available at: $<$ www.culture.gov.uk/reference_library/minister_speeches/5192.aspx $>$. ${ }^{208}$ Ibid. 
respect to traditional broadcasting standards and the Internet, Mr Burnham has stated, "The Internet shouldn't and mustn't sweep away all the values and standards that have served us well in the past". ${ }^{209}$ Concerns have also been raised by a cross-party group of MPs about services such as the BBC's "iPlayer", which makes it possible for anyone, specifically children, to view post watershed $(9 \mathrm{pm})$ content at anytime of the day online. ${ }^{210}$

A complainant may be able to take recourse through the judicial system claiming breach of confidence (privacy) or defamation (accuracy, fairness). Initiating legal proceedings in these areas is notoriously expensive, emotionally draining and time consuming, but it is the only avenue for an aggrieved party to go down to deal with most online content. Further, legal avenues cover less ground than content standards, which can deal with things such as minor inaccuracies or general unfairness, but once an Internet service provider is notified that material is potentially defamatory, it is arguably now required to take the material down or face losing a law suit. ${ }^{211}$

While media literacy may form part of the regulatory solution, it fails to address what this paper sees as fundamental problems in online programming content and the public's ability to realistically do anything about it. At present, except for illegal material, the United Kingdom does not regulate Internet content or apply broadcasting standards to it like Ofcom does with the traditional media platforms of radio and television. With respect to the Internet, Ofcom sees its future role as one of educating children and parents on how to safely use the Internet and avoid harmful material, rather than developing a free, robust and accessible public complaints procedure for broadcasting-type content online. It is possible, however, that the regulator's stance may change as more and more people begin to use the Internet like television and radio.

(iii) China

\footnotetext{
${ }^{209}$ Burnham, above n 207.

${ }^{210}$ Paul McNally "Ofcom defends 9pm watershed” (13 May 2008) The Guardian (online) <www.guardian.co.uk>.

${ }^{211}$ Laurence Godfrey v Demon Internet Limited [1999] 4 All ER, 342. A landmark precedent for the United Kingdom set in the online defamation case led the way for the effective establishment of a "notice and takedown" system.
} 
In 2007, China retained its status as the world's second largest Internet market with 137 million total users. ${ }^{212}$ China's Internet filtering regime is the most sophisticated effort of its kind in the world and has been described as both pervasive and effective. ${ }^{213}$ It is comprised of multiple levels of legal regulation and technical control and involves a great number of state agencies and thousands of public and private personal ones. ${ }^{214}$ The country's Internet regulations and legislation are guided by the principle of "guarded openness" - seeking to preserve the economic benefits of openness to global information, while guarding against foreign economic domination, and the use of the Internet by domestic or foreign groups to disseminate 'sensitive materials' and coordinate anti-regime activity. ${ }^{215}$ China's legal regulation of the Internet is extraordinarily complex, with the Open Net Initiative's research showing the regulatory regime comprises requirements and prohibitions issued by multiple bodies and administrative agencies, of which at least 12 have authority over Internet access and content to some degree. ${ }^{216}$

With the ongoing development of the Internet and the dramatic effects media convergence is having on China, its communist government is becoming increasingly nervous as more online information becomes available to its citizens about all manner of subjects, in particular, material related to freedom of expression and democracy. China is locked in a never ending cycle of trying to tighten its grip over the Internet through its massive content filtering operation. Without doubt, China's broadcasting regulations, whether online or via traditional media platforms, are some of the harshest in the world. It is interesting to note that, while many people in Western democratic countries believe China's Internet users are both aware and unhappy about their government's strict oversight and control of the Internet, recent surveys suggest otherwise. According to findings from the forth and most recent of a series of surveys about Internet use in China from 2000 to 2007, over 80 per cent of Chinese respondents say they think the Internet should be managed or controlled and, in 2007, almost 85 per cent say they

\footnotetext{
${ }^{212}$ Steven Schwankert "China Internet market grows to 137 million users" (23 January 2007) InfoWorld, $<$ www.infoworld.com>.

${ }^{213}$ Open Net Initiative (ONI), "Internet Filtering in China 2004-2005: A Country Study" <http://opennet.net/>. See ONI's research report on China's Internet regulation, which is available on its website at:

$<$ http://opennet.net/studies/china/>, 1 .

${ }^{214}$ Ibid, 1.

${ }^{215}$ Rights and Democracy: International Centre for Human Rights and Democratic Development "Review of China's Internet Regulations and Domestic Legislation" available at: $<$ www.ichrdd.ca $>$.

${ }^{216}$ Open Net Initiative, above n 213, 4.
} 
think the government should be responsible for doing it. ${ }^{217}$ However, these results should be viewed with scepticism due to governmental pressures placed on all Chinese to support the Communist Party.

While this paper does not propose a totalitarian regulatory framework for content broadcast via the Internet like that used in China, the country does provide a good example of what not to have - massive over-regulation of Internet content and a stifling of legitimate expression and accurate information online. It is, however, proof that the Internet does not necessarily have to be like the 'Wild West', but is more like a walled garden, with its contents being able to be controlled as it grows - for the most part.

\section{B Domestic Jurisdictional Issues}

If the BSA were to have its jurisdiction extended in the manner suggested in this paper, it may end up in a situation where it crosses jurisdictional paths with another regulatory agency that deals with online content. The most problematic and likely scenario is that the BSA would inevitably cross jurisdictional paths with the Press Council's sphere of influence in respect of online newspapers, and this could raise serious jurisdictional problems for both organisations.

\section{$1 \quad$ Problem scenario if BSA did have jurisdiction over audiovisual material contained in New Zealand-based news websites}

Take the situation where a New Zealand-based online newspaper (e.g. Fairfax Media Ltd's Stuff.co.nz) has on its website an article which is comprised of both written and audiovisual material - having video clips accompanying written reports is a phenomenon that is now common and rapidly increasing. The video connected to the article shows a five minute news report in which the reporter makes various comments about an event that occurred, some background information and the alleged individuals who were involved. Under the link to the video clip is the written associated text which also contains information about the event and the individuals who are allegedly involved. After reading and viewing this material, a person lodges

\footnotetext{
${ }^{217}$ Deborah Fallows "Most Chinese Say They Approve of Government Internet Control" PEW Internet \& American Life Project E-Gov and E-Policy Reports (27 March 2008) report available at: <www.pewInternet.org>. Survey conducted by Guo Ling, "Surveying Internet Usage and Impact in Five Chinese Cities" Research Centre of Social Development, Chinese Academy of Social Sciences (November 2007), 1.
} 
a complaint with the online newspaper that the article including both the written and audiovisual material is inaccurate, unbalanced, unfair and in breach of the named individual's privacy. The newspaper writes back to the complainant disagreeing with the contentions raised. Dissatisfied with the newspaper's response, the complainant refers the complaint to the BSA (if it were to be given jurisdiction as proposed by this paper) maintaining the material and reporter's comments contained in the article's video clip breached those standards. The complainant also complains to the PC alleging the article's written and perhaps audio/audiovisual material breached the Council's set of principles. It should be noted here that the PC seems to have already asserted jurisdiction over audio and audiovisual material available in online newspapers with domestic hard copies.

This scenario raises a number of potential jurisdictional issues and problems surrounding the roles to be played by the BSA and the PC. The first issue that could arise is if both the BSA and the PC were to decide that the written material and the video clip must be taken together in order to get the context of the article as a whole. This issue could well develop, as the information contained in the written material might be different to the information contained in the audiovisual material or the text might provide balancing information or information necessary to identify a person in a video clip. For example, the five minute video clip may contain a lot more information about the event and the individuals allegedly involved, than perhaps a small written piece that tells readers to view the video for more information. In this situation, the BSA and the PC may need to consider the video-clip and the written material together when making their determinations to consider the whole context of the information provided, as any alleged breach may be redressed or aggravated by combining the information contained both in the video clip and written article.

This raises jurisdictional issues such as the BSA infringing on the PC's territory by considering and making a determination on written material contained in an online newspaper or vice versa, where the PC infringes on the BSA's territory by making a determination considering the overall effect of the audiovisual material. It is worthy to note here that the BSA and the PC have different standards and perhaps different threshold for notions such as fairness. To make matters worse, the BSA and the PC may arrive at different outcomes in relation to the same 
material and hence their determinations on whether the applicable standards had been breached could be different. This would be a highly undesirable situation not only for the complainant who would receive two differing decisions, but also for the newspapers concerned, the BSA and the PC, as they may end up opposing each another and therefore reducing the credibility, robustness and effectiveness of the complaints process. Further, it may raise questions about the justifiability of a decision to uphold a complaint or about the appropriateness of having different standards or approaches applied to the same material.

One of the benefits of the proposed framework is that the BSA would have the mandate to determine complaints about broadcasting-type content on the websites of Internet broadcasters named on the government's list and any decision made by the PC in respect to such material would be ultra vires. This position is supported by the case of Electoral Commission and Cameron, which dealt with the issue of overlapping jurisdictions. ${ }^{218}$ The Cameron case involved a decision by the ASA to determine and uphold a complaint regarding an advertisement put out by the Electoral Commission promoting public awareness of the then new electoral system of Mixed Member Proportional. The Court of Appeal found that: ${ }^{219}$

The scheme of the Electoral Act and its legislative history emphasised the special status of the Electoral Commission, its judicial character, and its independence. These features all indicated that the legislature had conferred on the Electoral Commission the role of determining how to inform the public in electoral matters. In conferring that power, the legislature must be taken as implicitly directing that it was not for privately established organisations such as the [ASA] to determine how the Electoral Commission should carry out its statutory public information functions. Such organisations should not substitute their views for those of an expert body charged with particular responsibilities

It can be argued that, for the same sort of reasons outlined in the Cameron case, the BSA could override the authority of the PC with respect to broadcasting-type content contained in the online newspapers if the proposed framework was implemented. This is because the PC, as a privately established organisation, should not be able to substitute its views for those of the BSA (being a specialist body with quasi-judicial powers) who would be responsible for, under this

${ }^{218}$ Electoral Commission and Cameron (1997) 2 NZLR 421 (CA).

${ }^{219}$ Ibid, 433. 
paper's proposal, dealing with complaints relating to specific audiovisual and audio content made available online. However, if the legislation made it clear that the BSA's jurisdiction was exclusive this potential problem could be avoided.

Further, giving the BSA the proposed jurisdictional extension would be more beneficial to complainants for the following reasons: the BSA can award financial compensation to individuals whose privacy has been breached (currently up to $\$ 5,000)^{220}$ and can award costs to a successful complainant for legal advice sought in complex complaints. ${ }^{221}$ Another benefit is that the BSA can utilise its Commission of Inquiry powers and order discovery of documents or summon witnesses if it decides to hold a hearing. ${ }^{222}$ Thirdly, unlike the PC, any decision made by the BSA is appealable to the High Court by either party - as noted earlier, the PC requires complainants to sign a legal waiver before determining a complaint (See Chapter 2). Further, the content standards applied would be more comprehensive and would suit audiovisual and audio content far better than the PC's set of principles, because the content standards have been designed specifically for programming content, which is what the newspapers have on their sites in the form of video news reports. In contrast to the BSA, the PC has no specialised expertise in dealing with audiovisual or audio content, as they have only ever dealt with text and photographs. As such, it would be entirely inappropriate for the PC to move in the specialised area of regulating broadcast content. If the PC challenged this situation, the fact that the Act had been amended in the manner suggested and domestic online newspapers were on the government's list of Internet broadcasters, there would be very little the PC to do but accept it.

\section{EVALUATION OF REGULATORY OPTIONS?}

Having outlined the problems raised by the new converged media environment, this paper's solution and framework to deal with them, and the responses to potential criticisms and alternatives, it will be useful to look at why regulation of the media exists at all. The next section of this paper looks at the reasons behind and justifications for the types of media content regulation that currently exist in New Zealand. It then goes on to look at the arguments of

\footnotetext{
${ }^{220}$ Broadcasting Act 1989, s 13(1)(d).

${ }^{221}$ Ibid, s 16. This section outlines the BSA's power to award costs and expenses to parties.

222 Ibid, s 12.
} 
whether the current regulatory framework should be extended into the new converged world of Internet media and, if so, how far.

\section{A The Historical Reasons for Regulating Media Content}

With respect to television and radio, there are several major reasons why the New Zealand government has made the decision to impose rules and regulations on the content broadcast on these media platforms. "Regulation is usually justified on the basis that market forces alone are unable to deliver required public policy objectives", and "for content regulation, in particular, a key objective is the avoidance of harm". ${ }^{223}$ The rationale behind content regulation in New Zealand is much the same as many for other countries and can be distilled down to four major factors. These are as follows: ${ }^{224}$

- Television and radio are both thought to be powerful and influential media, with the capacity to affect public behaviour and opinion, and to cause significant harm and offence if unchecked, as well as significant good. Their effects on vulnerable groups, such as children, has been of particular concern;

- For much of history broadcasting regulation has hinged on the idea of broadcast bandwidth as a scarce and powerful resource. ${ }^{225}$ In the past, governments have placed a limit on the amount of spectrum available to broadcasting. This meant that a relatively small number of broadcasters had the ability of exercising a massive amount of influence - hence the perceived desirability of ensuring that their news, current affairs and factual programming met standards of impartiality, accuracy and fairness. There is also the notion that the spectrum is a publicly owned resource, justifying restrictions in the public interest on those permitted to use it;

- Television and radio are pervasive "push" services, which transmit scheduled content into people's homes. People have very little, if any direct control over the type of content being streamed into their lives through these media platforms, apart from being able to change channel or turning the transmitting device off;

\footnotetext{
${ }^{223}$ Millwood Hargrave, Lealand, Norris and Stirling, above n 57, 10.

${ }^{224}$ Foster, above n 202, 52.

${ }^{225}$ Brown and Price, above n 2, 8.
} 
- Governments have assumed that people needed protection because they would not have sufficient information to distinguish between advertising material and other content, or be able to work out which programmes they wished to avoid - hence the creation of the programme classification system.

In his 2007 report to England's Department of Culture Media and Sport on the future of broadcasting regulation, Robin Foster states that the above four factors underpin the rationale for today's regulatory system. ${ }^{226} \mathrm{He}$ also points out that this system has only lasted because of general public support and political consensus with respect to the near universal belief that some form of regulation on media content is appropriate and indeed justified. Hence in New Zealand's case, the government enacted the Broadcasting Act and created the BSA.

Due to relevance of subject matter, this dissertation focuses mainly on the protective reasons for content regulation, but the issue of media literacy becoming increasingly relevant as efforts are made to educate people about various media forms and content so they can better protect themselves. Protective regulation has been defined as having a social purpose and is frequently used in many jurisdictions as a justification for regulation. ${ }^{227}$ Its aim is to protect audiences and the subjects of programmes (i.e. people who feature in them) from particular content which, depending on the country and cultural sensitivities, is deemed to be inappropriate, offensive or, depending on any codes of broadcasting practice that exist, breach standards. The BSA's rationale is one of protective regulation, with a small component of proactive regulation through its media literacy objectives. The regulatory tools that are commonly employed by protective regulation, and used by the New Zealand government through the BSA, come in various forms including: ${ }^{228}$

- Content codes - the BSA has four codes of broadcasting practice. These codes have slightly different requirements placed on the different kinds of broadcasters depending on whether they broadcast content on free-to-air television, pay television or the radio;

\footnotetext{
${ }^{226}$ Foster, above n 202, 53.

${ }^{227}$ Millwood Hargrave, Lealand, Norris and Stirling, above n 57, 12.

${ }^{228}$ Millwood Hargrave, Lealand, Norris and Stirling, above n 57, 12.
} 
- Scheduling restrictions - for example, the BSA's Free-to-Air Television Code sets the children's viewing time watershed at $8.30 \mathrm{pm}$ (the time when AO 'adults only' programmes can be broadcast) and $9.30 \mathrm{pm}$ for programmes containing stronger sexual or violent material;

- Classification of broadcast material - for example, free-to-air television programmes are classified G (general audience), PGR (parental guidance recommended) AO (adults only) and AO 9.30pm;

- On-screen symbols during programmes - for example, the pay TV broadcaster SKY uses symbols such as ' $V$ ' for violence, or ' $S$ ' for sexual content;

- Pre-transmission warnings - in New Zealand these warnings may be both verbal and written on-screen and advise viewers of particular content such as coarse language, violence or sexual themes;

- Complaints mechanisms - most content regulators like the BSA offer audiences a free complaints system where breaches of broadcasting codes can be alleged and adjudicated.

\section{B Forms of Media Regulation}

Broadly speaking, statutory regulation, co-regulation and self-regulation are the three different forms of media regulation that exist in the world today. The concepts of co-regulation and self-regulation have become central to the current political and academic debate on alternatives to traditional forms of public authority control. ${ }^{229}$ Inherently, broadcasters extol the virtues of self-regulatory systems and many would love nothing more than for the BSA to be dissolved altogether. On the other hand, community organisations such as Media Matters in New Zealand $^{230}$ want more done to uphold what they consider to be declining moral standards in respect of television and Internet programming content. An outline of each type of regulation and a discussion of their positive and negative attributes follows.

\footnotetext{
${ }^{229}$ Carmen Palzer Co-Regulation of the Media in Europe: European Provisions for the Establishment of Coregulation Frameworks, ISRS plus, Legal Observations of the European Audiovisual Observatory, 2002, Issue 6, 1. ${ }^{230}$ Media Matters in NZ (formally Viewers for Television Excellence 'VOTE') is an organisation that advocates for greater media responsibility in the areas of sex and violence on television and electronic media and of media accountability in general. Its website can be accessed at: $<$ www.viewers.org.nz $>$.
} 


\section{Statutory Regulation}

Statutory regulation is sometimes referred to as command and control regulation and is basically government legislation which sets out various rules people and organisations must abide by. With this type of regulation the government, usually through an agency, is responsible for developing and enforcing a set of rules. In the case of New Zealand media, television and radio broadcasters are subject to statutory regulation through the Broadcasting Act 1989. While being a body independent of government, the BSA has a statutory basis, and as such, it is a type of statutory regulator: it has been given statutory powers to develop and enforce content rules for broadcasters who come under its jurisdiction. This is similar to the Office of Film and Literature Classification (OFLC), whose job it is to classify and censor a range of material including films, books, DVD's, billboards, computer games and t-shirts. New Zealand's censorship system has a protective role and has been established under the Films, Videos and Publications Classification Act 1993, which defines what is considered harmful or injurious to the public good and criteria for rating material. ${ }^{231}$

One of the major benefits of statutory regulation is that it provides the agencies in charge of regulating (like the BSA) with some teeth, that is to say they have powers to enforce the rules which are backed by statute. For example, if the BSA finds that a broadcaster has breached broadcasting standards and then orders it to pay costs to the Crown or to broadcast a statement and the infringing broadcaster does not comply, the BSA's orders can be enforced by the Ministry of Culture and Heritage in court. In direct contrast, the PC relies on its members' voluntary compliance when making an order directing a newspaper to publish a correction. In terms of applying broadcasting standards to particular Internet content in New Zealand, a major advantage of statutory regulation is that an Internet Code of Broadcasting Practice would have teeth. The Internet content providers who came under the BSA's jurisdiction would have no option but to comply with any order made, unless they decided to lodge a High Court appeal. However, it should be noted that the BSA would have no powers with respect to any Internet broadcaster who was based out of New Zealand.

\footnotetext{
${ }^{231}$ Office of Film and Literature Classification <www.censorship.govt.nz/index.html>.
} 
Statutory regulation also provides complainants with the confidence that their concerns are going to be dealt with by a body completely independent from those who they are making the complaint against - the broadcaster. People having confidence that a complaints system is free from bias and is transparent are fundamental principles to any system's effective operation. Where confidence in the system does not exist broadly amongst the general population the system might as well not exist, because people will be unlikely use it due to concerns over competence and perceived neutrality. Academics have also said that, "as one of the basic attributes of democratic sovereignty, regulation is established by democratically appointed authorities, and for this reason, statutory regulation is normally not challenged in terms of its authority to express the general interest". ${ }^{232}$ The democratic legitimisation of the rules created is one of the major advantages of statutory regulation.

However, statutory regulation does have weaknesses when compared to the other forms of regulation that could be applied to programming content on the Internet. Critics opposing enforced statutory regulation argue that this form of regulation is more appropriate for the traditional media platforms of television and radio, but that it is ill-suited to cope with the rapidly changing and converged Internet media environment. Globally, there has been renewed enthusiasm for voluntary self-regulation as an alternative to command and control measures. The research carried out by the Programme in Comparative Media Law and Policy at Oxford University, states that the reasons for this renewed enthusiasm for applying self-regulatory codes on Internet content providers include: dissatisfaction with the rigidity of statutory regulation at a time of change, perceived regulatory cost, and a new agenda on regulatory reform and deregulation driven by industry. ${ }^{233}$ The paper goes onto state that: ${ }^{234}$

However in recent years a more nuanced view has emerged in the specialist literature claiming that the distinction between hard law solutions that are perceived to be effective

\footnotetext{
${ }^{232}$ Palzer, above n 229, at [2].

${ }^{233}$ Centre for Socio-Legal Studies: Programme in Comparative Media Law and Policy research paper Selfregulation, the Media and the Internet (University of Oxford, 2000, England) 4. This research paper is available at: $<$ http://pcmlp.socleg.ox.ac.uk/selfregulation/iapcoda/030329-selfreg-global-report.htm $>$. This paper was part of a three year project carried out by Oxford University which aimed to investigate self-regulatory codes of conduct across the international boundaries and it covered a wide range of media consisting of the Internet, film, video games, television and mobile communications to assist with developing and implementing self-regulatory codes of conduct.

${ }^{234}$ Ibid, 4.
} 
but rigid and so called soft law solutions - perceived to be open to capture and overflexible, has been challenged. Sanctions and standards can be tougher in self-regulatory schemes, and in some cases compliance is greater because of increased "buy in" from an industry that is involved in development of its own self-regulatory solutions.

In the same vein, others have argued that a framework which is still based on mandatory rules could be ineffective, costly and undesirable with respect to regulating Internet content. Robin Foster states in his report on the future of broadcasting regulation, that a number of problems could arise if the government of the United Kingdom tried to regulate broadcastingtype Internet content via statute including: ${ }^{235}$

- It will become harder to regulate content effectively in a broadband world where content can be sourced from overseas, and there will be many hundreds of thousands of content providers, and intrusive regulation may have an adverse effect by stifling investment, innovation and growth in the sector;

- It would be difficult to decide who to include in such a system (just broadcasters, or a wide range of content packagers and suppliers?) and could risk the extension of regulation to entities such as newspaper publishers who have traditionally remained outside the broadcast regulation framework;

- Any regulatory demarcation between different types of content provider may set up undesirable incentives, such as content providers moving to on-demand service to escape regulation applied to broadcast services;

- Consumers may not want it - views differ about what are and are not acceptable standards, with many people placing a high value on the greater freedom of expression provided by the Internet.

So as one can see, there are valid arguments both for and against applying a statutory regulation-type framework to Internet programming content. As mentioned previously, this paper is concerned solely with broadcasting-type content on particular New Zealand-based websites, rather than Internet content as a whole. And, as will be discussed below, there are serious problems regarding the development of voluntary codes of practice, industry buy-in to such

\footnotetext{
${ }^{235}$ Foster, above n 202, 12.
} 
codes, enforcement of the standards/rules contained in any possible self-regulatory code, as well as issues surrounding the enforcement of any orders or sanctions imposed.

\section{Self-regulation}

At one end of the regulatory spectrum there is statutory regulation and at the other is selfregulation. Self-regulation is a regulatory framework under which industry bodies develop their own set of regulations in order to achieve certain social and commercial objectives and take full responsibility for monitoring compliance with those regulations. ${ }^{236}$ These industry-developed regulations can take the form of technical or quality standards or codes of conduct defining good and bad practice. ${ }^{237}$ Like in most democratic societies, New Zealand's PC operates in a selfregulatory environment, developing its own statement of principles. Similarly, New Zealand's advertising industry is self-regulating, with the ASA performing regulatory functions over all forms of advertising across all media platforms. It has been said that, "the advertising industry is model globally for successful self-regulatory practice". ${ }^{238}$

It has been argued by many media commentators, industry players and some high profile multi-national organisations that there are certain areas of the media, such as journalistic ethics, that ought not be subject to statutory regulation and which should be left to journalists and the industry to develop themselves. For example, during a European Ministerial Conference on Mass Media Policy, the following conviction was expressed in Resolution No.2, which concerned journalistic freedoms and human rights: ${ }^{239}$

\footnotetext{
That all those engaged in the practice of journalism are in a particularly good position to determine, in particular by means of codes of conduct which have been voluntarily established and applied, the duties and responsibilities which freedom of journalistic expression entails.
}

\footnotetext{
${ }^{236}$ Palzer, above $n$ 229, at [2].

${ }^{237}$ Ibid, at [2].

${ }^{238}$ Millwood Hargrave, Lealand, Norris and Stirling, above n 57, 14.

239 Tarlach McGonagle Co-Regulation of the Media in Europe: The Potential for Practice of an Intangible Idea, ISRS plus, Legal Observations of the European Audiovisual Observatory, 2002, Issue 10, 2. Extract from, The Media in a Democratic Society Resolution No. 2: Journalistic Freedoms and Human Rights, $4^{\text {th }}$ European Ministerial Conference on Mass Media Policy (Prague, December, 1994).
} 
Principle 8 of Resolution No.2 builds on the above statement saying that public authorities: ${ }^{240}$

Should recognise that all those engaged in the practice of journalism have the right to elaborate self-regulatory standards - for example, in the form of codes of conduct which describe how their rights and freedoms are to be reconciled with other rights, freedoms and interests with which they may come into conflict, as well as their responsibilities.

In the United Kingdom in 2003, the Association for Television On-Demand (ATVOD) was set up alongside the state media regulator Ofcom (Office of Communications) to be a selfregulator for the on-demand television industry. ${ }^{241}$ The industry players successfully argued that a framework of self-regulation was a more versatile and dynamic than statutory regulation, and was better suited to fast moving or emergent industries. ${ }^{242}$ As a trade-off, ATVOD was required to develop a code of practice, establish an effective complaints procedure for customers and member organisations, and appoint a chairman independent of industry or lay members. ${ }^{243}$ It is overseen by a government department which it regularly reports to, and it works closely with Ofcom. $^{244}$

While self-regulation is seen by some as a flexible framework which can respond rapidly to technical and social change, the system does have its drawbacks. First, it requires committed buy-in from all the major industry members to be effective. If a self-regulatory system can only get some members of an industry to accept and abide by any established standards, then it will be of little use. It can be argued that self-regulatory bodies such as the PC and the ASA have no teeth and they require members to voluntarily accept any decision and/or order made about a complaint. For example, there is nothing to stop a newspaper from declining to accept a decision made by the PC and ignoring any order that it might make. While this has not happened to date, the possibility is there. Equally, there is nothing to stop an advertising agency from refusing to comply with an order from the ASA to remove an advertisement. Both the PC and the ASA cannot force their members to do anything they do not want to do voluntarily.

\footnotetext{
${ }^{240}$ McGonagle, above n 239.

${ }^{241}$ Millwood Hargrave, Lealand, Norris and Stirling, above n 57, 14.

242 Ibid, 14.

243 Ibid, 14.

${ }^{244}$ Ibid, 15.
} 
Another example of self-regulation in New Zealand is the telecommunications industry's code relating to Internet and other broadcasting content available on mobile phones. The Mobile Content Code was endorsed by the telecommunications industry in 2005 and was developed as a mechanism for self-regulation of commercial content services provided via mobile phones. ${ }^{245}$ The code sets out industry agreed principles under which mobile content services will be provided to ensure they are provided in a socially responsible manner including an industry agreed position on the protection of minors from inappropriate content. ${ }^{246}$ On 9 September 2008 , the Telecommunications Carriers' Forum issued a new draft of the Mobile Phone Code for public submission. The draft code focuses on appropriate filtering and content classification restrictions, rather than broadcasting standards such as accuracy or privacy. The code sets out monitoring and enforcement obligations on mobile carriers, and details a complaints procedure which includes complainants being able to go to the DIA and OFLC if they believe the mobile content carrier has still incorrectly rated content after having dealt with their complaint. ${ }^{247}$ Signatories to the code include Telecom, Vodafone, Telstra Clear and Woosh Wireless. ${ }^{248}$

The major drawback of complete self-regulation is its lack of external accountability, especially when there is no industry-established body to deal with complaints such as the PC or the ASA. Where only in-house codes exist in a self-regulatory system, the criticism can be made that "no matter how ideologically-primed the in-house code of ethics of any given broadcasting entity and no matter how sophisticated the manner of its implementation, both remain essentially in-house concerns defined by their subjectivity". ${ }^{249}$ The argument is that such codes will likely be shaped, even warped, by the strong influence of owners, sometimes enforced, with journalists having little option but to tow the company line. As one media academic has put it: ${ }^{250}$

\footnotetext{
${ }^{245}$ Telecommunications Carriers' Forum: <www.tcf.org.nz>. The Telecommunications Carriers' Forum says that it plays a vital role in the New Zealand telecommunications industry by working collaboratively on the development of key industry standards and codes of practice that underpin the digital economy. A copy of the Mobile Code is available on its website

246 Ibid.

${ }^{247}$ Code of Practice for Provisions of Content vis Mobile Phones: Draft as at 9 September 2008, Section F, para 19.2 (Telecommunications Carriers' Forum, Auckland, 2008). An electronic copy of the draft code can be obtained online at: <www.tcf.org.nz>.

248 Telecommunications Carriers' Forum, above n 245.

${ }^{249}$ McGonagle, above n 239, 4.

${ }^{250}$ Ibid, 4.
} 
However, such in-house safe guards and codes of ethics and conduct are always open to suspicion and questioning: their very nature deprives them of the moral authority of codes negotiated and endorsed by broad industry representation.

Another perceived drawback is that one could argue that the only reason why selfregulatory complaints bodies such as the PC or ASA exist is because the threat of government regulation provides them with a good incentive to have rules and systems in place to deal with public complaints about content. If they did not establish these complaints bodies, undoubtedly the government would; "governments have adopted the familiar position of threatening direct intervention or statutory regulation in the event that self-regulation fails to deliver". ${ }^{251}$ Forced self-regulation may end up being half-hearted and wrongly motivated (i.e. to starve off statutory regulation), and although there is no evidence to suggest that the ASA or PC approach their tasks half-heartedly, one cannot help but wonder what would occur without the threat of imposed regulation hanging over them if they were failing to deliver.

If the New Zealand government did start looking into the idea of applying some form of broadcasting regulation to the Internet, broadcasters would not want to run the risk that they could be worse off with respect to limitations being placed on them if the government dictated the codes and standards under which they had to practice. In these circumstances, Internet broadcasters would be more likely than not to make moves to establish a self-regulatory code of practice. However, the government has not made any moves to regulate Internet broadcasters thus far, so the need for broadcasters to develop any code of practice or complaints procedure has not arisen. In saying that, TVNZ does have a complaints form on its website, but it mentions nothing about standards or which ones apply, timeframes or the complaints system itself and it is unclear whether the broadcaster's Complaints Committee reviews these complaints. Put quite simply, the broadcasters' hearts are not in it. Hence, in New Zealand there is no industry-created Internet Code of Broadcasting Practice and it is unlikely that one will be developed as there is no genuine motivation within the industry to self-regulate content. With respect to Internet content and self-regulation, researchers at Oxford University have stated: ${ }^{252}$

Self-regulation has become such a buzz-word that governments and international organisations...find themselves in the peculiar position of adopting self-regulation as a

${ }^{251}$ Centre for Socio-Legal Studies, above n 233, 6.
${ }^{252}$ Ibid, 6. 
policy position...The involvement of government and other bodies in encouraging and facilitating the development of codes of practice and other self regulatory mechanisms removes the spontaneity of self-regulation, and raises the question of whether industry organisations or individual firms have the motivation to pursue self-regulation in the long term, when neither regulatory oversight nor financial support for self-regulation are in place.

Within the new converged media environment, an increasingly popular form of regulation is co-regulation. Co-regulation has been described as "a generic term for forms of regulation that are designed to achieve public objectives and which contain elements of selfregulation as well as traditional command and control regulation". ${ }^{253}$ While the BSA has a statutory basis, it could quite rightly be said that it operates in a co-regulatory environment with radio and television broadcasters. The codes of broadcasting practice have been approved by the BSA after working in close connection with the major broadcasters on each platform. For the most part, the broadcasters have themselves created the contents of the codes of broadcasting practice, ${ }^{254}$ which has in-turn led to a greater acceptance of them by the media industry.

The Australian media regulator ACMA has adopted a co-regulatory framework, working with Internet content and service providers. ACMA only deals with Internet content that is prohibited or potentially prohibited under Australia's Broadcasting Act (i.e. not journalistic standards). ${ }^{255}$ The organisation believes that its current framework of co-regulation with Internet providers has arisen from the long-established system of broadcasting content regulation in Australia. ${ }^{256}$ As one Australian media academic put it, "While censorship arises as a contentious topic from time to time, Australians are broadly accustomed to, and many expect, some degree of government intervention in decisions about what can be shown, when and to whom". ${ }^{257}$

\section{$4 \quad$ Suitability of Co-Regulation for Internet Programming Content}

\footnotetext{
${ }^{253}$ Palzer, above n 229, at [3].

${ }^{254}$ Broadcasting Act 1989, s 21 (e). This section requires the BSA to encourage broadcasters both to develop and observe the codes of broadcasting practice.

${ }^{255}$ Australian Broadcasting Services Amendment (Online Services) Act 2000. This Act gives ACMA jurisdiction to regulate media content including some types of Internet content.

${ }^{256}$ Millwood Hargrave, Lealand, Norris and Stirling, above n 57, 14.

${ }^{257}$ Andree Wright Co-regulation of Fixed and Mobile Internet Content: Safety and Security in a Networked WorldBalancing Cyber-Rights and Responsibilities (Australian Communications and Media Authority, Sydney, 2005) 2.
} 
If the BSA were to have its jurisdiction extended to some Internet broadcasters, a decision would have to be made about what approach should be adopted with respect to the type of regulatory framework that would be implemented. While the BSA is technically a statutory regulator, it already takes a co-regulatory approach with television and radio broadcasters and it would be appropriate that this approach be extended to those Internet broadcasters who come under the BSA's regulatory umbrella. A co-regulatory approach, with a heavy emphasis on the self-regulatory part, would be the most effective framework to implement to deal with particular Internet content for a number of reasons. First, media convergence is re-shaping our communications markets, companies are no longer operating solely in their historical markets and this is leading to significant changes at every stage from creation of content and services through to delivery. ${ }^{258}$ Major changes in broadcasting have taken place against a backdrop of continuing technological and market convergence within the sector where the distinctions between broadcasting, telecommunications and information are blurring or disappearing at an increasing rate. ${ }^{259}$ There is little doubt that, in respect of this new converged media environment, the broadcasters themselves are in the best position to develop and implement content standards considering they have the ability to adjust to rapid change when it occurs. Flexibility in this new environment will be crucial, because the Internet has not fully developed yet and convergence of the media market is only going to increase. With respect to convergence and Internet broadcasting, we cannot, with absolute certainty, predict the types of changes or the speed at which these changes will occur or the flow-on effects which will result. In five years time the Internet will be a different beast to what it is now and perhaps it will be being used by people in ways we cannot predict now. Broadcasters must play a major role in developing and upholding standards in this dynamic media platform, because they can act in a speedy fashion where the BSA cannot. For example, broadcasters have the ability to take out or change offending material quickly and easily, unlike the BSA who must to go through a formal process, find a breach and make an order, which could then be appealed.

\footnotetext{
${ }^{258}$ Office of Communications - Initial Assessments of when to Adopt Self- or Co-regulation: Consultation Paper (Ofcom, England, 2008) 2.

${ }^{259}$ Ibid, 1.
} 
Second, the basic framework for a shared responsibility approach between the BSA and broadcasters already exists. It would seem the current system of radio and television broadcasters dealing with complaints in the first instance would aptly suit complaints about broadcasting-type Internet content. All that would be required is for an Internet Code of Broadcasting Practice to be developed between Internet broadcasters with final approval to be given by the BSA. As stated above, a co-regulatory system combines elements of self-regulation and traditional public authority regulation. In utilising this perspective, there are conceivably many different forms of co-regulatory models, depending on the combination of public authority and private sector elements. $^{260}$. A good approach would be for the government to amend the Act, as proposed by this paper, to initiate a co-regulatory system so the BSA could begin to create and then implement an Internet complaints system in conjunction with Internet broadcasters. The key element would be the development of binding rules and the broadcaster's liability for those rules and, as proposed above, the rules should be drawn up between the broadcasters and approved by the BSA.

Third, the BSA has the finances to help broadcasters develop and implement standards for Internet content, as well as help those that need it with setting up systems for dealing with complaints. As the BSA already does with radio and television, it would have the function of reviewing broadcasters' decisions if a complainant was dissatisfied with the decision or the action taken by a broadcaster. The fact that the BSA's current system of review is already wellestablished and funded would significantly reduce any compliance costs incurred by the older broadcasters, while the new players would have to make the investment - the cost of which would not be too onerous. The BSA could also provide assistance to the newly regulated Internet broadcasters who do not conduct business in the traditional regulated media platforms with the development of their internal complaint handling system.

Fourth, the types of standards that would apply to Internet broadcasts and the way in which they are to be applied and enforced could be quite different to those imposed on television and radio. In developing the standards, in particular their wording relating to what programming

${ }^{260}$ Palzer, above n 229, at [1]. 
material they apply to, broadcasters could give themselves room to move in terms of dealing with complaints about content. For example, a programme broadcast on the Internet may not need to be balanced if links have been provided to other sources of balancing information. Another example might be where a person or organisation feels that they have been treated unfairly in a programme and want to respond to criticisms, the broadcaster could attach an electronic tag linking the viewer to a letter from or interview with the affected party responding. If a person believes a programme breaches their privacy, say through unnecessary identification of a child, the broadcaster can take immediate action such as pixellating the child's features to stop any potential or on-going breach. These types of solutions are made possible because of the special nature of the Internet. The fact is that once material is on a website it could be there for a very long time. The term Internet-based 'new media' is actually talking about 'digital media', and once something is digitised, the ability over time to control, charge for it, regulate it or contain it exponentially decreases - digital media cannot be contained by the analogue rulebook. ${ }^{261}$ Developing new creative techniques to deal with the new problems digital media create is something that the BSA and broadcasters are going to have to work closely together on. However, while Internet broadcasters would be the first and most important port-of-call, the BSA would act both as a watchdog and safety-net in the event a broadcaster was not fulfilling its obligations or if the standards were not working effectively in practice.

Fifth, there is the option of a co-ordinated approach between online broadcasters and agencies including the BSA, OFLC, ASA, the PC and Internet NZ. Utilising a co-regulatory approach involving coordination between the various agencies may provide the best framework for dealing with complaints about broadcasting-type material online. While each agency would have its own defined jurisdictional areas, they could liaise closely with each other on issues arising out of the rapidly changing online media environment to find solutions to regulatory problems that will inevitably arise with ever-changing consumer habits in Internet use and technological advances. As mentioned in this paper, jurisdictional boundaries may become increasingly blurred and the need for co-hearings and joint determinations might arise. The defined areas of jurisdiction may look like this:

\footnotetext{
${ }^{261}$ Emily Bell "Digital media cannot be contained by the analogue rulebook" (23 March 2009) The Guardian, London, England.
} 
Figure 2. Table of online jurisdiction areas of agencies.

\begin{tabular}{|l|l|}
\hline Organisation & Areas of online Jurisdiction \\
\hline BSA & $\begin{array}{l}\text { All New Zealand-based regulated Internet broadcasters } \\
\text { (i.e. on the list) who provide audiovisual or purely } \\
\text { audio programming content on their websites. }\end{array}$ \\
\hline ASA & $\begin{array}{l}\text { All New-Zealand-based online advertising. } \\
\text { OFLC }\end{array}$ \\
\hline PC & $\begin{array}{l}\text { Continue current classification and censorship role of } \\
\text { contained in New Zealand-based online newspapers and } \\
\text { magazines. }\end{array}$ \\
\hline Internet NZ & $\begin{array}{l}\text { Remit for increasing media literacy, promotion of } \\
\text { Internet filtering software and developing self- } \\
\text { regulatory ISP (Internet Service Providers) code of } \\
\text { conduct. }\end{array}$ \\
\hline
\end{tabular}

In any event, this paper proposes a tiered co-regulatory approach in which the BSA, other regulatory bodies and broadcasters work together to find a common sense and practical solution to what is going to become a very big issue, as more people turn to the Internet for programming content.

\section{THE CONCEPT OF RESPONSIVE REGULATION}

This section draws on the theory of responsive regulation to suggest future proofing changes to the Act and to see how certain strategies could be used to increase acceptance and compliance by Internet broadcasters with respect to them coming under this paper's proposed jurisdictional extension for the BSA. As argued by this paper, there are parts of the Broadcasting Act which, if not 'future-proofed', will result in the reduced effectiveness and eventual obsolescence of the current content standards and complaints regime. The ongoing effects of 
media convergence and the inevitable large-scale shift of activities onto the Internet will mean that people will become increasing dissatisfied with their inability to complain about online broadcast material.

\section{A Responsive Regulation}

It is seems more than likely from the powers bestowed on the BSA by the Broadcasting Act - including the jurisdiction to "develop and issue codes of broadcasting practice...in any case where the BSA considers it appropriate" - that part of Parliament's intention was that the BSA could react in responsive manner in the face of a changing environment. This is not to say that the statutory regulations established by the Broadcasting Act are as flexible as self-regulatory regulations, due to lengthy processes involved in changing the wording of legislation. But what the drafters of the Act could not have foreseen in 1989 was the rapid pace of media convergence and effect the Internet would have on broadcasters and media consumers and the flexibility and responsiveness that would be required to deal with this broadcasting platform.

Responsive regulation can be distinguished from other strategies of market governance (such as strong government regulation or full scale deregulation) both in what triggers a regulatory response and what the regulatory response will be. ${ }^{262}$ In their book Responsive Regulation, US law Professor Ian Ayres and Australian Professor John Braithwaite say regulation should be responsive to industry structure in that different structures will be conducive to different degrees and forms of regulation. ${ }^{263}$ They state responsive regulation is not a clearly defined programme or set of prescriptions concerning the best way to regulate, but rather the best strategies are shown to depend on context, regulatory culture, and history - responsiveness is an attitude that enables a wide variety of regulatory approaches. ${ }^{264}$

They consider that: ${ }^{265}$

...regulation should respond to industry conduct, to how effectively industry is making private regulation work. The very behaviour of an industry or firms therein should channel the regulatory strategy to greater or lesser degrees of government intervention. Most

\footnotetext{
${ }^{262}$ Ian Ayres and John Braithwaite, Responsive Regulation: Transcending the Deregulation Debate (Oxford University Press, New York, 1992) 4.

${ }^{263}$ Ibid, 4.

${ }^{264}$ Ibid, 5.

${ }^{265}$ Ibid, 4.
} 
distinctively, responsiveness implies not only a new view of what triggers regulatory intervention, but lends us to innovative notions of what the response should be.

Looking at the regulatory culture and history of media regulation in New Zealand, the state has utilised a combination of regulatory models. With respect to programming content on television and radio, the government has used a combination of both an 'enforcement model' and compliance regulatory model. The government has taken the view that broadcasters should develop the codes of broadcasting practice, in conjunction with the BSA, and implement them via a complaints system. The model involves the BSA acting as a type of safety net or backstop for the instances when the broadcaster fails to respond to a complaint within the statutory timeframe, makes an incorrect decision about whether a breach of standards has occurred or takes insufficient action if the broadcaster has identified a breach. Under the current framework, the BSA is diplomatic and cooperates with broadcasters, in the belief that the broadcasters can see that it is in their long-term self-interest to comply with the content standards they had a large part in developing. This cooperation is assumed and compliance is encouraged through informal strategies of negotiation (like the updating of the codes of broadcasting practice), with the law being the last enforcement resort. Large broadcasters are protective of their reputation and informal pressures and publicity of breaches (publishing the BSA decisions or ordering the broadcast of a corrective statement) can be effective in getting them to conform to societal standards regarding the programming content they broadcast.

But, as mentioned throughout this paper, broadcasters have not taken any action with respect to imposing a self-regulatory content code for the programming material they have on their websites. Furthermore, the BSA is overturning a relatively significant percentage of broadcasters' decisions (refer to Chapter Three for statistics). In this new media environment, the government must act responsively to impose the required regulation to correct what the market has thus far failed to do. While this sounds like a pure enforcement model approach, certain responsive regulation strategies can be used to get industry buy-in and general support for the idea. For example, Ayre and Braithwaite argue that allowing an industry to negotiate the detail of what the rules will be and how a set of rules will be complied with, permits responsiveness and 
increases commitment to compliance. ${ }^{266}$ As with the other codes of broadcasting practice, the broadcasters would be heavily involved in deciding what content standards should be applicable, how they are worded, how they should operate, and how they should be enforced. While broadcasters may not want to have standards imposed on their Internet programming content, if their hand is forced by the state, they are much more likely to accept and comply if they have had the opportunity to be involved from the beginning.

Another major strategy of responsive regulation is the involvement of the community/public in regulatory decisions. Ayre and Braithwaite contend that involving public can have a number of benefits including the fact that having a third party at the negotiating table changes the dynamics between the regulator the industry subject to regulation. The BSA already uses the opinions of the public when making regulatory decisions, such as requesting public submissions on code reviews. In terms of a proposed Internet code, after the BSA and broadcasters have devised a draft code, it can be released to the public for comment and the information gained from this can then be considered and incorporated where appropriate.

Once an agreement on the Internet code's content has been achieved, its enforcement and any sanctions that may apply can be discussed. Recognising that the Internet is a very different medium to television and radio, any regulation imposed must reflect the nature and context in which the material subject to regulation exists. The types of sanctions that could be imposed on a broadcaster, depending on the standards breached, could vary widely and be extremely adaptive to the circumstance. The ability to use a 'big stick' should occasionally be demonstrated and the BSA should be able to, where reasonable and appropriate, order material to be taken down (see discussion of new powers in Chapter Four).

Due to the Internet's fluid nature, there are many options available with respect to dealing with breaches of standards and novel approaches will inevitably be developed over time to deal with infringing material in a manner that suits this medium. The best way to respond to programming content on the websites of New Zealand-based broadcasters is to utilise a

\footnotetext{
${ }^{266}$ Ayres and Braithwaite, above n 262, 5.
} 
responsive co-regulatory framework that uses a tiered approach in dealing with complaints, and one that ensures industry participation and buy-in.

\section{THE NEW ZEALAND BILL OF RIGHTS ACT 1990}

The following chapter looks at the implications of the New Zealand Bill of Rights Act 1990 (BORA) with respect to the proposed legislative amendments and the development of an Internet Code of Broadcasting Practice. It includes an analysis of whether this jurisdictional extension and imposition of an Internet code would be consistent with the BORA.

The BORA states that its provisions apply to acts done, "By any person or body in the performance of any public function, power, or duty conferred or imposed on that person or body by or pursuant to law". ${ }^{267}$ As the BSA is a body that performs a public function imposed by the Broadcasting Act, the organisation must act in a manner consistent with the obligations set out in the BORA.

Further, the BORA states that where a Bill being introduced appears inconsistent with the rights and provisions contained in the Bill of Rights, the Attorney General must report the inconsistency to Parliament. ${ }^{268}$

Section 14 of the BORA provides that, "Everyone has the right to freedom of expression, including the freedom to speak, receive and impart information and opinions of any kind in any form". ${ }^{269}$ The broadcasting standards regime limits broadcasters' right to freedom of expression contained in section 14 of the BORA. A succinct explanation of this limitation it is that: ${ }^{270}$

The very raison d'être of the broadcasting standards regime is to define and enforce a set of circumstances in which limits can be imposed on the freedom of broadcasters to say what they like, how they like and when they like. It imposes those limits first, by setting out broadcasters' own statutory responsibilities to maintain certain broadcasting standards and secondly, by empowering an independent BSA to impose binding sanctions for default.

\footnotetext{
${ }^{267}$ Bill of Rights Act 1990, s 3(a).

268 Ibid, s 7.

${ }^{269}$ Ibid, s 14.

${ }^{270}$ Claudia Geiringer and Steven Price "Moving from Self-Justification to Demonstrable Justification: The Bill of Rights and the Broadcasting Standards BSA", in Law Liberty, Legislation Jeremy Finn and StephenTodd (eds) (LexisNexis, Wellington, 2008) pp295-338, 301.
} 
As a qualifier to all the rights contained in the Act, section 5 provides, "Subject to section 4 of the Bill of Rights, the rights and freedoms contained in this Bill of Rights may be subject only to such reasonable limits prescribed by law as can be demonstrably justified in a free and democratic society". Therefore, section 5 requires that any limits placed on the rights contained in the BORA be justifiable.

Prior to any changes being made to the Broadcasting Act to partially regulate some Internet broadcasters, an assessment would have to be made concerning whether the new proposed limitations being imposed on the broadcasters' rights were both proportionate and reasonable in the circumstances when considering the legislative objectives being sought by the changes.

In $R v$ Oakes $^{271}$, the Supreme Court of Canada created a test for determining whether a limit on a right contained in the Canadian Charter of Rights and Freedoms (the Charter) was demonstrably justified under section 1 of the Charter, upon which section 5 of the New Zealand Bill of Rights is based. ${ }^{272}$ The first part of the test related to the objective of the limitation imposed on the right, and the second part involved a three step proportionality inquiry. ${ }^{273}$ While this proportionality inquiry has been refined over the years, the New Zealand Supreme Court has endorsed it saying "whether a limit on a right or freedom is justified under section 5 is essentially an inquiry into whether a justified end is achieved by proportionate means". ${ }^{274}$ In other words: ${ }^{275}$

This test involves a 'proportionality' inquiry in which attention is given to the legitimacy and sufficiency of the conflicting legislative objective, to whether there is a 'rationale connection' between the violating measure and that objective, to whether the restriction on the right goes further than is necessary in order to achieve the statutory objective, and to whether the salutary effects of the legislation outweigh its deleterious effects.

\footnotetext{
${ }^{271} R v$ Oakes [1986] 1 SCR 103. This decision was refined by later decisions of the Canadian Supreme Court including $R \vee$ Chaulk [1990] 3 SCR 1303.

${ }^{272}$ Andrew Butler and James Shaerf Limiting Fundamental Rights: How on Earth is s 5 Supposed to Work in Practice? (Using the Bill of Rights in Civil and Criminal Litigation, New Zealand Law Society Seminar, July 2008, 23, 24. The seminar booklet available from the New Zealand Law Society's department of Continuing Legal Education.

${ }^{273} \mathrm{Ibid}, 25$.

${ }^{274} R v$ Hansen [2007] 3 NZLR 1 (SC).

${ }^{275}$ Geiringer and Price, above n 270, 331.
} 
In order to comply with section 5 of the BORA, any limit placed on the rights of Internet broadcasters must clear two hurdles. ${ }^{276}$ First, any limitations must be "prescribed by law" and second, they must comply with the mutually reinforcing concepts of "reasonableness" and "demonstrable justification". ${ }^{277}$ This involves a proportionality inquiry: the more serious the effects of the measure, the more important the objective must be in order for the measure to constitute a demonstrably justifiable limit. ${ }^{278}$

The following is an attempt to apply the two-stage test to the proposed amendments to the Act and the development and application of an Internet Code of Broadcasting Practice to those organisations deemed to be Internet broadcasters under this paper's suggested regulatory framework.

\section{A Prescribed by Law}

First, Parliament must assess whether the limit placed on the broadcasters' section 14 right would be "prescribed by law". Parliament has recognised the importance of maintaining broadcasting standards in the Broadcasting Act 1989.

The proposed changes to the Broadcasting Act are essentially an extension of the current broadcasting standards regulation to specific Internet broadcasters and, as previously stated, would only impact on the audio and audiovisual content provided by the major New Zealandbased media players on their websites. The code of broadcasting practice applicable to Internet broadcasters' programming content, which would be approved by the BSA, would operate in the same manner as those applied to other platforms, while wording of the standards and their application could be different in order to suit the medium. In any event, it would be readily established that the proposed changes would be prescribed by law, as they would be set out in statute and form part of the updated Broadcasting Act.

\section{B Demonstrable Justification}

\footnotetext{
${ }^{276}$ Geiringer and Price, above n 270, 317.

${ }^{277}$ Ibid, 317.

${ }^{278}$ Butler and Shaef, above n 272, 25.
} 
The second part of the test requires a consideration of whether the proposed amendments to the Act and subsequently the contents of the Internet code, would place a demonstrably justified limitation on the broadcasters' right to freedom of expression. The following paragraphs set out the significant social objectives addressed by the proposed changes, the evidence that these objectives address a pressing social need, why this paper's proposals are likely to achieve those ends, the effect the changes will have on broadcasters' freedom of speech and whether the solution to fix the problem is proportional.

\section{Significant Social Objectives Addressed by the Proposed Changes.}

While protection of freedom of expression is the cornerstone of the standards regime, there can be little argument with the view that the overwhelming majority of New Zealanders want certain boundaries to broadcasters' freedom of speech and creative freedom, and an organisation to ensure the limitations are observed. ${ }^{279}$ For example, very few would argue for or accept that explicit hard-core pornography should be allowed to be broadcast on free-to-air television, very few people would accept a broadcaster routinely encouraging criminal behavior, few would feel comfortable with broadcasters who, for no discernable public interest, grossly invaded vulnerable people's privacy and humiliated those people in the name of entertainment. ${ }^{280}$ That is why the government's legislative objectives regarding media accountability of radio and television broadcasters and the standards their content must comply with are set out in the Broadcasting Act. The significant social objectives addressed by the current broadcasting standards regime include: ${ }^{281}$

- The desire to protect people from harm and abuse - especially those who require special protection such as children;

- The need to prevent broadcasters violating community norms relating to things such as sexual material, violence, liquor promotion, maintenance of law and order and content that it considered highly offensive;

- Ensuring informed choice - providing the audience with classifications and warnings where appropriate;

\footnotetext{
${ }^{279}$ Broadcasting Standards Authority, above n 150, 2.

${ }^{280} \mathrm{Ibid}, 2-3$.

${ }^{281}$ Ibid, 3.
} 
- Ensuring reporting is fair, accurate and ethical and that the public receives a diversity of viewpoints on important topics;

- Having ready redress for injustices that are not easily or affordably addressable in other ways (e.g. defamation or privacy actions brought through the courts).

The changes to the Act and the framework proposed by this paper would ensure that a system was put in place to uphold and promote the legislative and social objectives outlined above and to hold those broadcasters regulated under the proposed framework to account for the content they make available on their websites. Further, the application of content standards goes beyond what can be recovered in the courts (e.g. fairness) or what is covered by the OFLC and where there is an overlap, the BSA's regime is cheaper, faster, more accessible, and is especially justified for audiovisual programming because of the extra harms it can do.

2 Evidence These Social Objectives Address a Pressing Social Issue: The Rational Connection.

As mentioned throughout this paper, convergence has created a new media environment and the current regulatory system is becoming increasingly out-of-date and will eventually become unfit for purpose. Traditional platform broadcasters have much of the same material available on their websites now as they do on the old platforms, and many are streaming programming content live via the Internet. Having a wild west-type environment for broadcasters to operate in without the need to be concerned with the social objectives mentioned above is, in this paper's view, a pressing social issue which must be addressed to ensure media accountability and to foster a healthy mainstream online media environment.

Further, the social objectives involved here are appropriate and necessary, in this paper's view, for dealing with the pressing social issue of having a virtually unregulated Internet broadcasting industry that has no established set of content standards which apply to it. The proposed changes to the online environment through the imposition of Internet broadcasting standards is a practical and workable way to addresses the issues brought about by broadcasters using the Internet as their new platform to distribute programming content. 
While broadcasters may want to self-regulate their websites, the fact is that between 2007-2009 an average of 23 percent of the complaints referred to the BSA were upheld, which is evidence that the broadcasters' current approach is failing on occasion and the safety net provided by the BSA is required. ${ }^{282}$ Also, none of the major players including TVNZ or MediaWorks have made any steps to create an Internet code or develop a robust complaints process for people wanting to complain about their online programming content.

\section{Why the Proposed Changes Are Likely to Achieve the Desired Result}

The proposed changes to the Act and the development and imposition of an Internet code would ensure broadcasters subject to the regulation would take the same level of care with their Internet material as they do in their radio and television material. That is to say, they would act consistently with the social objectives outline above and, if they failed to do so, the public would have recourse through the BSA. The proposed changes to the Act and subsequent Internet code would promote high levels of journalistic professionalism and ethics on a media platform that is increasing becoming the one-stop-shop for media consumers to receive news and entertainment content (see statistics on public's internet usage in Chapter 2). The suggested amendments to the Act and the development and implementation of an Internet code would be an appropriate progression of the existing standards regime to the new converged media platform of the Internet. This form of responsive regulation is necessary to ensure the public interest is properly served through ensuring, amongst other things, that ethical journalistic practices are maintained and to provide the public with the comprehensive and accessible complaints system they deserve.

The proposed extension of the BSA's jurisdiction would be both reasonable and desirable because: it is in the best interests of the New Zealand public, other media regulators (such as the ASA and PC) already have jurisdiction over online content, broadcasters have failed to implement an Internet broadcasting code themselves and media convergence will increasing led to many people using the Internet as their main source for accessing programming content. Further, the changes would create a level playing field amongst all New Zealand-based broadcasters and they would be a proportionate response, to deal with a problem, in a manner

\footnotetext{
${ }^{282}$ Broadcasting Standards Authority, above n 152, 10.
} 
where the broadcasters' minimal loss of freedom of expression would not be greater than the gain of the competing public interest to be able to hold the media accountable for its actions. As stated by the House of Lords, "Public opinion cannot be totally disregarded in the pursuit of liberty". 283

\section{$4 \quad$ Impacts on Broadcasters’ Freedom of Speech}

The right to freedom of speech is fundamental to any properly functioning democracy. Equally, the public's confidence in receiving accurate news information, the idea that people and organisations should be treated fairly by the media, that balance is provided in discussions concerning controversial issues of public importance, and matters relating to the privacy of the individual, are also fundamental to a healthy society. Free speech literature is dominated by the theory that freedom of speech is particularly valuable because it provides society with the best chance of discovering the truth. ${ }^{284}$ Free speech writer Frederick Schauer has said: ${ }^{285}$

Open discussion, free exchange of ideas, freedom of enquiry, and freedom to criticize, so the argument goes, are necessary conditions for the effective functioning of the process of searching for truth. Without this freedom we are said to be destined to stumble blindly between truth and falsehood.

This open discussion and freedom to criticise takes place in a 'market place of ideas' in which people have the liberty to seek out truth in order to achieve the desirable goal of advancing knowledge to better society. ${ }^{286}$ Under the 'market place of ideas' theory the truth will most likely surface when all opinions may freely be expressed, when there is an open and unregulated market for the trade in ideas - by relying on the operation of the market to evaluate any opinion, we subject opinions to a test more reliable than appraisal of any one individual or government. $^{287}$ In its purist form, however, this theory allows for all opinions to be freely expressed and exchanged, even blatantly incorrect or dangerous ones, such as discriminatory or derogatory forms of speech. The theory is also concerned with getting to the truth or accuracy of a particular issue, as opposed to other concerns dealt with by broadcasting standards such as the

\footnotetext{
${ }^{283}$ Prolife Alliance v British Broadcasting Corporation, above n 183, at [19] per Lord Hoffman.

${ }^{284}$ Frederick Schauer Free Speech - A Philosophical Inquiry (Cambridge University Press, United States, 1982) 15.

${ }^{285}$ Ibid, 15.

${ }^{286} \mathrm{Ibid}, 17$. For more on free speech theory see also - E Barendt, Freedom of Speech, (2ed, Oxford University Press, New York, 2005)

${ }^{287}$ Ibid, 16.
} 
maintenance of law and order, privacy and fairness. So, while the market place of ideas is fundamental to a free and democratic society, it has limitations placed on its application due to the social objectives seeking to be achieved by the government. These social objectives include media accountability, and have led to the creation of broadcasting standards and the BSA, as well as the OFLC and industry-run ASA and PC.

Speech and dissemination of information is plainly not a self-regarding act; affecting others is most often the point of speaking or communicating. ${ }^{288}$ Words such as deceive, persuade, convince, mislead, distress and alarm are based around logic that presupposes that speech or distribution of information will affect others. ${ }^{289}$ Freedom of expression can, and frequently does, cause harm including harms to the interests and rights of individuals, harm to society and harm to the governing apparatus of the state. ${ }^{290}$ When looking at what weight to attach to the competing interests of the players that would be affected by the imposition of an Internet code, one must look at the value of the information or the expression upon which a limitation is sought. As stated by Justice Tipping: ${ }^{291}$

The more value to society the information imparted or the expression in question may possess, the heavier will be the task of showing the limitation is reasonable and justified.

The key driver for media regulation in a free and democratic society is that it must be created for and demonstrably serve the public interest - this possibly being the only constant in today's evolving media ecosystem. ${ }^{292}$ If regulation is effective and serves its public interest purpose well (i.e. promotes and achieves the social objectives it is designed to), then the restrictions it imposes are more likely to be seen as reasonable and justified by society as a whole and the courts. The overarching purpose of regulating television and radio content through the imposition of broadcasting standards - and newspapers and advertising through various other regulators - is to achieve specific social objectives which the various codes and sets of principles are designed to achieve.

\footnotetext{
${ }^{288}$ Schauer, above n 284, 10.

289 Ibid, 10.

${ }^{290}$ Ibid, 10.

${ }^{291}$ Hosking $v$ Runting [2005] 1 NZLR 1, at [235] per Tipping J.

${ }^{292}$ Martin Hirst Balancing Act: A Review of the Balance Provision in the New Zealand Broadcasting Standards, (Broadcasting Standards Authority, Wellington, 2008) 6.
} 
Broadcasters operate in this market place of ideas and they impart information to others and exercise their free speech rights. The role of broadcasters in entertaining and informing the public is an immensely important one and, unless there is good reason, the market place should be left to function without interference. Like all rights, however, there must be limits imposed and rules by which to play. As stated by New Zealand's High Court, "the right of freedom of expression is not an unlimited and unqualified right". ${ }^{293}$ In terms of broadcasting, where the free market place of ideas fails to achieve the general set of social objectives, the legislation acts as a safety net to ensure accountability and opportunity for redress. Further, the impacts on regulated Internet broadcasters' freedom of speech will be minimal. In most cases, Internet broadcasters already operate through mediums which have content standards and methods for redress (e.g. TVNZ, MediaWorks and Fairfax). It should be remembered that it is only when the BSA considers that standards have been infringed that any official restriction on speech occurs. However, it is true that the mere existence of regulation itself can create a chilling effect on freedom of expression, and broadcasters may run different stories or change stories in fear of the BSA making a finding against it. But officially, Internet broadcasters would be able to put whatever they wished on their websites until a complaint has been upheld - even then, a link or pixellation maybe all that is required. The BSA is only a safety net and as mentioned previously, the Internet provides broadcasters with quick fix solutions to deal with valid complaints quickly in the first instance, thus discontinuing any harm caused.

As argued throughout this paper, media convergence, the BSA's lack of online jurisdiction and a lack of desire on the part of broadcasters to create a robust complaints system for the public to use means that there is not backstop for redress when there ought to be. Further, the impacts on the Internet broadcasters' freedom of expression would be the same as those already felt under the current regime by those broadcasters providing programming content on radio and television.

\section{Proportionality}

There can be broad disagreement across the broadcasting industry about the outcomes of particular complaints referred to the BSA, because of the value judgments inherent in

\footnotetext{
${ }^{293}$ P v D and Independent News Auckland Ltd [2000] 2 NZLR 591, per Nicholson J
} 
determining complaints on issues such as fairness or good taste and decency. As such, a lot of decisions are contestable, and the BSA sometimes gets it wrong. There are costs associated with imposing standards on broadcasters as well as impacts on the proper functioning of the market place of ideas. Therefore, there are reasons to be careful about imposing the new Internet content regulations proposed by this paper. The following section outlines why the proposed changes are proportional, why some broadcasters would disagree, and the response this paper has to their arguments.

The two concepts of 'reasonable' and 'demonstrably justified' combine to mandate an inquiry into the 'proportionality' of the proposed limit on free speech. ${ }^{294}$ As stated by Geiringer and Price: ${ }^{295}$

The essence of this proportionality inquiry is thus a balancing exercise between two sets of values: those underlying the right to freedom of expression and those underlying the broadcasting standards regime.

When determining whether an imposed limitation on a broadcaster's freedom of expression is demonstrably justifiable, the big question is whether the solution to the problem is proportional. That is to say, are there less restrictive ways to achieve the same aims or will the changes do more harm than good? The current set of broadcasting standards broadly reflect a set of common values that the government and the society it represents see as important, such as the promotion of children's interests, good taste and decency, fairness, accuracy in news reporting and the privacy of the individual (this can be evidenced by the government's decision to specifically name these as objectives to be dealt with by content standards in the Act). The current standards are based on societal norms and a generally accepted set of principles which are aimed at fostering a healthy and accountable mainstream media environment and which the New Zealand public generally supports. ${ }^{296}$

\section{(a) Broadcasters' free speech concerns}

\footnotetext{
${ }^{294}$ Geiringer and Price, above n 270, 319.

295 Ibid, 319.

${ }^{296}$ Broadcasting Standards Authority Freedoms and Fetters - Broadcasting Standards in New Zealand (BSA, Wellington 2006) 32-33. Discussion on what people involved in research focuses groups thought was important when balancing broadcasters' right to freedom of expression with the need for content standards such as accuracy in news.
} 
Many broadcasters, however, argue that it should be up to the industry itself to deal with broadcasting standards and that it is self-regulation which is required and appropriate, not a government appointed statutory body telling them what they can or cannot do under threat of sanction. Most broadcasters are of the view that any extension of the BSA's jurisdiction, especially an extension to particular online programming content, would be disproportionate and unwarranted. For example, Radio Pacific's Programme Director has said: ${ }^{297}$

\footnotetext{
We have a pretty good understanding of what we do. Companies have responsibilities to their customers and we don't need a statutory body to look after us. We can do that. It's a matter of good business.
}

Broadcasters and the journalists working for them already worry about the 'chilling effect' and the perceived harms that the imposed regulations have on their freedom of expression and hence their ability to conduct their jobs in the manner of their choosing. In mid 2009, journalist and media commentator Colin Peacock undertook an assessment of the BSA's decisions from a journalists' perspective. ${ }^{298}$ In that assessment he noted that there was an inherent conflict between the day-to-day reality that broadcast journalists work with and the requirement to adhere to a set of prescribed principles such as those that make up the codes of broadcasting practice. ${ }^{299}$ With respect to the Authority's application of broadcasting standards, he believed that journalists sometimes feel that the BSA: sets the bar too high, has taken a narrow view of what is in the public interest, has been persuaded by the arguments of wellresourced and/or highly motivated complainants, fails to take into account fully the realities of broadcast journalism today, unfairly restricts their freedom of expression (on occasion), discourages risk-taking or courageous journalism that could prove to be in the public interest, and has a higher expectation of privacy in its decisions than some journalists and programmemakers consider healthy for serving the public interest. ${ }^{300}$

The concerns listed above are just a small portion of those expressed by journalists in Peacock's assessment over a wide range of issues relating to content standards, their interpretation by the BSA and the restrictions that are placed on broadcasters' freedom of

\footnotetext{
${ }^{297}$ Broadcasting Standards Authority Freedoms and Fetters - Broadcasting Standards in New Zealand (BSA, Wellington 2006) 55. Extract from: Morris W Shanahan Case Study: What radio talk broadcasters think, 46.

${ }^{298}$ Peacock, above n 184.

${ }^{299}$ Ibid, 11.

${ }^{300}$ Ibid, 11-12.
} 
expression. Programme hosts have also, at times, lashed out at what they perceive to be unfair restrictions on what they consider to be legitimate exercises of their freedoms to express their points of view. For example, in 2009 the BSA upheld a complaint against radio talk show Michael Laws about comments he made in relation to members of the New Zealand Fire Service. ${ }^{301}$ Mr Laws responded to the Authority's decision by issuing a press release (as mayor of Wanganui) saying the BSA should be "disbanded", its decision was a "joke" and that it was an example of the Authority stifling freedom of speech. ${ }^{302}$ Another criticism of the Authority's application of standards is that it is too sensitive to the feelings of people featured in broadcasts subject to complaint. ${ }^{303}$ This criticism has some validity, for example the High Court recently overturned a decision of the Authority which found a woman drink driver was unfairly singled out when she was filmed coming out of court and being pursued by reporters as she tried to run away after being found guilty of drink driving for a second time. ${ }^{304}$ Justice Mallon found that: ${ }^{305}$

I am conscious that the BSA is the specialist body that has the experience and expertise to make these assessments. Nevertheless, I am satisfied that the BSA failed to take into account material relevant considerations which led it to a view that limited freedom of expression in a way that was not justified. The unfairness to the woman was not of a kind that breached the fairness standard.

Over the years, the BSA has had decisions overturned by the High Court, which means that it does, on the seldom occasion, get it wrong. This may also include occasions when an appeal has not been lodged as well. Further, broadcasters might argue that the BSA only upholds a relatively small percentage of the total complaints and that most of these are fairly minor and do not eventuate in penalties. It would also be fair to say that it is a very expensive exercise for the courts to review the BSA's decisions and that some complaints have been declined to be determined, in whole or in part, which demonstrates a limit to the BSA's competence.

\footnotetext{
${ }^{301}$ Broadcasting Standards Authority, New Zealand Fire Service and Radio Works Ltd; Decision No. 2009-018.

${ }^{302}$ Michael Laws, press release: Talkback host Laws says fire chiefs deserved it, available at

$<$ www.mayormichael.co.nz $>$. See also Alice Neville "Let's get ready to rumble" (12 July 2009) New Zealand

Herald (online version), Auckland, available at

$<$ http://www.nzherald.co.nz/nz/news/article.cfm?c_id=1\&objectid=10583939>.

${ }^{303}$ Peacock, above n 184, 14.

${ }^{304}$ Television New Zealand v Green [2009] NZAR 69 (HC).

${ }^{305}$ Ibid, at [63].
} 
In terms of whether this paper's proposed changes are demonstrably justifiable, one can persuasively argue that the digital revolution has created a climate of change and therefore regulatory regimes like that of the BSA must also adapt, in order to avoid being caught in a techno-legal time gap which renders old codes and standards obsolete and to ensure a system that safeguards the continuing public interest is in place. ${ }^{306}$ It should be remembered that one of the major functions of the BSA is to protect broadcasters' freedom of expression and that it only upholds a minority of complaints (17\% in 2008). One of the many definitions of news is that: news is something, someone, somewhere does not want published. And it is the BSA's job to ensure that the broadcasters' right to report freely on whatever topics they wish is defended, so long as standards are adhered to. The former Minister of Broadcasting, Steve Maharey, has argued that, "the proliferation of electronic news sources - with text, images, audio and video available over the Internet might increase the need for regulation in order to preserve media accountability". ${ }^{307}$ It is abundantly clear that this change in the media environment is likely to be the norm for at least the next decade, due to an acceleration in technological advancement, a greater consumer take-up of new technologies, new networking capabilities, more Internet-linked mobile devices, and re-engineered business models for 'old' and 'new' media. ${ }^{308}$

The limitations on the broadcasters' freedom of expression, with respect to their online activities, would be no more (probably a lot less) than what they are already subjected to when providing the public with programming content on radio and television. For those broadcasters operating on both old and new delivery platforms, they already have systems in place (or should have) to deal with complaints alleging breaches of standards. It would not be an unreasonably onerous task to include the audiovisual or audio content available on their websites into their existing complaints handling systems. For the new-age broadcasters only delivering content via the Internet (and who the government deem to be Internet broadcasters) the BSA would be available to provide assistance and guidance where necessary. When looking at the conflicting legislative objectives of free speech rights and broadcasting standards, the changes proposed in this paper would be a proportionate intrusion on broadcasters' freedom of expression, because

\footnotetext{
${ }^{306}$ Martin Hirst, above n 292, 4.

${ }^{307}$ Ibid, 10.

${ }^{308}$ Foster, above n 202, 6.
} 
the measures do not go any further than necessary to achieve the important social and legislative objectives relating to broadcasting in New Zealand.

\section{$6 \quad$ Summary}

While the proposed framework is fairly general, and offers some scope for abuse in particular cases if applied in an overly restrictive manner, the courts have said that general powers, including those the BSA, must be exercised consistently with the BORA. ${ }^{309}$ If the BSA oversteps the mark, an appeal process is available to broadcasters who feel a decision unjustifiably restricts their freedom of expression. Accordingly, the changes to the Act and implementation and enforcement of an Internet Code of Broadcasting Practice would place a demonstrably justifiable and reasonable limit on Internet broadcasters' freedom of expression and would therefore be consistent with the BORA.

\section{CONCLUSION}

There is no doubt that the media play a fundamental role in society both as the major source for information and as a public watchdog. The power of the media and the history of its regulation has been the subject of discussion earlier in this paper and it is because of the media's power to influence the public that it has had regulations imposed on it. While media/broadcasters' freedom of expression is hugely important, so too is the contrary social objective of limiting their freedoms where appropriate - the greater the harm to individuals or society resulting from breaches of journalistic ethics and standards, the more ready the government should be to impose restrictions and sanctions on them to ensure responsibility and accountability.

Due to rapid technological developments, New Zealand's current regulatory and legislative framework does not adequately address the issues raised by new media platforms, nor the specific context in which these issues arise. The traditional concepts of broadcasting and who can be defined as being a broadcaster are becoming increasingly removed from the modern day

\footnotetext{
${ }^{309}$ See, for example, Television New Zealand Limited and KW (18 December 2008) HC CIV-2007-485-001609, at [14].
} 
reality. Efforts to protect the 'cyberspace' from being made subject to regulation are going to diminish in the face of a large-scale shift of activities onto the Internet.

While it is obvious that a free and democratic society should not attempt to impose heavy or onerous regulation on the Internet (though it probably could not even if it tried - "the Internet perceives censorship as damage and routes around it" ${ }^{, 310}$ ), online content standards are appropriate in some circumstances. To have a wild west-type environment on the Internet where broadcasters, who would normally be subject to content standards on other platforms, can provide any content they please and the public have no recourse other than expensive court action is an entirely inadequate situation.

It is argued that the weight in favour of imposing content standards on specific New Zealand-based Internet broadcasters is greater than the weight that should be attached to the broadcasters' freedom to provide whatever content they want, no matter how harmful, on their websites without any independent body (other than a court) to hold them accountable. At the end of the day, all that would be required of Internet broadcasters would be to make reasonable efforts to ensure that facts are correct and to make a correction if they are not, to respect the privacy of the individual unless there is sufficient public interest, to treat people and organisations fairly and to ensure that they do not encourage people to break the law. In essence, the upholding of bottom-line journalistic standards - not the most onerous of requests for mainstream media outlets that consider themselves to be credible and trustworthy sources of information and who play a crucial role proving the truth and keeping the New Zealand public well informed.

Regulating the Internet using the framework suggested in this dissertation will provide an effective and robust regime for dealing with complaints about New Zealand-based Internet content. It will be beneficial to the country as a whole, because it will ensure that members of the public have a free, comprehensive and accessible complaints system available to them without having to resort the courts.

\section{The End}

\footnotetext{
${ }^{310}$ Jack Goldsmith and Tim Wu Who Controls the Internet? Illusions of a Borderless World (Oxford University Press, New York, 2006) 3.
} 


\section{Bibliography}

\section{A. Statutes \\ 1. New Zealand}

Bill of Rights Act 1990

Broadcasting Act 1989

Films, Videos, and Publications Classifications Act 1993

\section{Australia}

Australian Broadcasting Services Act 1992

Australian Broadcasting Services Amendment (Online Services) Act 2000

\section{B. Cases}

\section{New Zealand}

Comalco NZ Ltd v Broadcasting Standards Authority (1995) 9 PRNZ 153.

Electoral Commission and Cameron (1997) 2 NZLR 421 (CA).

Hosking $v$ Runting [2005] 1 NZLR 1.

Ministry of Health $v$ CanWest TVWorks Ltd (10 October 2007) Broadcasting

Standards Authority 012/07.

$P \vee D$ and Independent News Auckland Ltd [2000] 2 NZLR 591.

$R v$ Hansen [2007] 3 NZLR 1 (SC).

Solicitor General for New Zealand v Siemer HC AK CIV 2008404472.

TV3 Network Services Ltd v Broadcasting Standards Authority And S [1995] 2

NZLR 720.

Television New Zealand v Davies (31 March 2005) Broadcasting Standards Authority 207/04.

Television New Zealand v Green [2009] NZAR 69 (HC).

Television New Zealand Limited and K W (18 December 2008) HC CIV-2007-485001609.

Television New Zealand Limited and Lion Nathan and Others Decision No. 2009-069.

\section{Australia}

Jones $v$ Toben [2002] FCA 1150.

\section{Canada}

$R v$ Chaulk [1990] 3 SCR 1303.

$R v$ Oaks [1986] 1 SCR 103. 


\section{United Kingdom}

Laurence Godfrey v Demon Internet Limited [1999] 4 All ER, 342, (Eng). Prolife Alliance v British Broadcasting Corporation [2003] UKHL 23.

\section{Texts}

R. E. Allen (ed) The Concise Oxford Dictionary (8 ed, Oxford University Press, New York, 1991).

Ian Ayres and John Braithwaite, Responsive Regulation: Transcending the Deregulation Debate (Oxford University Press, New York, 1992).

Sir Ian Barker and Professor Lewis Evans, Review of the New Zealand Press Council (New Zealand Press Council, Wellington, 2007).

Gracie Lawson-Borders Media Organizations and Convergence: Case Studies of Media Convergence Pioneers ( Routledge, New Jersey, 2005).

Broadcasting Standards Authority Freedoms and Fetters - Broadcasting Standards in New Zealand (BSA, Wellington 2006).

Russell Brown and Steven Price The Future of Media Regulation in New Zealand: Is Their One? (Broadcasting Standards Authority, Wellington, 2006).

Martin Hirst Balancing Act: A Review of the Balance Provision in the New Zealand Broadcasting Standards, (Broadcasting Standards Authority, Wellington, 2008).

Professor John Burrows Assessment of Broadcasting Standards Authority Decisions (Broadcasting Standards Authority, Wellington, 2006).

Ursula Cheer (ed)The Real Deal: Essays in Law and Advertising (The Centre for Commercial and Corporate Law Inc, Christchurch, 2008).

Jack Golsmith and Tim Wu Who Controls the Internet? Illusions of a Borderless World (Oxford University Press, New York, 2006).

Henry Jenkins Convergence Culture: Where Old and New Media Collide (New York Press, New York, 2006)

Colin Peacock Principles and Pragmatism: An assessment of the Broadcasting Standard Authority - Decisions From a Journalists Perspective (Broadcasting Standards Authority, Wellington, 2009). 
Frederick Schauer Free Speech - A Philosophical Inquiry (Cambridge University Press, United States, 1982).

Jeremy Finn and StephenTodd (eds) (LexisNexis, Wellington, 2008).

Andree Wright Co-regulation of Fixed and Mobile Internet Content: Safety and Security in a Networked World - Balancing Cyber-Rights and Responsibilities (Australian Communications and Media Authority, Sydney, 2005).

\section{Journals, Reports \& Seminar Papers}

Advertising Standards Authority, Annual Report (Advertising Standards Authority, 2007, Wellington)

Andrew Butler and James Shaerf Limiting Fundamental Rights: How on Earth is 5 Supposed to Work in Practice? (Using the Bill of Rights in Civil and Criminal Litigation, New Zealand Law Society Seminar, July, 2008).

Broadcasting Standards Authority, Annual Report (Broadcasting Standards Authority, 2007, 2008, 2009, Wellington)

Centre for Socio-Legal Studies: Programme in Comparative Media Law and Policy research paper Self-regulation the Media and the Internet (University of Oxford, 2000, England).

Debroah Fallows "Most Chinese Say They Approve of Government Internet Control" PEW Internet \& American Life Project E-Gov and E-Policy Reports (27 March 2008).

Robin Foster Future of Broadcasting Regulation (Report commissioned for the Department for Culture, Media and Sport, 2007, United Kingdom)

Debra Harker, Michael Harker and Glen Wiggs Responsive Advertising Regulation: A case Study from New Zealand (Australian Journal of Political Science, Vol. 40, No.4, pp 1-14, 2005).

New Zealand Ministry of Culture and Heritage "Broadcasting and New Digital Media: Future of Content Regulation" - Consultation Paper, (Wellington, 2008)

Tarlach McGonagle Co-Regulation of the Media in Europe: The Potential for Practice of an Intangible Idea, ISRS plus, Legal Observations of the European Audiovisual Observatory, 2002, Issue 10.

Office of Communications - Initial Assessments of when to Adopt Self- or Co-regulation: Consultation Paper (Ofcom, England, 2008) 
Carmen Palzer Co-Regulation of the Media in Europe: European Provisions for the Establishment of Co-regulation Frameworks, ISRS plus, Legal Observations of the European Audiovisual Observatory, 2002, Issue 6.

Pew Research Centre Internet Overtakes Newspapers as News Outlet (23 December, Pew Research Centre Publications, 2008).

Ian Walden Regulating broadcasting in a converging environment: Without frontiers and without a fuss! (Media and Arts Law Review, vol 12 No.4, 2007, Australia).

\section{E. Newspaper Articles/Media Statements}

Emily Bell "Digital media cannot be contained by the analogue rulebook" (23 March 2009) The Guardian, London, England.

Andy Burnham, Minister for the Department of Media, Culture and Sport, Secretary of State speech to the Convergence Think Tank, speech available at

$<$ www.culture.gov.uk/reference_library/minister_speeches/5192.aspx $>$.

John Garnaut "Nervous China tightens grip on Internet" (12 January 2008) Sydney Morning Herald (online).

Michael Laws, press release: Talkback host Laws says fire chiefs deserved it, available at $<$ www.mayormichael.co.nz $>$.

Yu Le "China closes 91 Websites in crackdown" (12 January 2009) MSNBC News (online).

Hon Trevor Mallard "Next phase of broadcasting review announced" Media Statement: Office of the Minister of Broadcasting, Trevor Mallard, and the Office of the Minister of Communications and InformationTechnology, David Cunliffe (Wellington, 22 September 2008).

Paul McNally "Ofcom defends 9pm watershed" (13 May 2008) The Guardian (online).

Wilson Owen "Lawmakers tackle the web wild west" (12 March 2008) The Independent Financial Review, Auckland.

Paul Revoir "Is this the end of the television set? $\mathrm{BBC} 1$ to broadcast live on the Internet" (5 June 2008) DailyMail Online, United Kingdom.

Steven Schwankert "China Internet market grows to 137 million users" (23 January 2007) InfoWorld. 
Bruce Simpson "Devolution of the Internet" (12 March 2008) Aardvark Daily, New Zealand.

Tanalee Smith "Uproar as Great Aussie Firewall threatens Internet freedom" (29 December 2008) The New Zealand Herald (online version).

Brian Stelter "Golden Years of Television Finf New Life on the Web" (28 April 2008) The New York Times (online). New York.

Viamoana Tapaleao "Internet-based Pacific TV in Works" (13 October 2008) The New Zealand Herald.

\section{Websites}

Australian Media and Communications Authority $<$ www.acma.gov.au $>$ Advertising Standards Authority $<w w w . a s a . c o . n z>$ Broadcasting Standards Authority $<$ www.bsa.govt.nz $>$

C4 www.c4.co.nz

Daily Mail $<$ dailymail.co.uk $>$

Department of Internal Affairs $<w w w . d i a . g o v t . n z>$

Electronic Frontiers Australia Incorporated <www.efa.org.au $>$

Fairfax Limited $<$ www.stuff.co.nz $>$

Hulu $<$ www.hulu.com $>$

Internet $\mathrm{NZ}<\mathrm{www}$.Internetnz.net.nz $>$

Media Matters in NZ < www.viewers.org.nZ $>$

Ministry of Culture and Heritage $<$ www.mch.govt.nz $>$

MSNBC < www.msnbc.com>

New York Times $<$ www.nytimes.com $>$

Office of Communications $<$ www.ofcom.org.uk $>$

Office of Film and Literature Classification $<$ www.censorship.govt.nz $>$

Open Net Initiative $<$ http://opennet.net/research/regions/au $>$

Scoop $<$ Scoop.co.nz $>$

Sydney Morning Herald $<$ www.smh.com.au $>$

Prime Television $<$ www.primetv.co.nz $>$

Telecommunications Carriers' Forum $<$ www.tcf.org.nz $>$

Television New Zealand Limited $<$ www.tvnz.co.nz $>$

Telsatraclear $<$ www.telstraclear.net.nz $>$

The New Zealand Herald <www.nzherald.co.nz $>$

The New Zealand Radio Guide $<$ www.nzradioguide.co.nz $>$

TVWorks Ltd $<$ www.3news.co.nz. $>$ and $<$ www.tv3.co.nz $>$

Vodafone New Zealand Ltd $<$ www.vodafone.co.nz $>$

The New Zealand Press Council, <www.presscouncil.org.nz $>$

Veoh $<$ www.veoh.com $>$

YouTube $<$ www.youtube.com $>$

Ziln $<$ www.ziln.co.nz $>$ 
